\author{
Aus der Abteilung Pädiatrie I \\ mit Schwerpunkt Pädiatrische Hämatologie und Onkologie \\ (komm. Leiter: Prof. Dr. med. M. Lakomek) \\ im Zentrum Kinderheilkunde und Jugendmedizin \\ der Medizinischen Fakultät der Universität Göttingen
}

\title{
Retrospektive Analyse klinischer Daten von 358 Patienten mit hereditärer Sphärozytose
}

\author{
INAUGURAL- DISSERTATION \\ zur Erlangung des Doktorgrades \\ der Medizinischen Fakultät \\ der Georg-August-Universität zu Göttingen
}

vorgelegt von

Benjamin Kreische

aus

Göttingen

Göttingen 2010 
Dekan: Prof. Dr. med. C. Frömmel

1. Berichterstatter: Prof. Dr. med. Lakomek

2. Berichterstatter: $\quad$ PD Dr. med. Riggert

3. Berichterstatterin: Prof. Dr. rer. nat. Virsik-Köpp

Tag der mündlichen Prüfung: 26. September 2011 


\section{Inhaltsverzeichnis}

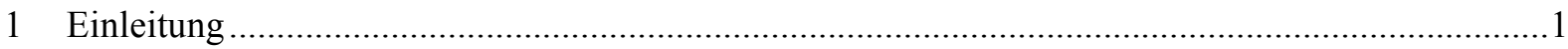

1.1 Hämolytische Anämien durch Erythrozytenmembrandefekte .................................................1

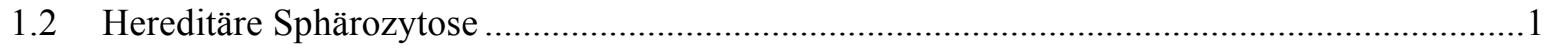

1.3 Symptomatik der hereditären Sphärozytose ……...............................................................

1.4 Einteilung der hereditären Sphärozytose in Schweregrade ......................................................

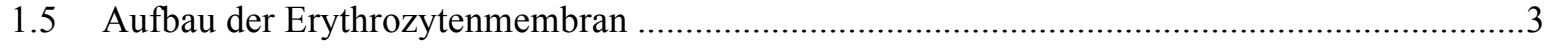

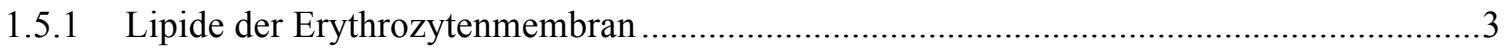

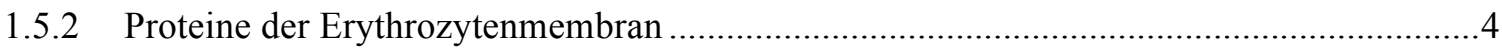

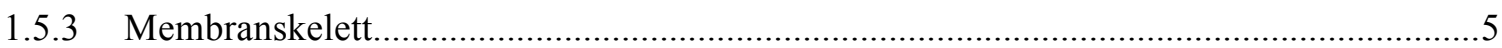

1.5.4 Eigenschaften und Funktion des Membranskeletts.................................................................

1.5.5 Verbindung von Membranskelett und Doppellipidmembran ...............................................6

1.6 Genetik und molekulare Defekte der hereditären Sphärozytose.................................................7

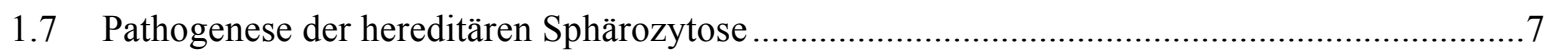

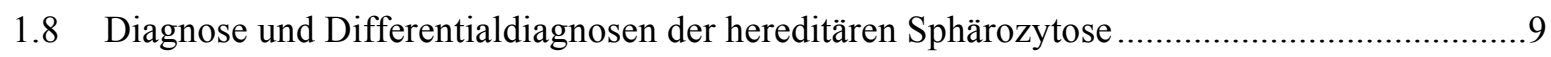

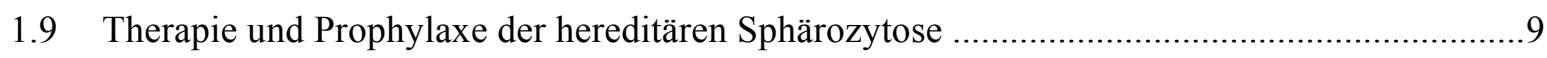

1.10 Komplikationen der hereditären Sphärozytose ....................................................................11

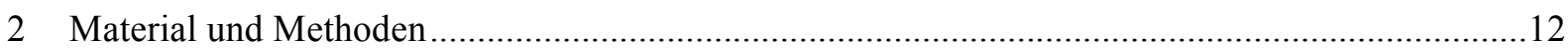

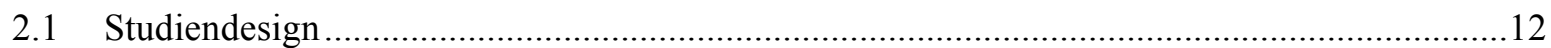

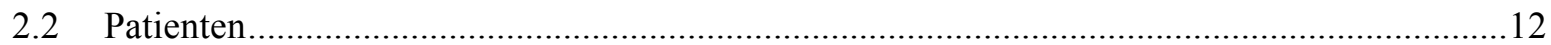

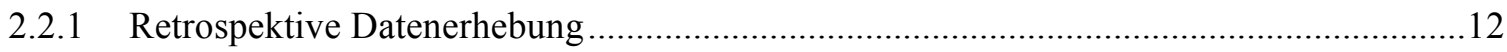

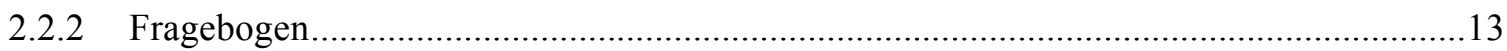

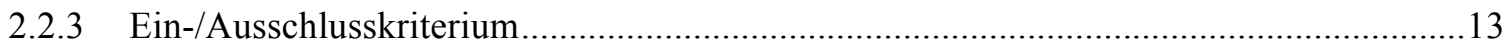

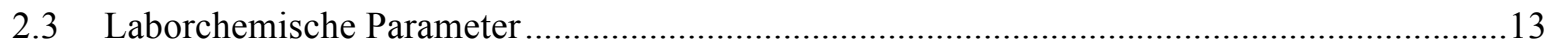

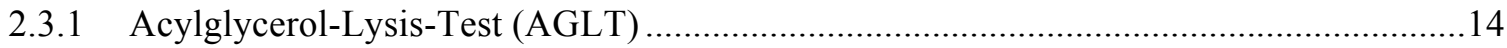

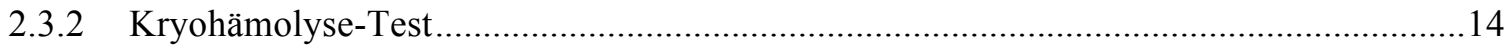

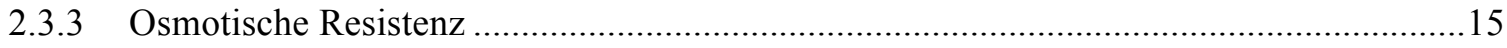

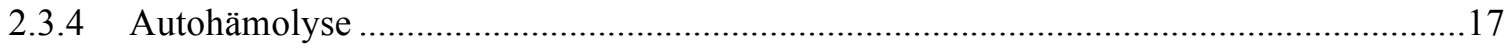

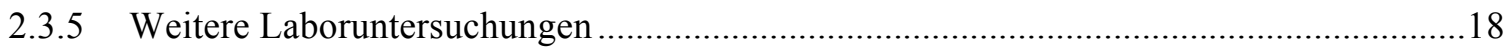

2.4 Auswertung und graphische Darstellung der Ergebnisse ....................................................18

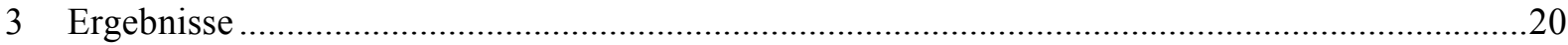

3.1 Analyse der Altersverteilung der Patienten mit Sphärozytose ….........................................20

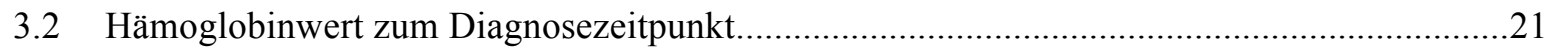

3.3 Alterskorrelierte Retikulozytenwerte zum Diagnosezeitpunkt .............................................23 
3.4 Alterskorrelierte Bilirubinwerte (gesamt) zum Diagnosezeitpunkt .......................................25

3.5 Acylglycerol-Lysis-Test (AGLT) zum Diagnosezeitpunkt ................................................25

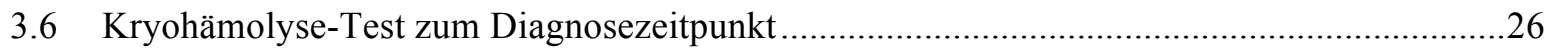

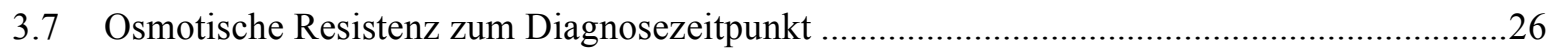

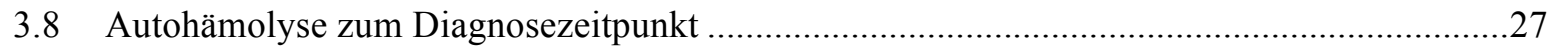

3.9 Alterskorrelierte mittlere korpuskuläre Hämoglobinkonzentration (MCHC) zum

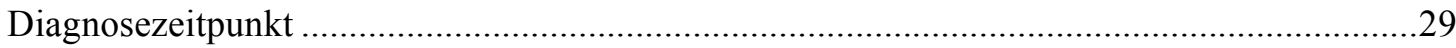

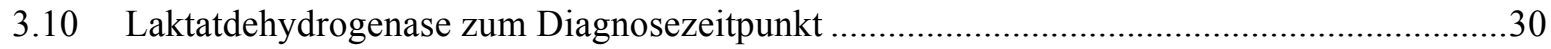

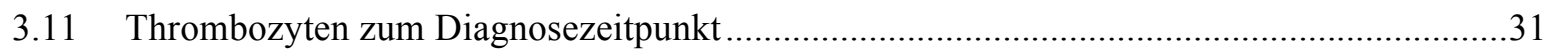

3.12 Auftreten eines Icterus neonatorum bei Patienten mit Sphärozytose …….............................32

3.13 Durchführung einer Phototherapie bei Icterus neonatorum....................................................32

3.14 Austauschtransfusionsbehandlung bei Hyperbilirubinämie ..................................................33

3.15 Diagnosestellung innerhalb von vier Wochen nach Austauschtransfusion oder Icterus-praecox- und/oder Icterus-gravis-Diagnose ……......................................................... 34

3.16 Transfusionsbehandlungen im Zusammenhang mit der Sphärozytose-Erkrankung ..............35

3.17 Gallensteinauftreten bei Patienten mit Sphärozytose ...........................................................38

3.18 Cholezystektomiebehandlung bei Patienten mit Sphärozytose …..........................................39

3.19 Splenektomiebehandlung bei Patienten mit Sphärozytose ....................................................41

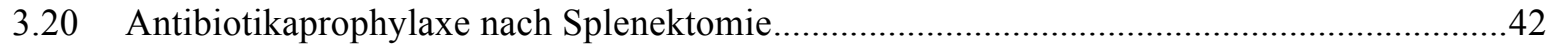

3.21 Analyse hämolytischer/aplastischer Krisen bei Patienten mit HS.........................................42

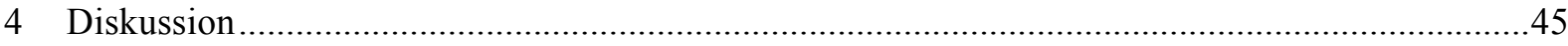

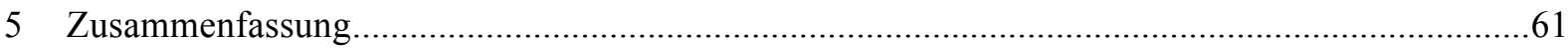

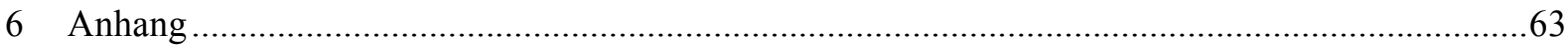

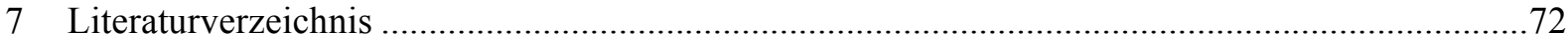




\section{Abkürzungsverzeichnis}

AGLT

AT

AWMF

$\mathrm{Hb}$

$\mathrm{HbF}$

Hkt

HS

LDH

$\mathrm{MCH}$

$\mathrm{MCHC}$

$\mathrm{MCV}$

$\min$.

OPSI-Syndrom

OR

PK-Mangel

RDW

$\operatorname{sog}$.

STIKO

u.a.

z.B.
Acylglycerol-Lysis-Test

Austauschtransfusion

Arbeitsgemeinschaft der Wissenschaftlichen Medizinischen Fachgesellschaften

Hämoglobin

fetales Hämoglobin

Hämatokrit

hereditäre Sphärozytose

Laktatdehydrogenase

mean corpuscular hemoglobin (mittleres korpuskuläres Hämoglobin)

mean corpuscular/cellular hemoglobin concentration (mittlere korpuskuläre Hämoglobinkonzentration)

mittleres korpuskuläres Volumen

Minute(n)

overwhelming postsplenectomy infection syndrome

osmotische Resistenz

Pyruvatkinase-Mangel

red blood cell distribution width

(Erythrozytenverteilungsbreite)

sogenannte

ständige Impfkommission

und andere(s)

zum Beispiel 


\section{Abbildungsverzeichnis}

Abbildung 1.1 Schematisches Modell der Erythrozytenmembran ....................................................................6

Abbildung 1.2 Pathogenese der hereditären Sphärozytose ...........................................................................8

Abbildung 2.1 Osmotische Resistenz im frischen Blut und nach 24-stündiger Inkubation mit

Kochsalzlösungen verschiedener Konzentrationen bei $37^{\circ} \mathrm{C}$....................................................................17

Abbildung 3.1 Altersverteilung der Patienten bei Diagnosestellung.............................................................20

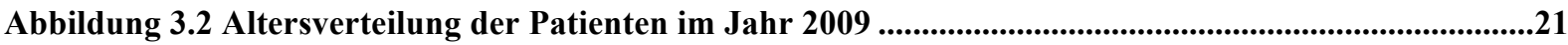

Abbildung 3.3 Alterskorrelierte Übersicht des Hb-Wertes zum Diagnosezeitpunkt ....................................21

Abbildung 3.4 Alterskorrelierter erniedrigter Hb-Wert zum Diagnosezeitpunkt............................................22

Abbildung 3.5 Erhöhte alterskorrelierte Retikulozytenwerte zum Diagnosezeitpunkt ..................................23

Abbildung 3.6 Erniedrigte alterskorrelierte Retikulozytenanzahl zum Diagnosezeitpunkt............................24

Abbildung 3.7 Übersicht alteskorrelierter Retikulozytenwerte zum Diagnosezeitpunkt ................................24

Abbildung 3.8 Alterskorrelierter Bilirubinwert zum Diagnosezeitpunkt ........................................................25

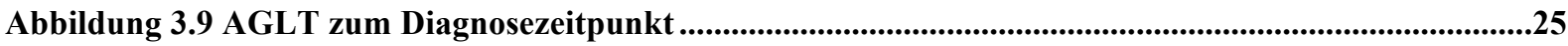

Abbildung 3.10 Kryohämolyse-Test zum Diagnosezeitpunkt .....................................................................26

Abbildung 3.11 Osmotische Resistenz im Frischblut zum Diagnosezeitpunkt ...........................................26

Abbildung 3.12 Osmotische Resistenz der Erythrozyten im inkubierten Blut zum Diagnosezeitpunkt ......27

Abbildung 3.13 Autohämolyse ohne Zusätze zum Diagnosezeitpunkt ...........................................................28

Abbildung 3.14 Autohämolyse mit Glukosezusatz zum Diagnosezeitpunkt ................................................28

Abbildung 3.15 Alterskorrelierter MCHC -Wert zum Diagnosezeitpunkt .......................................................29

Abbildung 3.16 Alterskorrelierte MCHC-Wert-Erhöhung zum Diagnosezeitpunkt ......................................29

Abbildung 3.17 Übersicht über alterskorrelierte LDH-Werte zum Diagnosezeitpunkt ................................30

Abbildung 3.18 Auftreten eines erhöhten alterskorrelierten LDH-Wertes zum Diagnosezeitpunkt.............30

Abbildung 3.19 Alterskorrelierte Thrombozytenwerte zum Diagnosezeitpunkt..........................................31

Abbildung 3.20 Auftreten eines Icterus neonatorum bei Patienten mit Sphärozytose ...................................32

Abbildung 3.21 Phototherapiebehandlung bei Auftreten eines Icterus neonatorum .....................................32

Abbildung 3.22 Durchführung einer Austauschtransfusion bei Hyperbilirubinämie .....................................33

Abbildung 3.23 HS-Diagnosestellung innerhalb von vier Wochen nach Austauschtransfusion .....................34

Abbildung 3.24 Diagnosestellung innerhalb von 4 Wochen bei festgestelltem

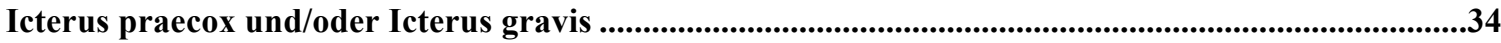

Abbildung 3.25 Übersicht über die Anzahl an Transfusionen bei Patienten mit Sphärozytose.....................35

Abbildung 3.26 Altersverteilung bei Patienten mit 1-3 Transfusionen......................................................36

Abbildung 3.27 Altersverteilung bei Patienten mit mehr als 3 Transfusionen .............................................36

Abbildung 3.28 Altersverteilung bei Patienten mit regelmäßigen Transfusionen .........................................37

Abbildung 3.29 Altersdurchschnitt der Patienten mit hereditärer Sphärozytose in Korrelation

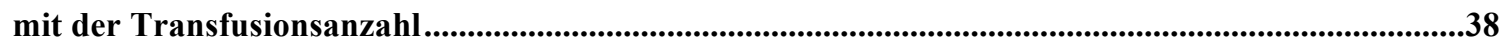

Abbildung 3.30 Auftreten von Gallensteinen bei Patienten mit HS ............................................................38

Abbildung 3.31 Altersverteilung von Patienten beim Auftreten des 1. Gallensteins......................................39

Abbildung 3.32 Altersverteilung bei Cholezystektomie von Patienten mit Sphärozytose ...............................40

Abbildung 3.33 Altersverteilung bei Splenektomie von Patienten mit Sphärozytose ......................................41

Abbildung 3.34 Durchführung einer Antibiotikaprophylaxe bei Patienten mit Sphärozytose nach Splenektomie.

Abbildung 3.35 Analyse des Auftretens hämolytischer/aplastischer Krisen bei Patienten mit Sphärozytose

Abbildung 3.36 Auftreten hämolytischer/aplastischer Krisen vor Splenektomie bei Patienten mit hereditärer Sphärozytose.

Abbildung 3.37 Auswirkung der Splenektomie auf hämolytische/aplastische Krisen ..................................44 


\section{Tabellenverzeichnis}

Tabelle 1.1 Klinische Schweregrade der hereditären Sphärozytose 


\section{Einleitung}

\subsection{Hämolytische Anämien durch Erythrozytenmembrandefekte}

Im Kindesalter gehören hämolytische Anämien zu den gravierendsten hämatologischen Krankheitsbildern der Welt (Beutler und Luzzatto 1999). Eine durch einen Erythrozytenmembrandefekt ausgelöste hämolytische Anämie ist eine Form der Anämie mit korpuskulärer Ursache, die durch den verfrühten Abbau von Erythrozyten entsteht. Die mechanische Stabilität und die Verformbarkeit des Erythrozyten wird durch Wechselwirkungen der einzelnen Membranproteine untereinander und Wechselwirkungen mit der Doppellipidschicht beeinflusst. Veränderungen können zu Störungen, insbesondere zur Abnahme der Widerstandsfähigkeit gegenüber Scherkräften führen. Durch die erschwerte Milzpassage wird der Erythrozyt früher abgebaut und es folgt eine hämolytische Anämie (Dacie 1985). Die am häufigsten auftretende Anämie, die durch Erythrozytenmembrandefekte entsteht, ist die hereditäre Sphärozytose. Seltener sind Formen wie die hereditäre Elliptozytose, Stomatozytose, Xerozytose oder Poikilozytose (Davies und Lux 1989, Schröter und Eber 1989, Salomao et al. 2010).

\subsection{Hereditäre Sphärozytose}

Die hereditäre Sphärozytose (HS), angeborene Kugelzellanämie, ist die verbreitetste angeborene hämolytische Anämie in Mitteleuropa. In Deutschland geht man von 33000 Patienten mit Sphärozytose aus, das entspricht einer Häufigkeit von 1:2500. Durch einen Membrandefekt in den Erythrozyten bilden sich Sphärozyten. Weitere Hauptsymptome der Erkrankung sind Splenomegalie, hämolytischer Ikterus und die Erhöhung der osmotischen Fragilität. Bei 70\% der Patienten liegt eine Anämie vor (Eber 2006).

\subsection{Symptomatik der hereditären Sphärozytose}

Die Symptomatik weist vor allem klinische Zeichen wie Anämie, hämolytischer Ikterus und Splenomegalie auf. Es kann zu Müdigkeit, Abgeschlagenheit, mangelnder Leistungsfähigkeit und Belastbarkeit, Blässe, Kopfschmerzen, Dyspnoe, Konzentrationsstörungen und Tachykardie kommen. Die Familienanamnese ist meist positiv. Auf Grund der gesteigerten Hämolyse, die auf Grund der Membranveränderungen der Erythrozyten stattfindet, können bereits im Kindesalter Gallensteine und aplastische Krisen auftreten (Eber 2006, Ritter et al. 2006, Eber und Lux 2004). 


\subsection{Einteilung der hereditären Sphärozytose in Schweregrade}

Unter Berücksichtigung der Hämoglobinkonzentration, der Bilirubinkonzentration und der Retikulozytenanzahl lässt sich das Krankheitsbild der HS in vier Schweregrade einteilen: eine leichte, mittelschwere, schwere und sehr schwere Form (Tabelle 1).

Tabelle 1.1 Klinische Schweregrade der hereditären Sphärozytose (Eber 2006, S.1)

\begin{tabular}{|c|c|c|c|c|}
\hline & Leichte HS & Mittelschwere HS & Schwere HS $^{1}$ & Sehr schwere HS $^{2}$ \\
\hline $\begin{array}{c}\text { Anteil an Patienten } \\
(\%)\end{array}$ & $25-33$ & $60-70$ & $\approx 10$ & $3-4$ \\
\hline Hämoglobin (g/l) & $110-150$ & $80-110$ & $60-80$ & $<60$ \\
\hline Retikulozyten (\%) & $1,5-6$ & $\geq 6$ & $\geq 10$ (meist $>15)^{3}$ & $\geq 10$ \\
\hline Bilirubin (mg/dl) & $1-2$ & $\geq 2$ & $>2-3$ & $\geq 3$ \\
\hline $\begin{array}{c}\text { Osmotische } \\
\text { Fragilität }\end{array}$ & & & Deutlich erhöht & Deutlich erhöht \\
\hline $\begin{array}{c}\text { Frisches Blut } \\
\text { Inkubiertes Blut }\end{array}$ & $\begin{array}{c}\text { Dormal oder gering } \\
\text { erhöht }\end{array}$ & Deutlich erhöht & Deutlich erhöht; \\
\hline $\begin{array}{c}\text { Sphärozyten u.a. im } \\
\text { Blutausstrich }\end{array}$ & $\begin{array}{c}\text { Oft nur vereinzelt } \\
\text { Transfusionen }\end{array}$ & Deutlich vermehrt & Deutlich vermehrt & $\begin{array}{c}\text { Mikrosphärozyten } \\
\text { und Poikilozyten }\end{array}$ \\
\hline
\end{tabular}

Patienten mit der leichten Form der HS (ca. 1/3 der Fälle) zeigen meistens eine nahezu kompensierte hämolytische Anämie. Die Retikulozytenwerte liegen zwischen 1,5 und 6\%. Die totale Bilirubinkonzentration liegt zwischen 1 und 2mg/dl. Die osmotische Fragilität ist im frischen Blut normal bis gering erhöht, im inkubierten Blut deutlich erhöht. Sphärozyten sind im Blutausstrich oft nur vereinzelt $\mathrm{zu}$ sehen und eine Erythrozytentransfusion wird nur bei schwerer Anämie in Folge einer aplastischen Krise benötigt.

Am häufigsten erkranken die Patienten an der mittelschweren Form der HS (60 bis 70\%). Der Hämoglobinwert ist auf 80 bis $110 \mathrm{~g} / 1$ erniedrigt. Die Retikulozytenanzahl ( $\geq 6 \%$ ) und die totale Bilirubinkonzentration ( $\geq 2 \mathrm{mg} / \mathrm{dl}$ ) sind erhöht. Die osmotische Fragilität ist im frischen und im inkubierten Blut deutlich erhöht, und im Blutausstrich sind deutlich vermehrt Sphärozyten $\mathrm{zu}$ finden. Jenseits der Neugeborenenperiode liegt die Erythrozytentransfusionsanzahl zwischen null und zwei.

Seltener sind Patienten mit der schweren Form der HS (ca. 10\%). Die Hämoglobinkonzentration ist auf 60 bis $80 \mathrm{~g} / 1$ erniedrigt. Sowohl die Retikulozytenanzahl $(\geq 10 \%)$ als auch die

\footnotetext{
${ }^{1}$ Patienten benötigen in den ersten beiden Jahren gehäufte, z. T. regelmäßige Transfusionen

${ }^{2}$ Patienten müssen regelmäßig transfundiert werden, um einen Hämoglobinwert über $60 \mathrm{~g} / 1 \mathrm{zu}$ halten.

${ }^{3}$ Die Retikulozyten sind infolge der verzögert einsetzenden Erythropoese z.T. nur mäßig erhöht.

${ }^{4}$ jenseits der Neugeborenenperiode
} 
totale Bilirubinkonzentration (zwischen 2 und 3mg/dl) ist deutlich erhöht. Die osmotische Fragilität im frischen und im inkubierten Blut ist stark erhöht und im Blutausstrich sind eindeutig vermehrt Sphärozyten zu finden. In den ersten beiden Lebensjahren benötigen die Patienten gehäuft, zum Teil regelmäßig, Transfusionen. Es sind mindestens drei Erythrozytentransfusionen notwendig.

Die sehr schwere Form der HS tritt vereinzelt auf (3 bis 4\%). Die Patienten benötigen regelmäßig Transfusionen, um einen Hämoglobinwert über $60 \mathrm{~g} / 1 \mathrm{zu}$ halten. Auf Grund der Transfusionen entwickelt sich um das vierte bis fünfte Lebensjahr häufig eine Eisenüberladung (Eber 2006). Es liegt eine Retikulozytose $(\geq 10 \%)$ und eine Hyperbilirubinämie $(\geq 3 \mathrm{mg} / \mathrm{dl}$ ) vor. Wie auch bei der mittelschweren und der schweren Form, ist die osmotische Resistenz sowohl im frischen als auch im inkubierten Blut deutlich erhöht. Im Blutausstrich sind Mikrosphärozyten und Poikilozyten zu finden.

\subsection{Aufbau der Erythrozytenmembran}

Erythrozyten sind im Körperkreislauf starken Scherkräften ausgesetzt. Um ihnen standzuhalten, sind sie äußerst elastisch und besonders resistent gegen mechanische Belastungen. Das ermöglicht der besondere Aufbau der Erythrozytenmembran. Sie besteht aus zwei Anteilen. 45\% macht die äußere Plasmamembran aus, die aus einer Lipiddoppelschicht besteht. In die Lipiddoppelschicht sind Membranproteine eingelagert, die sie teilweise durchdringen (Singer und Nicolson 1972). Der zweite Anteil ist das innenliegende Membranskelett, das 55\% der Membran ausmacht und aus einem Netzwerk von Proteinen und Glykoproteinen besteht (Lux und Palek 1995).

\subsubsection{Lipide der Erythrozytenmembran}

Die Lipiddoppelschicht besteht aus zwei einzelnen Lipidschichten, die zueinander spiegelbildlich angeordnet sind. Sie setzt sich aus Phospholipiden, unverestertem Cholesterol und Glykolipiden zusammen (Lux und Palek 1995). Die Phospholipide bestehen aus zwei Untergruppen und sind asymmetrisch angeordnet. An der äußeren Seite der Lipiddoppelschicht befinden sich die Cholinphospholipide Phosphatidylcholin und Sphingomyelin. Die Aminophospholipide Phosphatidylethanolamin und Phosphatidylserin liegen zusammen mit den Phosphatidylinositolen an der Innenseite der Lipiddoppelschicht (de Jong et al. 1999; Kuypers 1998). Zwischen den Phospholipiden befindet sich Cholesterol. Es erhöht die Stabilität der Membran und bewirkt zusammen mit Proteinen in der Zellmembran ein Einund Ausschleusen von Signalstoffen. Die Glykolipide befinden sich auf der Außenseite der 
Lipiddoppelschicht und haben eine Rezeptorfunktion. Durch den Austausch zwischen Cholesterol und Phospholipiden mit den Plasmaproteinen wird die Membran erneuert (Reiche 2003, Renooij und van Golde 1977).

Leichte Veränderungen der Zusammensetzung und der Asymmetrie der Erythrozytenmembran sind ohne besondere Formveränderung möglich (Beck 1978), doch entstehen bei Ausdehnung der inneren Lipidschicht Stomatozyten (schlüsselförmige Erythrozyten) und bei Ausdehnung der äußeren Lipidschicht Echinozyten (Erythrozyten mit einer Stechapfelform). Dieser Effekt der beiden Lipidschichten wird als „,bilayer couple effect“ bezeichnet (Sheetz und Singer 1974, Fischer 1992).

\subsubsection{Proteine der Erythrozytenmembran}

In der Erythrozytenmembran befinden sich zahlreiche Membranproteine, von denen 10 bis 15 gehäuft auftreten. Sie lassen sich in integrale und in periphere Proteine unterteilen.

Die Lipiddoppelschicht enthält die integralen Proteine. Dazu gehören der Anionenaustauscher Bande 3 (Blutgruppe Ii) und die Glykoproteine A, B und C.

Bande 3 ist das häufigste Protein in der Membran der Erythrozyten. Es besteht aus zwei Domänen, deren unterschiedliche Funktion voneinander getrennt sind. Die N-terminale zytoplasmatische Domäne (45 kD) verbindet das Membranskelett mit der Doppellipidmembran mittels Interaktionen zwischen Ankyrin, Protein 4.1 und Protein 4.2. Die Hauptfunktion der C-terminalen Membrandomäne (56 kD) ist die Vermittlung eines Anionenaustausches über die Membran (Jarolim et al. 1995 b). Die Glykophorine besitzen die Blutgruppenantigene $\mathrm{MN}$ und $\mathrm{Ss}$, die sich an der Oberfläche der Lipiddoppelschicht befinden und kohlenhydrathaltig sind. Besonders hervorzuheben ist die Verbindung zwischen Glykophorin $\mathrm{C}$ und Protein 4.1. Sie gehört neben der Bande-3-Ankyrin-Verbindung zu den Hauptverbindungen zwischen der Lipiddoppelschicht und dem Membranskelett.

Die innere Oberfläche der Erythrozytenmembran wird durch das Membranskelett gebildet. Es ist ein Geflecht bestehend aus den peripheren Proteinen Spektrin, Ankyrin, Aktin, Tropomyosin, Adduzin, Protein 4.1, Protein 4.9 (Dematin) und Protein 4.2 (Pallidin) (Eber und Lux 2004). 


\subsubsection{Membranskelett}

Das Membranskelett stellt die elastische Eigenschaft der Erythrozyten her und entsteht durch die Vernetzung der peripheren Proteine.

Das Protein Spektrin ist lang gestreckt und elastisch. Ein Spektrinmolekül (Spektrindimer) besteht aus einer $\alpha$ - und einer $\beta$-Kette, die in entgegengesetzter Richtung ineinander geschlungen sind und eine Helix bilden. Dabei ist das N-terminale Peptid (80.000 D) der $\alpha$ Spektrinkette mit dem C-terminalen Ende der $\beta$-Spektrinkette verknüpft. 5\% des Spektrins liegen als Dimere vor (Liu et al. 1984). Kopf an Kopf lagern sich die Spektrindimere zu Tetrameren zusammen und bilden letztendlich Oligomere. Aufgedreht vorliegend, erreichen sie eine Länge von 76nm. Maximal kann es zu einer Dehnung bis zu 200nm Länge kommen, danach folgt die Ruptur (Lux und Palek 1995).

Die Spektrintetramere besitzen Bindungsstellen für Aktin, Ankyrin und Protein 4.1. Sowohl Aktin als auch Ankyrin bindet am Ende und nahe der Mitte der Spektrintetramere (McGough and Josephs 1990, Karinch et al. 1990). Durch eine Verknüpfung durch Aktinfilamente an den Schwanzenden der Spektrintetramere entsteht eine sechseckige Form. Es binden durchschnittlich sechs Spektrintetramere an ein Aktinfilament. Aktin bildet aus ca. 13 Monomeren ein Oligomer und liegt als kurze Doppelhelix vor (Byers und Branton 1985). Die AktinfilamentSpektrintetramer-Verbindungen werden durch andere Proteine wie Adduzin, Protein 4.9 und Tropomyosin stabilisiert (Matsuoka et al. 2000, Gardner und Bennett 1987, Siegel und Branton 1985). Vor allem trägt aber Protein 4.1 zur Stabilität der Aktinfilament-Spektrintetramer-Verbindung bei (Ohanian et al. 1984). Es bindet nahe der Aktinbindungsstelle an das Schwanzende der $\beta$-Spektrinkette.

\subsubsection{Eigenschaften und Funktion des Membranskeletts}

Die Eigenschaften der Spektrinmoleküle und die Anordnung der Proteine geben dem Membranskelett die ausgeprägte Elastizität und Flexibilität, die für die Kreislaufpassage der Erythrozyten bedeutend ist. Der Erythrozyt hat eine charakteristisch diskoide Form und eine Fähigkeit, wiederholt passive Verformungen zu überstehen (Mohandas und Chasis 1993). Die Membran selbst hält nur einer Kompression von 3-4\% stand (Lux und Palek 1995). Das Ausmaß einer Verformung der Erythrozyten hängt von Stärke und Dauer der Belastung auf die Membran ab. Wenn Kräfte länger einwirken, kann es zu neuen Verbindungen der Membrananteile und damit zu einer Verformung kommen (Lux und Palek 1995, Evans und Hochmuth 1976). Dabei ermöglicht das Membranskelett eine Beibehaltung der 
Oberflächengröße trotz Formveränderung der Erythrozyten. Durch zunehmende Bindung von Hämoglobin oder denaturiertem Hämoglobin an Bande 3 kommt es zu einer Zunahme der Membrandicke. Als Folge kann es zu einer statischen Verformung kommen und die diskoide Ausgangsform des Erythrozyten nicht wieder hergestellt werden (Mohandas und Chasis 1993, Evans et al. 1984).

\subsubsection{Verbindung von Membranskelett und Doppellipidmembran}

Über die Proteine Ankyrin und Protein 4.1 ist das Membranskelett an die integralen Proteine Bande 3 und die Glykophorine A, B und C der Doppellipidmembran gebunden.

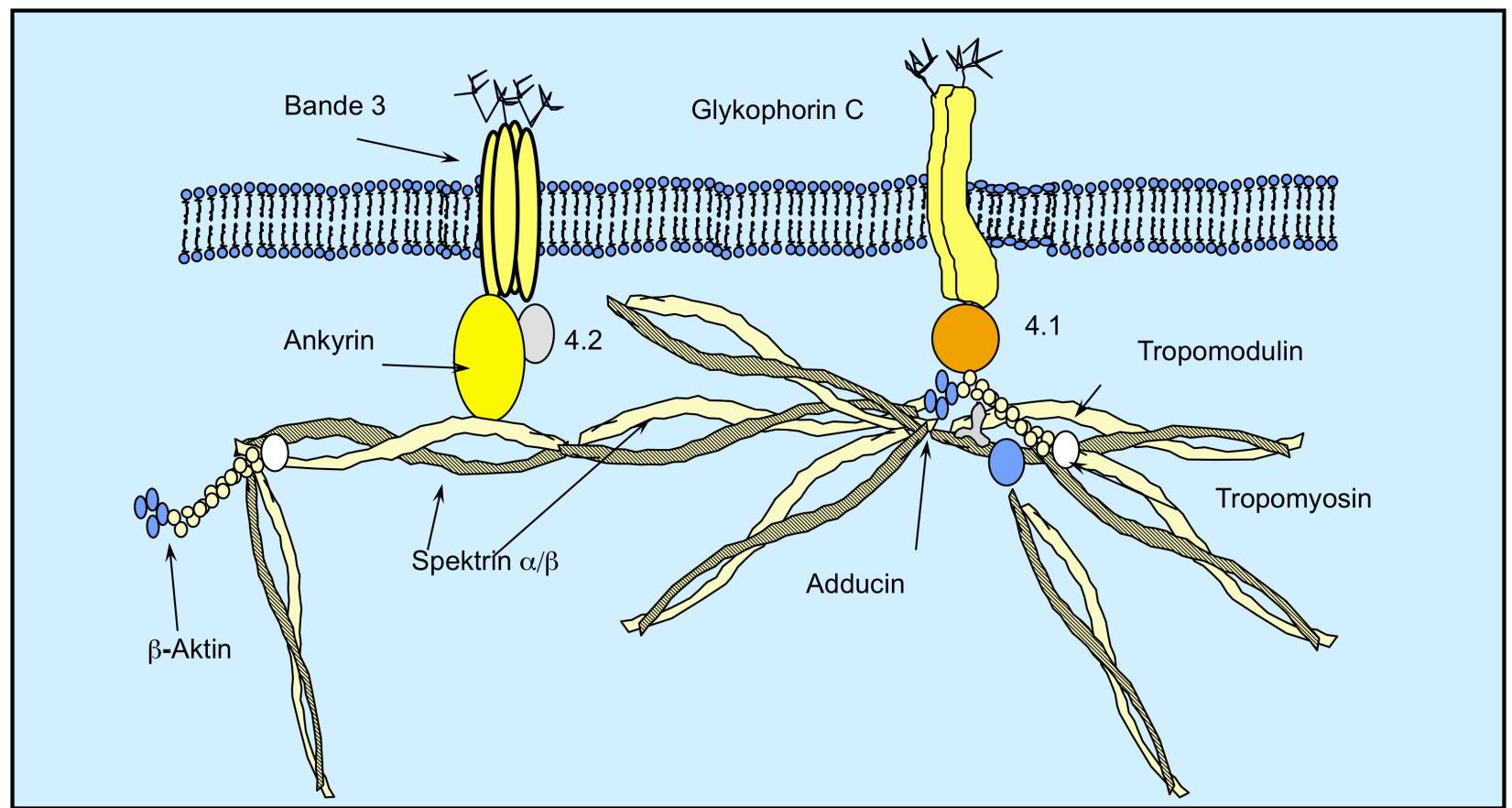

Abbildung 1.1 Schematisches Modell der Erythrozytenmembran (mit freundlicher Genehmigung von Prof. Dr. med. M.Lakomek, Göttingen) Die integralen Membranproteine Bande 3 und Glykophorin sind in die Lipiddoppelschicht eingelagert. Durch ein Geflecht, bestehend aus den peripheren Proteinen, wird an der Innenseite der Erythrozytenmembran das Membranskelett gebildet.

4.1 - Protein $4.1 ; 4.2$ - Protein 4.2

Ankyrin ist ein 206-kD-Molekül, das zwei voneinander unabhängige, hochaffine Bindungen zu der $\beta$-Kette von Spektrin und zu Bande 3 besitzt (Bennett und Stenbuck 1979, Bennett und Stenbuck 1980). Es besteht aus drei Domänen. An der N-terminalen Domäne binden Bande 3 und Tubulin. Die Ankyrin-Bande-3-Verbindung ist die wichtigste Bindung des Membranskeletts an die Doppellipidmembran. Sie wird zusätzlich durch die Bindung von Protein 4.2 stabilisiert. An der mittleren Domäne binden Spektrin, Vimentin und Desmin (Georgatos und Marchesi 1985, Davis und Bennett 1990). Die C-terminale Domäne hat eine regulatorische Funktion und kann die Verbindung von Spektrin und Bande 3 stärken oder schwächen (Davis et al. 1992). 
Protein 4.1 ist ein Anionenkanal und verbindet neben den Proteinen des Membranskeletts Spektrin und Aktin untereinander auch das Membranskelett mit Proteinen der Lipidmembran Bande 3 und Glykophorin A, B und C. Bei Fehlen von Protein 4.1 kommt es zu einer gesteigerten Fragilität der Erythrozytenmembran und damit zu einer gesteigerten Hämolyse (Tchernia et al. 1981). Die Verbindung von Protein 4.1 und Glykophorin C der Lipidmembran ist allerdings schwächer als die oben beschriebene Membranskelett-Lipidmembran-Verbindung zwischen Ankyrin und Bande 3 (Ritter et al. 2006).

Die Verbindungen der Proteine in der Membran untereinander werden durch Proteinphosphorylierung stark beeinflusst. Häufig wird durch zunehmende Phosphorylierung ihre Affinität vermindert (Bennett 1990).

\subsection{Genetik und molekulare Defekte der hereditären Sphärozytose}

Bei der hereditären Sphärozytose liegt in 2/3 der Fälle ein autosomal-dominanter Erbgang, bei $20 \%$ ein Defekt durch Neumutation in der mütterlichen Keimbahn und bei etwa $15 \%$ ein autosomal-rezessiver Erbgang vor (Eber und Lux 2004).

Der Membrandefekt tritt vor allem als Ankyrin-Defekt, $\beta$-Spektrin-Defekt oder als Bande 3Defekt auf. Seltener gibt es Fehler im Gen für die $\alpha$-Kette des Proteins Spektrin oder für Bande 4.2. Bei vielen der dominant vererbten Fälle kommt es zu einem Frameshift oder zu einer Nonsens-Mutation der Gene für Ankyrin, Bande 3 oder $\beta$-Spektrin. Es gibt keine Häufung bestimmter molekularer Defekte. Deshalb ist auch eine molekulargenetische Diagnostik nur in wenigen Fällen, wie z.B. pränatale Diagnostik auf Grund schwerer familiärer Verläufe, gerechtfertigt (Eber 2006; Herold 2006; Ritter et al. 2006).

\subsection{Pathogenese der hereditären Sphärozytose}

Meist betreffen die fehlerhaften oder fehlenden Proteine die Bindung von Ankyrin, Spektrin und/oder Protein 4.2 an Bande 3 (Jarolim et al. 1995 a). Die Folge ist die für die Pathogenese der Sphärozytose entscheidende verminderte Konzentration an Proteinen im Membranskelett der Erythrozytenmembran. Durch den Membranmaterialverlust wird die Membranfläche verkleinert, doch bleibt das Zytoplasmavolumen gleich. Außerdem nimmt die Bindung der Lipiddoppelschicht an das Membranskelett ab. Diese Faktoren sorgen für eine Instabilität des Gerüstes der Erythrozyten in vertikale Richtung und einen Verlust der bikonkaven Form, so dass Sphärozyten entstehen (Iolascon et al. 2003, Ritter et al. 2006). 


\title{
Hereditäre Sphärozytose Pathogenese
}
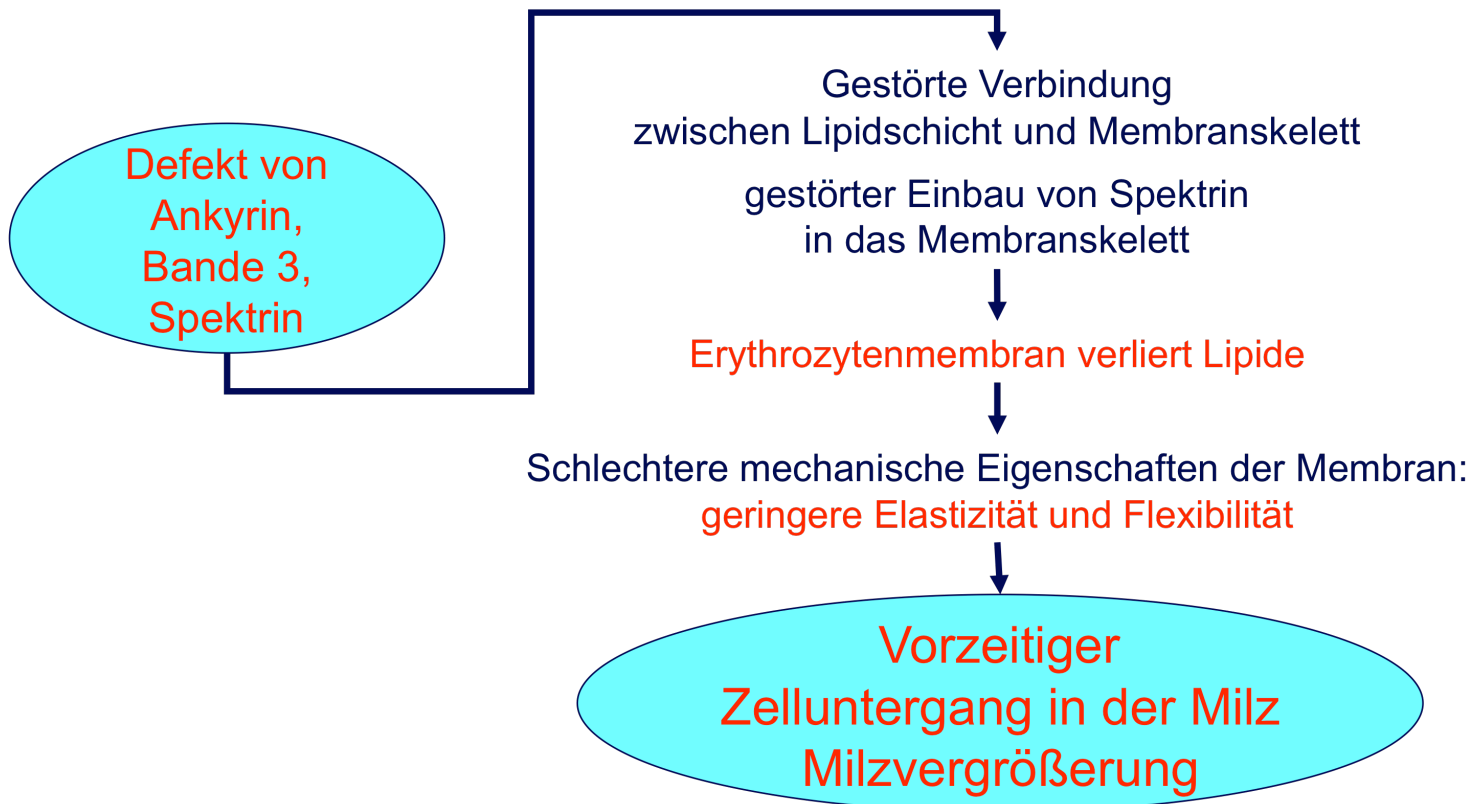

\begin{abstract}
Abbildung 1.2 Pathogenese der hereditären Sphärozytose
(mit freundlicher Genehmigung von Prof. Dr. med. M.Lakomek, Göttingen) Ein Membrandefekt führt zum Verlust von Lipiden aus der Erythrozytenmembran, mit der Folge schlechterer mechanischer Eigenschaften der Erythrozyten, die ausschlaggebend für eine vorzeitige Hämolyse sind.
\end{abstract}

Durch die defekte Struktur kommt es ferner zur Störung der Ionenpermeabilität (Liu et al. 1995), so dass die Erythrozytenmembranen hyperpermeabel für Natriumionen werden. Für eine Aufrechterhaltung der intrazellulären Ionenkonzentration ist dann ein erhöhter aktiver Natriumauswärtsstrom notwendig, der zu einem Hypermetabolismus führt (Cooper und Jandl 1969).

Im Rahmen der Milzkonditionierung der Erythrozyten werden kleinste Membranlipidareale aus der Sphärozytenmembran, die nicht von einem Membranskelett ausgekleidet sind, als Mikrovesikel abgeschnürt (Cooper und Jandl 1969, Weed et al. 1969). Wenn ein kritischer Membranverlust erreicht ist, ist der Phagozytenkontakt mit den veränderten Erythrozyten um das 30- bis 300-fache gegenüber der Kontaktzeit normaler Erythrozyten verlängert und die Sphärozyten werden früher als physiologischerweise üblich hämolysiert (Eber und Lux 2004). Ihre physiologische Überlebenszeit von 120 Tagen ist dadurch auf etwa 23 Tage verkürzt (Becker et al. 1993). 


\subsection{Diagnose und Differentialdiagnosen der hereditären Sphärozytose}

Die Diagnose der HS kann bei Vorliegen von mindestens zwei Zeichen der gesteigerten Hämolyse (Retikulozytose, indirektes Bilirubin erhöht, LDH erhöht, Ahaptoglobinämie) und erhöhter osmotischer Fragilität der Erythrozyten gestellt werden. Die Hämolysezeichen können mit der typischen klinischen Symptomatik einhergehen (Anämie mit Folgeerscheinungen, Ikterus). $\mathrm{Zu}$ den Hauptbefunden gehört fakultativ eine Splenomegalie, positive Familienanamnese, Nachweis von Sphärozyten im Blutausstrich, erhöhte Anisozytose und eine Anämie, die bei ungefähr 2/3 der Patienten auftritt.

Nebenbefundlich kann es zu einer erhöhten MCHC (>35\%), einer verminderten Spektrinkonzentration und zu anderen Defekten der Erythrozytenmembran, wie erniedrigte Bande 3-Konzentration und/oder erniedrigter Ankyrinkonzentration, kommen (Eber 2006).

Differentialdiagnostisch müssen im Neugeborenenalter Erkrankungen wie die RhInkompatibilität oder die AB0-Inkompatibilität ausgeschlossen werden. Sie stellen sich mit einem positiven direkten Coomb's Test und dem Nachweis einer Antikörperbeladung der Erythrozyten dar. Bei älteren Kindern müssen immunhämolytische Anämien, wie Wärmeantikörper oder biphasische Antikörper vom Donath-Landsteiner-Typ, ausgeschlossen werden. Bei den immunhämolytischen Anämien ist der direkte Coomb's Test positiv und es lassen sich IgG, IgM und die Aktivierung des Komplementsystems nachweisen.

Bei negativer Familienanamnese und nur leicht erhöhter osmotischer Fragilität der Erythrozyten sollten Enzymdefekte, wie zum Beispiel der Pyruvatkinase-Mangel (PK-Mangel), ausgeschlossen werden. Wie die Enzymdefekte kann auch eine Stomatozytose eine hämolytische Anämie auslösen. Bei der Stomatozytose sind im Blutausstrich vermehrt Mikrosphärozyten und Stomatozyten zu finden, das MCV ist erhöht (Eber 2006).

\subsection{Therapie und Prophylaxe der hereditären Sphärozytose}

Kausale Therapiemöglichkeiten sind nicht vorhanden und bei leichtem Krankheitsverlauf ist eine Therapie in der Regel nicht notwendig. Symptomatische Therapien, wie Bluttransfusionen, sind nur bei schwerer Anämie erforderlich und werden meist auch erst bei vorliegender klinischer Symptomatik und/oder einem Hb-Abfall unter 50 bis $60 \mathrm{~g} / \mathrm{l}$ durchgeführt. Bei Frühund Neugeborene müssen altersabhängig andere Hb-Grenzwerte beachtet werden.

Bei schwereren Formen ist die Splenektomie die Therapie der Wahl. Durch sie wird nicht die ursächliche Formanomalie beseitigt, doch bleibt der vorzeitige Erythrozytenabbau in der Milz 
aus. Es kommt in beinahe allen Fällen zu einer Normalisierung der Erythrozyten- und Retikulozytenzahlen. Bei Patienten mit der seltenen sehr schweren Form kann weiterhin eine Hämolyse existieren. Der Bilirubinspiegel ist in den ersten Jahren nach der Splenektomie wieder normal, Retikulozytenzahl und Bilirubinspiegel steigen im Verlauf jedoch langsam wieder an, erreichen aber nicht die hohen präoperativen Werte. Die HS ist die häufigste Indikation für eine Splenektomie in der Kindheit. Trotz guter Ergebnisse muss die Indikation zu einer Splenektomie sorgfältig abgewogen werden. Es besteht lebenslang eine erhöhte Gefahr einer meist pneumokokkenbedingten Postsplenektomie-Sepsis. Die schwerste Form der Infektion stellt das OPSI-Syndrom (overwhelming postsplenectomie infection syndrome) dar. Auf Grund der Postsplenektomie-Sepsisgefahr sollten Kinder möglichst erst ab dem sechsten Lebensjahr und keinesfalls vor dem dritten Lebensjahr splenektomiert werden (Eber und Lux 2004; Ritter et al. 2006). Heute wird die subtotale Splenektomie bevorzugt, die die Infektionsgefahr minimieren soll. Dabei wird ein Großteil der Milz bis auf einen Rest von 10 $\mathrm{ml}$ (Eber et al. 2001; Eber 2006) bis $30 \mathrm{ml}$ (Bader-Meunier et al. 2001) entfernt.

Möglichst zwei Wochen vor der Splenektomie werden die Patienten gegen Pneumokokken mit dem 23-valenten unkonjugierten Impfstoff geimpft. Wurde die Pneumokokkenimpfung vor der Splenektomie versäumt, soll zwei bis vier Wochen nach der Splenektomie der konjugierte 7-valente Impfstoff verwendet werden. Daraufhin ist dann eine Boosterimpfung mit dem 23-valenten Impfstoff zu empfehlen. Nach fünf Jahren findet eine Auffrischimpfung mit unkonjugiertem Impfstoff statt. Wenn keine Haemophilus-influenzae-Typ-b-Impfung oder ein zu geringer Titer vorliegt, sollte für eine Grundimmunisierung ab dem zweiten Lebensmonat mit dem Konjugatimpfstoff drei Mal im Abstand von mindestens vier Wochen geimpft werden und eine vierte Impfung in einem Abstand von mindestens sechs Monaten zur dritten Impfung verabreicht werden. Es wird auch eine Meningokokkenimpfung empfohlen. Kindern unter zwei Jahren wird zunächst der konjugierte Meningokokken-C-Impfstoff injiziert und nach dem vollendeten zweiten Lebensjahr die Impfung durch einen 4-valenten PolysaccharidImpfstoff (Meningokokken A, C, W135, Y) ergänzt. Patienten nach dem zweiten Lebensjahr wird zunächst der konjugierte Meningokokken-C-Impfstoff und nach sechs Monaten der 4-valente Polysaccharid-Impfstoff verabreicht (Eber 2006, STIKO 2009, Eber et al. 2001).

Das Risiko einer Pneumonie, Sepsis oder Meningitis durch bekapselte Bakterien, wie Pneumokokken, Haemophilus oder Meningokokken und durch Parasiten wie Malaria, ist um mehrere 100 mal erhöht. Deshalb wird prophylaktisch nach der Splenektomie eine antibiotische Dauermedikation mit Penicillin per os für mindestens 3 Jahre oder bis zum 
vollendeten zehnten Lebensjahr durchgeführt. Nach der Prophylaxe muss lebenslang bei jeder hochfieberhaften Infektion sofort ein Breitbandantibiotikum, z.B. Amipen mit $\beta$-Laktamasehemmer, gegeben werden.

Sofern die Patienten unter Gallensteinen leiden, wird eine Cholezystektomie angeraten. Bei der mittelschweren Form der Sphärozytose, wird eine gleichzeitige subtotale Splenektomie und Cholezystektomie befürwortet (Eber 2006, Ritter et al. 2006).

\subsection{Komplikationen der hereditären Sphärozytose}

Das frühzeitige Auftreten von Gallensteinen ist die häufigste Komplikation. Sie ist zurückzuführen auf den hämolysebedingten hohen Bilirubinspiegel (Iolascon et al. 2003, John-Hopkins-University 2010). Bei zusätzlichem Auftreten von erblich bedingtem Morbus Gilbert-Meulengracht ist das relative Risiko für das Auftreten von Gallensteinen zusätzlich erhöht (Garg und Kumar et al. 2008).

Eine der vermehrt auftretenden Komplikationen bei Patienten mit HS sind hämolytische Episoden, die häufig viraler Genese sind. Zeitweise können Transfusionen erforderlich sein. Für schwere, transfusionsbedürftige aplastische Krisen ist meist eine Infektion mit Parvovirus B19 der Auslöser. Derart schwere Krisen treten meist nur einmalig im Leben auf, da das Virus nach einer Infektion eine lebenslange Immunität hinterlässt. Bei dieser Infektion fehlt bei Patienten mit hämolytischer Anämie das für Ringelröteln (Erythema infectiosum) typische Wangen- und Rumpfexanthem. Der bei den aplastischen Krisen ausgeprägte Hämoglobinabfall führt zu Symptomen der kardiovaskulären Insuffizienz, die im Extremfall bei schwerer Anämie zum Tod führen kann (Ritter et al. 2006).

Bei Patienten, die regelmäßig transfundiert werden, entwickelt sich häufig eine deutliche Hämochromatose, die eine eisenausschleusende Chelation-Therapie erforderlich machen kann (Eber 2006, Ritter et al. 2006). Bei Patienten mit sehr schwerer HS kann es ohne regelmäßige Transfusionen oder Splenektomie zu Wachstumsstörungen und verspäteter sexueller Entwicklung kommen (Eber und Lux 2004).

Vereinzelt entwickeln erwachsene Patienten mit Sphärozytose schmerzlose Unterschenkelgeschwüre oder eine chronische erythematöse Dermatitis der Beine. Es kann auch zu Gichtanfällen kommen. Extramedulläre Tumoren, die meist im Thorax paraspinal lokalisiert auftreten, gehören zu den seltenen Komplikationen (Ritter et al. 2006). 


\section{Material und Methoden}

\subsection{Studiendesign}

Die Studie wurde als retrospektiv-deskriptive Studie angelegt. Es ist die bis jetzt größte deutsche Untersuchung von Patienten mit hereditärer Sphärozytose mit dem Ziel, die Erkrankung Sphärozytose sowie ihre Besonderheiten und Komplikationen detailliert zu erfassen. Durch die große Fallzahl (358 Patienten) entstanden valide Daten, die in diesem Umfang bis jetzt noch von keiner früheren Studie dargestellt wurden.

\subsection{Patienten}

Im Rahmen des sogenannten ENERCA-Projektes wurden 358 Patientinnen und Patienten mit Sphärozytose untersucht. ENERCA (European Network for Rare and Congenital Anaemias) ist ein europäisches und von der Europäischen Kommission, Generaldirektion „Gesundheit und Verbraucherschutz" in Brüssel unterstütztes Netzwerk und EU-Projekt für seltene angeborene oder später erworbene Anämien.

Kooperierende deutsche Zentren im Rahmen dieses EU-Projektes waren das Johannes Wesling Klinikum in Minden, die Medizinische Hochschule Hannover, das Zentrum für Kinderheilkunde und Jugendmedizin im Klinikum Bremen-Mitte und die Kinder- und Jugendarztpraxis von Prof. Dr. med. Stefan Eber in München.

\subsubsection{Retrospektive Datenerhebung}

Anhand von Computerdaten, Entlassungsbriefen und Untersuchungsprotokollen der im jeweiligen Krankenhaus betreuten Patienten wurden Patienten mit der Diagnose Sphärozytose herausselektiert und im Zeitraum zwischen September 2006 und Dezember 2009 registriert.

Von diesen Patienten wurden alle verfügbaren Krankenakten wie Laborbefunde, Aufnahmeberichte, Verlaufsberichte, Kurvenblätter, Verordnungsbögen, Notarztprotokolle und Arztbriefe zusammengestellt.

Aus diesen Akten wurden folgende Daten ermittelt:

- Alter, Geschlecht, Diagnosedatum, Familienstammbaum

- Coombs-Test zum Diagnosezeitpunkt, Hämoglobin (Hb) zum Diagnosezeitpunkt, mittleres korpuskuläres Volumen (MCV) zum Diagnosezeitpunkt, 
mittleres korpuskuläres Hämoglobin $(\mathrm{MCH})$ zum Diagnosezeitpunkt, mittlere korpuskuläre Hämoglobinkonzentration (MCHC) zum Diagnosezeitpunkt, Retikulozyten in Promille und absolut zum Diagnosezeitpunkt, Thrombozyten zum Diagnosezeitpunkt, Leukozyten zum Diagnosezeitpunkt

- Bilirubin total und direkt zum Diagnosezeitpunkt, Laktatdehydrogenase (LDH) zum Diagnosezeitpunkt

- Acylglycerol-Lysis-Test (AGLT), Osmotische Resistenz im frischen und im 24-Stunden inkubierten Blut, Autohämolyse ohne und mit Glukosezusatz

- Zeitpunkt und Art der Splenektomie, Aufenthaltsdauer im Krankenhaus nach Splenektomie, Restvolumen der Milz nach Splenektomie bei Wiedervorstellung, overwhelming postsplenectomy infection (OPSI) syndrome, Antibiotikaprophylaxe nach Splenektomie, Impfprophylaxe vor Splenektomie (Pneumokokken, Meningokokken, Haemophilus Influenza b), Thrombosevorkommen und Thromboseprävention nach Splenektomie, Auftreten des ersten Gallensteins, Alter bei Cholezystektomie

- Zeitpunkt der ersten hämolytischen/aplastischen Krise, Anzahl der hämolytischen/aplastischen Krisen und Induktion (viral), Bluttransfusionen, Auftreten, Art und Dauer eines Ikterus, Therapie des Ikterus (Phototherapie, Austauschtransfusion)

- Beinulzera, Neurologische Symptome, Probleme in der Schwangerschaft der Mutter.

\subsubsection{Fragebogen}

Es wurde ein Fragebogen entworfen (Anhang), der zusammen mit einer Aufklärung und einer Einverständniserklärung zur Verarbeitung personenbezogener Daten an die Patientinnen und Patienten bzw. deren Eltern geschickt wurde.

\subsubsection{Ein-/Ausschlusskriterium}

Es wurden nur Patientinnen und Patienten mit Sphärozytose in die Auswertung aufgenommen. Ausschlusskriterien bezüglich Alter, Geschlecht, Krankheit, Krankheitsstatus, Vortherapie gab es nicht.

\subsection{Laborchemische Parameter}

Im Folgenden werden vier Labortests beschrieben, die für die Diagnostik der hereditären Sphärozytose angewandt wurden. 


\subsubsection{Acylglycerol-Lysis-Test (AGLT)}

Der AGLT ist ein einfacher, schneller und kostengünstiger Screening-Test, um die gesteigerte Säure-Glyzerin-Lyse und damit die verminderte osmotische Resistenz der Erythrozyten, wie sie bei der Sphärozytose auftritt, nachzuweisen (Zanella et al. 1980). Er ist weniger aufwändig als die Bestimmung der osmotischen Resistenz durch Inkubation von Erythrozyten in verdünnten Salzlösungen, doch werden durch den AGTL auch nicht alle Patienten mit Sphärozytose erkannt. Der Test wurde 1980 von Zanella et al. für die Sphärozytosediagnostik beschrieben und wird in unserer Klinik leicht modifiziert (Veränderung im Phosphatpuffer und der Glycerollösung) angewandt.

Benötigte Geräte: 1 Photometer, 1 Eppendorf-Pipette à $1000 \mu 1$ mit entsprechenden Pipettenspitzen, 1 Eppendorf-Pipette à $20 \mu 1$ mit entsprechenden Pipettenspitzen, 2 Reagenzgläser mit Stopfen, 1 Reagenzglasständer, 2 Küvetten, Stoppuhr, Wasserbad $\left(25^{\circ} \mathrm{C}\right)$

Benötigte Substanzen: $20 \mu 1$ EDTA-Vollblut, $6 \mathrm{ml}$ phosphatgepufferte Saline ${ }^{5}$ (PBS, pH 6,9, $\left.25^{\circ} \mathrm{C}\right), 2 \mathrm{ml}$ Glycerollösung ${ }^{6}\left(25^{\circ} \mathrm{C}\right)$

Durchführung: Zu Beginn jeder Testdurchführung wird das Photometer mittels PBS (1ml) bei $625 \mathrm{~nm}$ kalibriert. $2 \mathrm{ml}$ Glycerollösung und $6 \mathrm{ml}$ PBS werden im Wasserbad auf $25^{\circ} \mathrm{C}$ erwärmt. Für den AGLT werden nun $20 \mu 1$ EDTA-Vollblut und $5 \mathrm{ml} \mathrm{PBS}\left(\mathrm{pH} 6,9,25^{\circ} \mathrm{C}\right.$ ) in ein Reagenzglas mit Stopfen pipettiert und per Hand gemischt. Von dieser Lösung wird $1 \mathrm{ml}$ in eine Küvette pipettiert und mit $2 \mathrm{ml}$ Glycerollösung bei Zimmertemperatur gemischt. Zeitgleich wird die Stoppuhr gestartet. Die Küvette wird nun in das Photometer gestellt. In vorgegebenen Zeitintervallen (15 sec., $30 \mathrm{sec} ., 1 \mathrm{~min} ., 2 \mathrm{~min} ., 3 \mathrm{~min} ., 4 \mathrm{~min} ., 5 \mathrm{~min} ., 10 \mathrm{~min}$, 15 min., $30 \mathrm{~min}$.) wird die Hämolysezeit photometrisch bei $625 \mathrm{~nm}$ bestimmt. Nach dem Erreichen der Halbwertzeit bzw. nach Ablauf von 30 min. wird der Test beendet.

Bei einem Wert größer als 30 min. handelt es sich um einen Normalbefund. Wenn der AGLT kürzer als 1 bis 2 Minuten ist, gilt er als eindeutig pathologisch. Der AGLT wird in unserer Klinik immer im Zusammenhang mit dem Kryohämolyse-Test betrachtet, um die Diagnose einer Sphärozytose eindeutig stellen zu können.

\subsubsection{Kryohämolyse-Test}

Der hypertone Kryohämolyse-Test ist eine weitere Methode, um das Ausmaß der osmotischen Fragilität der Erythrozyten zu bestimmen. Patienten mit hereditärer Sphärozytose zeigen eine

\footnotetext{
${ }^{5 / 6}$ modifizierte Lösungen des von Zanella et al. 1980 im Br J Haematol publizierten Tests
} 
signifikant höhere Kryohämolyse als gesunde Vergleichsgruppen (Iglauer et al. 1999). Deshalb wird dieser Test auch für die Sphärozytosediagnostik verwendet.

Benötigte Geräte: 1 Eppendorf-Pipette à $50 \mu 1$ mit entsprechenden Pipettenspitzen, 1 Eppendorf-Pipette à $1000 \mu 1 \quad$ mit entsprechenden Pipettenspitzen, Wasserbad $\left(37^{\circ} \mathrm{C}\right)$, Reagenzglasständer, 2 Reagenzgläser, 1 Eisbad, 1 Zentrifuge, 3 Küvetten

Benötigte Substanzen: $100 \mu$ EDTA-Blut, $2 \mathrm{ml}$ Sucrose-Puffer: Sucrose (0,7 Molar) gelöst in Phosphatpuffer $\left(\mathrm{NaH}_{2} \mathrm{PO}_{4}\right.$ und $\left.\mathrm{H}_{2} \mathrm{O}, \mathrm{pH} 7,4\right), 7 \mathrm{ml}$ Aqua dest. $\left(20^{\circ} \mathrm{C}\right)$

Durchführung: Das Photometer wird mittels 1ml Aqua dest. bei 546nm kalibriert. $2 \mathrm{ml}$ Sucroselösung werden auf $37^{\circ} \mathrm{C}$ in einem Wasserbad vorgewärmt. $2 \mathrm{ml}$ Sucroselösung werden mit $50 \mu 1$ EDTA-Blut in ein Reagenzglas pipettiert und per Hand geschwenkt. Diese Lösung wird nun $10 \mathrm{~min}$. bei $37^{\circ} \mathrm{C}$ im Wasserbad inkubiert. Jetzt wird die Lösung per Hand erneut geschwenkt, daraufhin $10 \mathrm{~min}$. in ein Eisbad gestellt und danach 5 min. bei $3000 \mathrm{U} / \mathrm{min}$. zentrifugiert. Der Überstand der zentrifugierten Lösung wird in eine Küvette pipettiert und bei $546 \mathrm{~nm}$ gemessen (H1). Parallel dazu werden in ein zweites Reagenzglas $50 \mu$ LDTA-Blut in $2 \mathrm{ml}$ Aqua dest. gegeben. $200 \mu \mathrm{l}$ dieses Hämolysats werden in ein Reagenzglas mit $4 \mathrm{ml}$ Aqua dest. pipettiert, gemischt und bei 546nm gemessen (H2).

Nach der Formel: $x \%$ Hämolyse $=\frac{H 1 \times 100}{H 2 \times 21}$ wird der Kryohämolyse-Wert errechnet .

Der AGLT und der Kryohämolyse-Test werden im Zusammenhang betrachtet. Wenn der AGLT-Wert kürzer als 1 bis 2 Minuten und der Kryohämolyse-Test-Wert größer als 6\% ist, kann die Diagnose der Sphärozytose gestellt werden. Zusätzlich sollte das Differentialblutbild mit den hämatologischen Parametern ( $\mathrm{Hb}$, Erythrozyten, Hkt, $\mathrm{MCV}, \mathrm{MCH}, \mathrm{MCHC}$, Retikulozyten), sowie die Hämolyseparameter unkonjugiertes Bilirubin, Haptoglobin und LDH betrachtet werden. Bei nicht eindeutig pathologischen AGLT- und Kryohämolysewerten oder diskrepanten Werten (ein Test pathologisch, ein Test normal) und auffälligen hämatologischen und hämolytischen Parametern wird die osmotische Resistenz als erweiterte Diagnostik durchgeführt.

\subsubsection{Osmotische Resistenz}

Da sich nicht alle Formen der Sphärozytose mit AGLT und Kryhämolyse diagnostizieren lassen, ist eine erweiterte Diagnostik mittels Bestimmung der osmotischen Resistenz und der Autohämolyse notwendig. Die Widerstandsfähigkeit von Erythrozyten gegen die 
hämolysierende Wirkung hypotoner Lösungen wird als osmotische Resistenz/Fragilität bezeichnet. Eine erhöhte osmotische Fragilität der Erythrozyten ist bei Patienten mit Sphärozytose obligatorisch (Eber 2006). Sie wird in modifizierter Form nach Parpart et al. (1947) im frischen Blut und nach 24-stündiger Inkubation mit Kochsalzlösungen verschiedener Konzentrationen bei $37^{\circ} \mathrm{C}$ gemessen.

Benötigte Geräte: 32 Zentrifugenröhrchen, Reagenzglasständer, 1 Eppendorf-Pipette à $20 \mu 1$ mit entsprechenden Pipettenspitzen, 1 Eppendorf-Pipette à $500 \mu 1$ mit entsprechenden Pipettenspitzen, 1 Eppendorf-Pipette à $1000 \mu \mathrm{l}$ mit entsprechenden Pipettenspitzen, 16 Küvetten

Benötigte Substanzen: 2ml Citrat-Blut, gepufferte NaCl-Stammlösungen $\left(\mathrm{NaCl}, \mathrm{Na}_{2} \mathrm{HPO}_{4}\right.$, $\mathrm{NaH}_{2} \mathrm{PO}_{4}$ x $\left.2 \mathrm{H}_{2} \mathrm{O}, \mathrm{pH} 7,4\right): 0 \%, 0,1 \%, 0,2 \%, 0,3 \%, 0,35 \%, 0,4 \%, 0,45 \%, 0,5 \%, 0,55 \%, 0,6 \%$, $0,65 \%, 0,75 \%, 0,85 \%, 0,9 \%, 1,0 \%, 1,2 \%$, Transformationslösung $\left(\mathrm{KCN}, \mathrm{K}_{3} \mathrm{Fe}(\mathrm{CN})_{6}\right.$, $\left.\mathrm{NaHCO}_{3}\right)$

Durchführung: In 16 Zentrifugenröhrchen werden jeweils $2 \mathrm{ml}$ der folgenden NaCl-Pufferlösungen pipettiert: $0 \%, 0,1 \%, 0,2 \%, 0,3 \%, 0,35 \%, 0,4 \%, 0,45 \%, 0,5 \%, 0,55 \%, 0,6 \%, 0,65 \%$, $0,75 \%, 0,85 \%, 0,9 \%, 1,0 \%, 1,2 \%$. Nun wird in jedes Röhrchen $20 \mu 1$ des Citratblutes hinzugegeben, gemischt und bei Raumtemperatur 30 min. inkubiert. Die übrig gebliebene Citrat-Blutmenge wird bei $37^{\circ} \mathrm{C}$ inkubiert. Sie wird für die Bestimmung der osmotischen Resistenz nach 24 Stunden benötigt. Die 16 Blut-/NaCl-Mischungen werden nach den oben genannten $30 \mathrm{~min}$. erneut gemischt, dann $5 \mathrm{~min}$. bei $2000 \mathrm{U} / \mathrm{min}$. zentrifugiert. Von diesem Überstand werden jeweils $500 \mu 1$ in 16 vorbereitete Röhrchen mit der Transformationslösung pipettiert. Nach 30 min. Inkubation bei Raumtemperatur erfolgt die Messung bei $546 \mathrm{~nm}$. Zuvor wurde das Photometer mit Transformationslösung bei 546nm kalibriert. Alle Proben werden gemessen und der Hämolyseprozentsatz jeder einzelnen Probe auf den Wert 100\% Hämolyse bezogen. Der Hämolyseprozentsatz wird mittels der Formel $\frac{E}{E 100 \% \text { Hämolyse }} \times 100$ berechnet.

Für die Bestimmung der osmotischen Resistenz des Blutes nach 24 Stunden Inkubation bei $37^{\circ} \mathrm{C}$ wird in der gleichen Art und Weise vorgegangen. Die Werte werden in eine Kurve eingetragen. Auf der Ordinate wird der Prozentsatz der Hämolyse, auf der Abszisse die NaClKonzentration der Lösung notiert. 


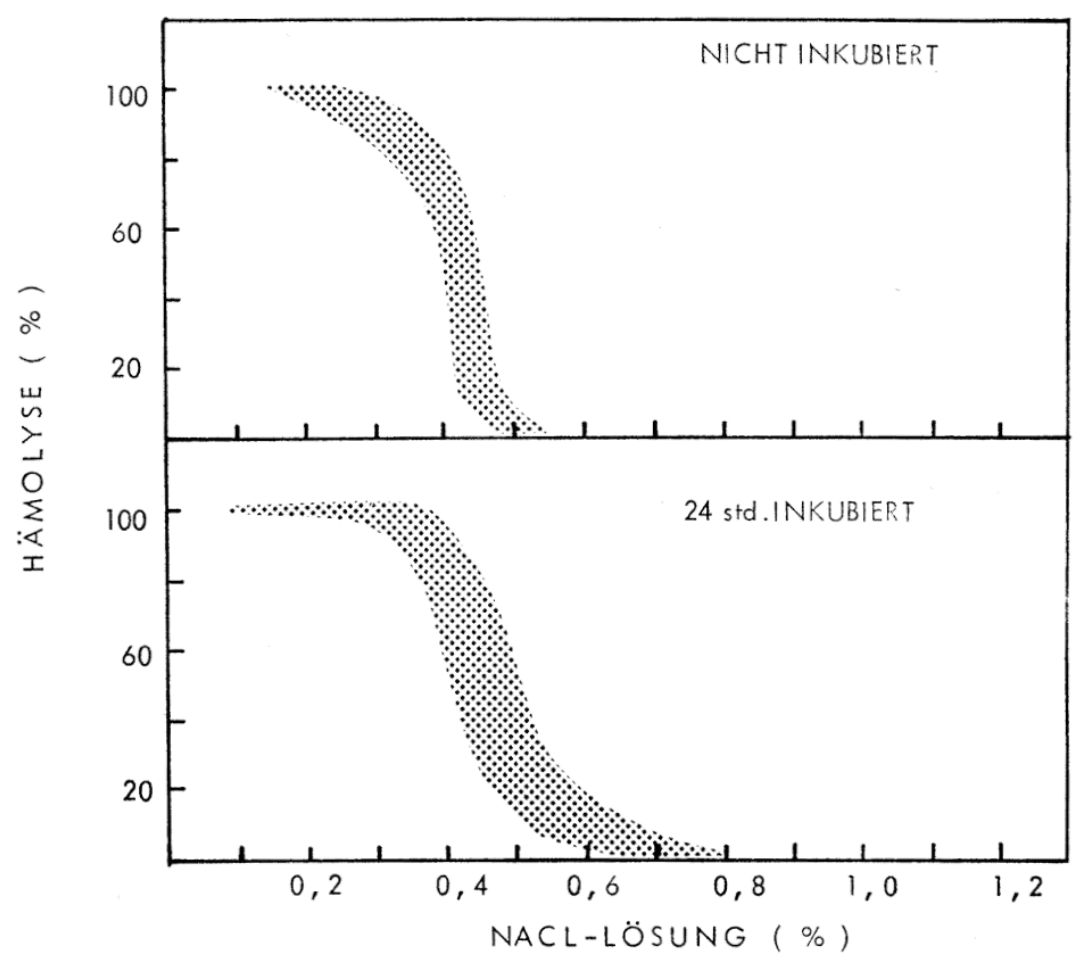

Abbildung 2.1 Osmotische Resistenz im frischen Blut und nach 24-stündiger Inkubation mit Kochsalzlösungen verschiedener Konzentrationen bei $37^{\circ} \mathrm{C}$. Es wird die Hämolyse der Erythrozyten im Verhältnis zur Kochsalzkonzentration angegeben. Der grau schraffierte Bereich ist der Normbereich (Mittelwert \pm 2 Standardabweichungen).

Als Normbereich wird der Mittelwert \pm 2 Standardabweichungen angenommen (Schröter und Kashnitz, 1983). Im Diagramm ist der Normbereich durch Punkte schraffiert.

\subsubsection{Autohämolyse}

Der Autohämolysetest wurde 1956 von Young et al. beschrieben und untersucht die bei Inkubation auftretende Lyse von Erythrozyten. Bei Patienten mit Sphärozytose liegt eine gesteigerte Autohämolyse vor, die unter Glukosezusatz meist korrigierbar ist. Der Test zur Autohämolyse mit und ohne Glukosezusatz wurde modifiziert und wird wie folgt durchgeführt.

Benötigte Geräte: 4 sterile Röhrchen mit Stopfen, 5 Reagenzgläser, Reagenzglasständer, 6 Küvetten

Benötigte Substanzen: $4 \mathrm{ml}$ Citrat-Blut, $50 \mu \mathrm{l}$ 10\%ige Glukose-NaCl-Lösung, $26 \mathrm{ml}$ Transformationslösung $\left(\mathrm{KCN}, \mathrm{K}_{3} \mathrm{Fe}(\mathrm{CN})_{6}, \mathrm{NaHCO}_{3}\right)$ 
Durchführung: Es werden $4 \mathrm{ml}$ Citrat-Blut benötigt und wie folgt in sterile Röhrchen pipettiert:

Röhrchen a) $1 \mathrm{ml}$ Blut ohne Zusatz

Röhrchen b) $1 \mathrm{ml}$ Blut mit Zusatz von $50 \mu \mathrm{l}$ 10\%iger Glukose-NaCl-Lösung

Röhrchen c) $1 \mathrm{ml}$ Blut ohne Zusatz zur Plasmagewinnung

Ansatz a und b werden bei $37^{\circ} \mathrm{C} 48$ Stunden inkubiert. Ansatz c wird bei 3000 Umdrehungen/min. zentrifugiert. Das Plasma wird in ein steriles Röhrchen pipettiert und bis zur Messung bei $4^{\circ} \mathrm{C}$ aufbewahrt. Nach 24 Stunden und nach 48 Stunden werden Ansatz a und $b$ jeweils durch mehrfach vorsichtiges Schwenken gemischt, um eine gleichmäßige Verteilung der Erythrozyten $\mathrm{zu}$ gewährleisten. Das Photometer wird mit $1 \mathrm{ml}$ Transformationslösung bei 546nm kalibriert. Der Hämatokritwert von Ansatz a und Ansatz b wird bestimmt (Hkt(a) und Hkt(b)). $20 \mu \mathrm{l}$ von Ansatz a und b werden in jeweils $5 \mathrm{ml}$ Transformationslösung pipettiert und gemischt, $30 \mathrm{~min}$. inkubiert (Raumtemperatur) und 546nm gemessen. Der Rest der Ansätze a und b wird $5 \mathrm{~min}$. bei $3000 \mathrm{U} / \mathrm{min}$. zur Plasmagewinnung zentrifugiert. Von den Proben a, b und c werden dann 200 $\mu 1$ Plasma in jeweils $5 \mathrm{ml}$ Transformationslösung pipettiert und per Hand geschwenkt.

Nach 30 min. Inkubation bei Raumtemperatur erfolgt die Messung des Hb-Gehaltes ( $\mathrm{Hb}(\mathrm{a} 2)$, $\mathrm{Hb}(\mathrm{b} 2), \mathrm{Hb}(\mathrm{c}))$ bei $546 \mathrm{~nm}$. Der Autohämolyseprozentsatz wird -unter Berücksichtigung der durch die Inkubation bedingten Hämatokritveränderungen- folgendermaßen berechnet:

$x \%$ Hämolyse $=\frac{E \text { ink.Plasma }}{10} \times \frac{E \text { nicht ink.Plasma }}{10} \times \frac{100-H k t}{E \text { Vollblut }}$

\subsubsection{Weitere Laboruntersuchungen}

Routinemäßig wurde ein Blutbild (Leukozyten, Erythrozyten, Hämoglobin, Hämatokrit, MCV, MCH, MCHC, Thrombozyten, Retikulozyten) sowie LDH, Haptoglobin, Bilirubinkonzentration und der Coombs-Test bestimmt.

\subsection{Auswertung und graphische Darstellung der Ergebnisse}

Die Auswertung, Verarbeitung und graphische Darstellung der Parameter erfolgte mit den Computerprogrammen EXCEL und WORD 2008 für Mac, Version 12.2.4 (100205). Die Patientendaten der verschiedenen Zentren wurden zunächst komplett in eine 
EXCEL-Haupttabelle aufgenommen, um später in kleinere Tabellen sortiert und aufgeteilt zu werden. In den kleineren Tabellen erfolgte die weitere Auswertung mit anschließender graphischer Darstellung und Übertragung in das Schreibprogramm WORD. Auf Grund der physiologischen Veränderungen der Blutwerte in Abhängigkeit vom Lebensalter, liegen die Normblutwerte in der Pädiatrie häufig altersbezogen vor (z.B. Hämoglobin, Retikulozyten, Bilirubin u.a.). So wurden die Daten dem Patientenalter entsprechend (alterskorreliert) ausgewertet. Die Literatur wurde mit Hilfe von EndNote X3 (Bld 5276) verwaltet. 


\section{Ergebnisse}

\subsection{Analyse der Altersverteilung der Patienten mit Sphärozytose}

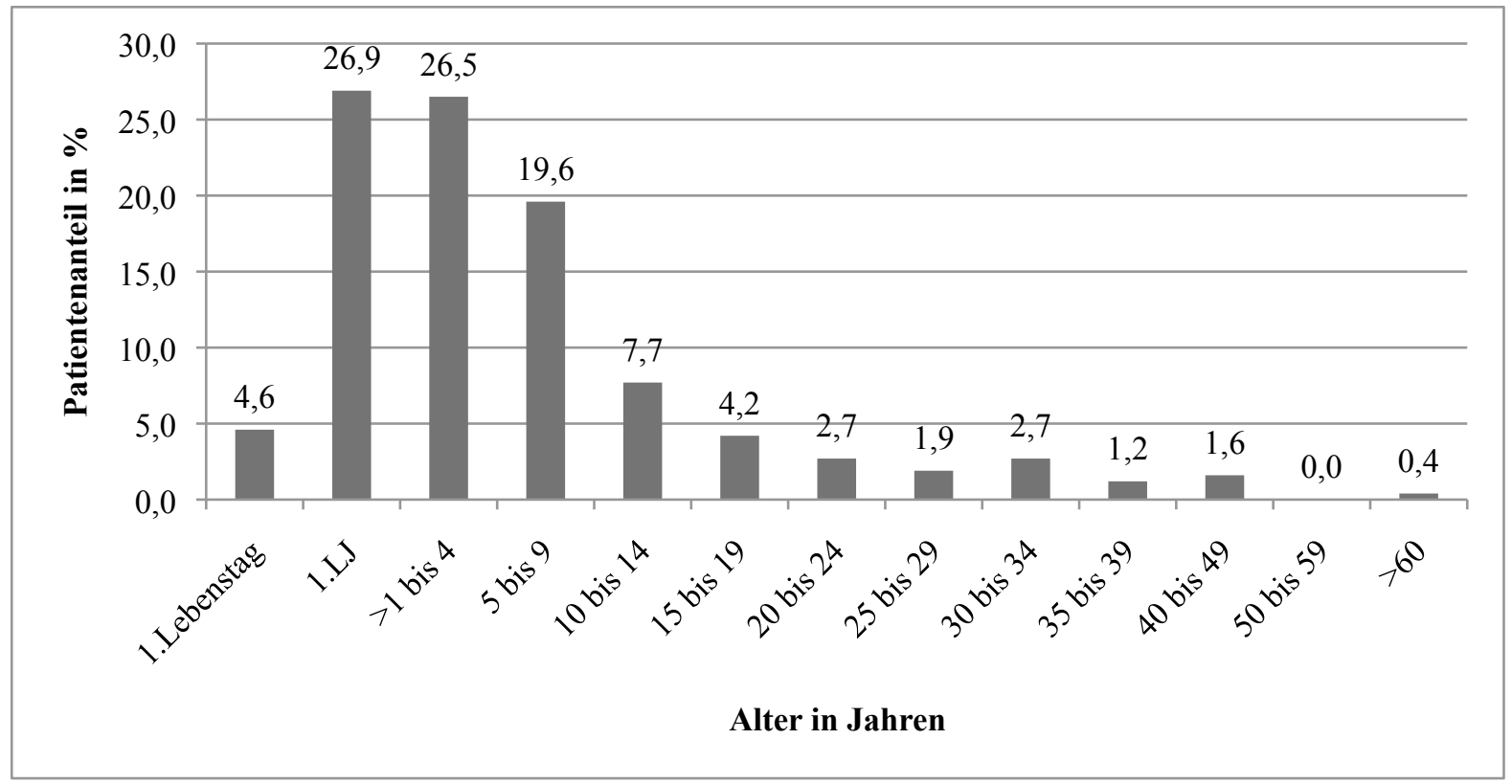

Abbildung 3.1 Altersverteilung der Patienten bei Diagnosestellung. 77,6\% der Patienten mit Sphärozytose waren bei der Diagnosestellung jünger als 9 Jahre.

Es wurden insgesamt 358 Patientinnen und Patienten untersucht, von denen 48,3\% (173 von 358) weiblich und 51,7\% (184 von 358) männlich waren. Bei 72\% der Patienten (260 von 358) wurde bei Diagnosestellung das Alter registriert. Die Analyse zeigte, dass $77,6 \%$ bis zum neunten Lebensjahr diagnostiziert wurden. Die meisten Patienten erhielten die Diagnose der HS im ersten Lebensjahr (4,6\% und 26,9\%, 82 von 260) und im Alter zwischen einem und vier Jahren (26,5\%, 69 von 260). Knapp 20\% (51 von 260) wurden im Alter von fünf bis neun Jahren diagnostiziert. Ab einem Alter von zehn Jahren wurde die Diagnose immer seltener gestellt (siehe Abb. 3.1). Der Altersmittelwert bei Diagnosestellung lag bei 7,27 Jahren. 


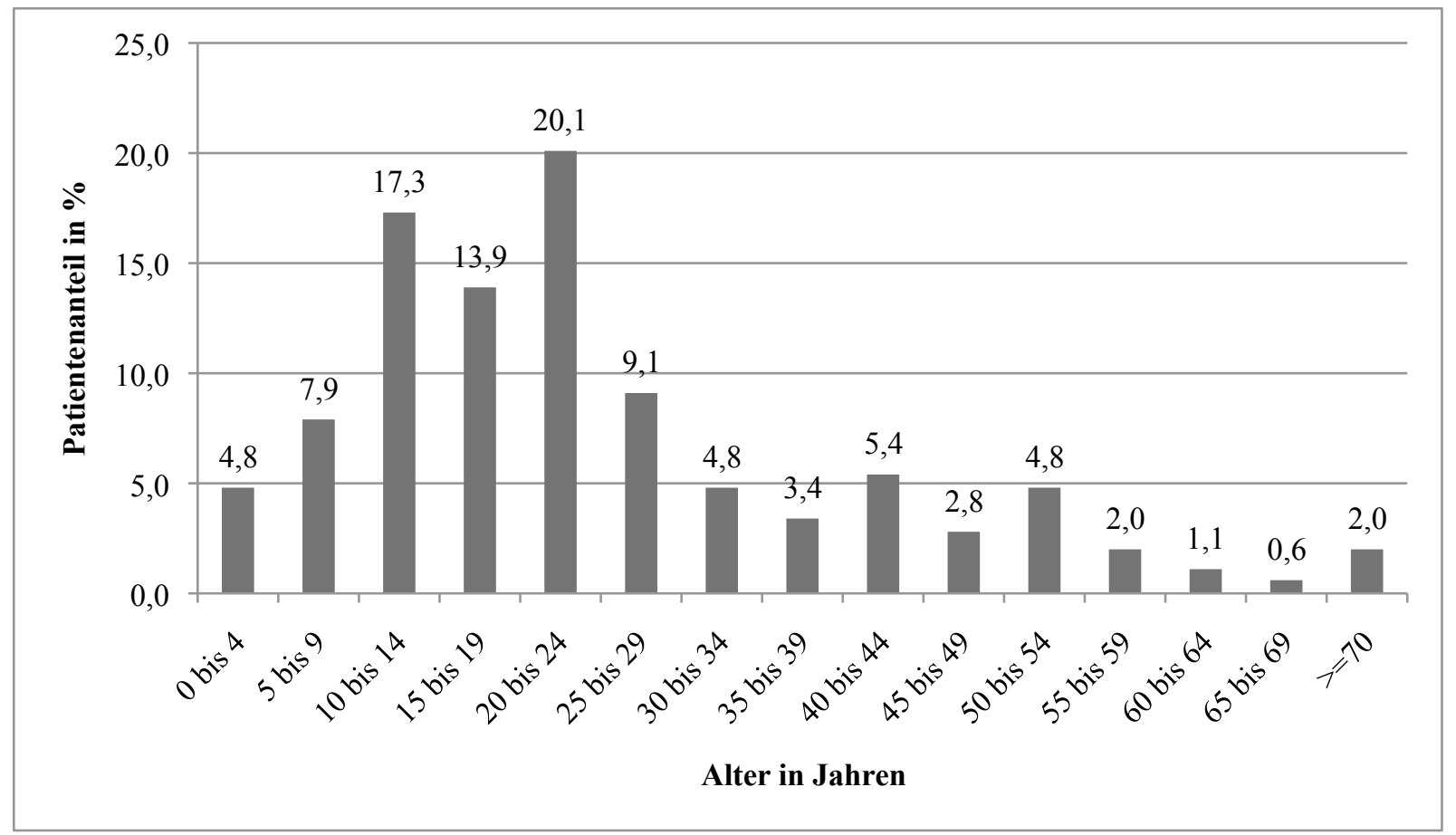

Abbildung 3.2 Altersverteilung der Patienten im Jahr 2009. 51,3\% der Patienten mit Sphärozytose waren im Jahr 2009 zwischen 10 und 24 Jahre alt.

Von 98,6\% der erfassten Patienten (353 von 358) lag bei der Auswertung ein Geburtsdatum vor. Die Altersverteilung zeigt, dass 51,3\% der Patienten (181 von 353) im Jahr 2009 zwischen zehn und 24 Jahre alt waren. 12,7\% (45 von 353) waren jünger als zehn Jahre und 9,1\% (32 von 353) zwischen 25 und 29 Jahren. Der Anteil der Patienten, die älter als 30 Jahre alt waren variiert zwischen 0,6\% und 5,4\% (siehe Abb. 3.2). Das Durchschnittsalter lag im Jahr 2009 bei 25,25 Jahren.

\subsection{Hämoglobinwert zum Diagnosezeitpunkt}

Da viele Patienten mit Sphärozytose initial durch eine Anämie auffällig werden, wurde der alterskorrelierte Hämoglobinwert (Hb-Wert) bei Diagnosestellung der Sphärozytose analysiert. Es lagen von 62,6\% aller Patienten (224 von 358) Daten vor.

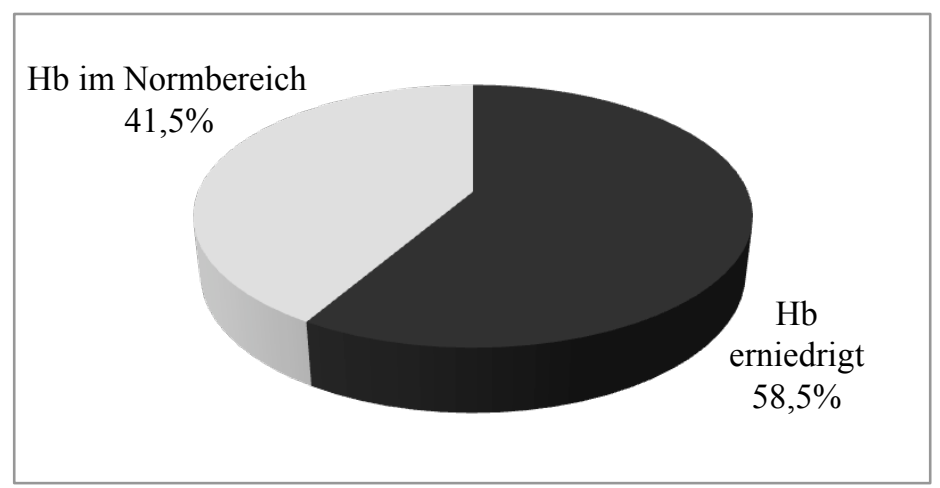
Abbildung 3.3 Alterskorrelierte Übersicht des Hb-Wertes zum Diagnosezeitpunkt. Bei 58,5\% der Patienten mit Sphärozytose lag zum Zeitpunkt der Diagnose- stellung ein erniedrigter Hämoglobinwert vor. 
Es zeigte sich, dass bei 58,5\% der Patienten (131 von 224) der alterskorrelierte $\mathrm{Hb}$-Wert bei Diagnosestellung erniedrigt war und bei 41,5\% (93 von 224 Patienten) im Normbereich lag (siehe Abb. 3.3).

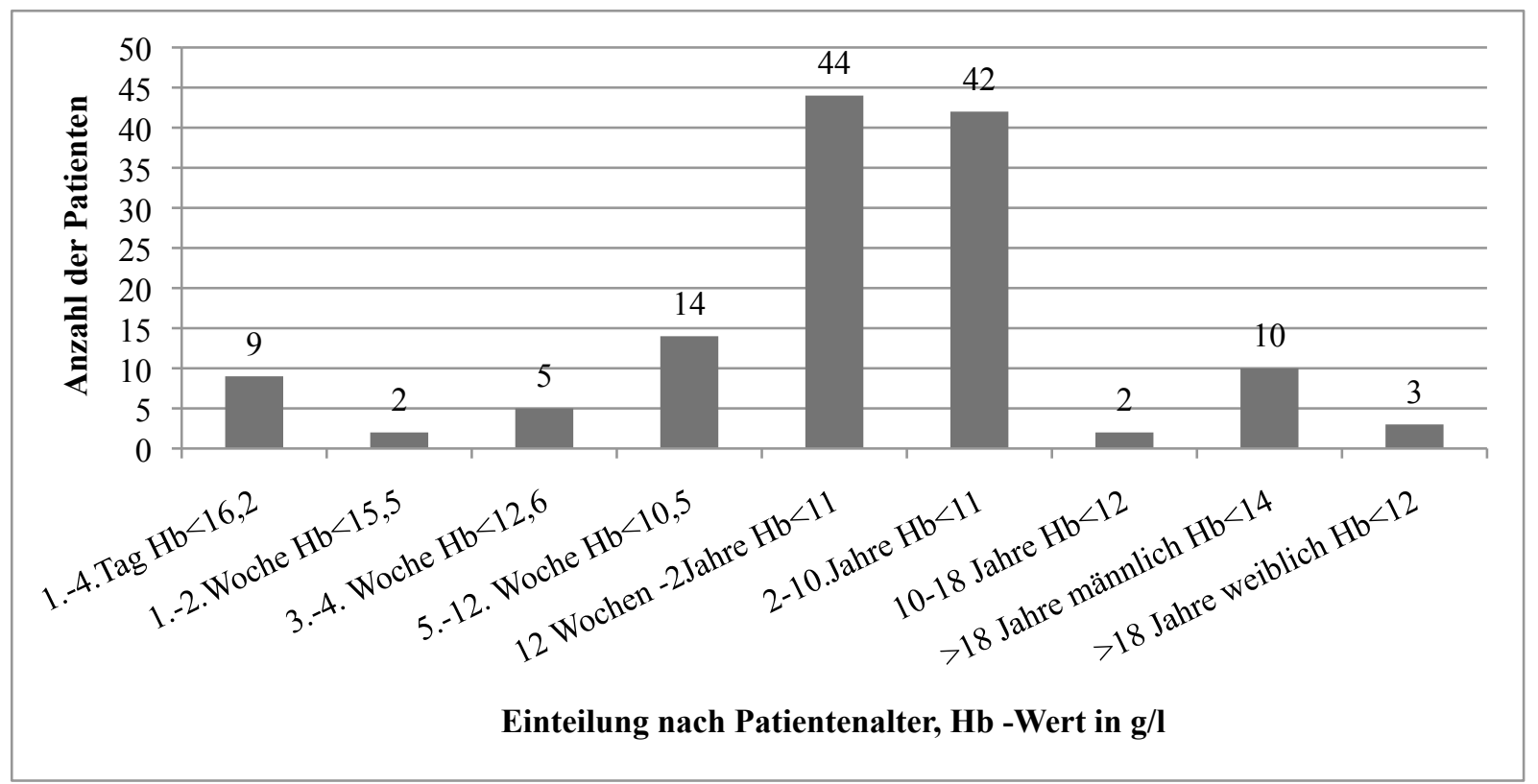

Abbildung 3.4 Alterskorrelierter erniedrigter Hb-Wert zum Diagnosezeitpunkt. Eine Häufung der Patientenanzahl mit erniedrigten Hb-Werten trat bei Diagnosezeitpunkten im Alter zwischen 12 Wochen und 10 Jahren auf.

Die genaue Analyse zeigte eine Häufung zu niedriger Hb-Werte bei Diagnosestellungen im Alter zwischen zwölf Wochen und zwei Jahren (44 von 131 Patienten) und im Alter zwischen zwei und zehn Jahren (42 von 131 Patienten). In allen anderen Altersgruppen war der alterskorrelierte $\mathrm{Hb}$-Wert bei zwei bis 14 Patienten erniedrigt (siehe Abb. 3.4). 


\subsection{Alterskorrelierte Retikulozytenwerte zum Diagnosezeitpunkt}

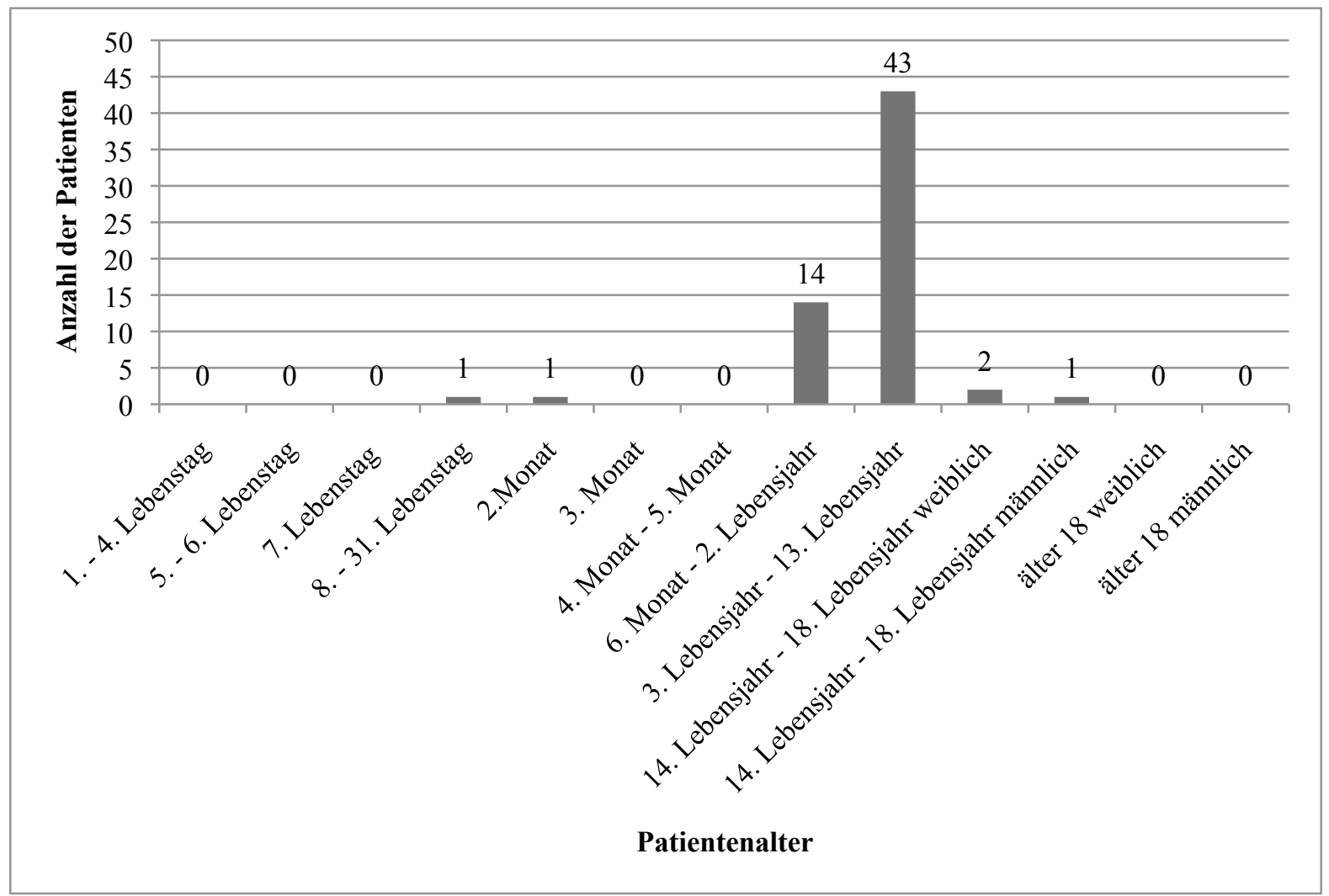

Abbildung 3.5 Erhöhte alterskorrelierte Retikulozytenwerte zum Diagnosezeitpunkt. Eine Häufung alterskorrelierter erhöhter Retikulozytenwerte zum Diagnosezeitpunkt trat zwischen dem dritten und 13. Lebensjahr auf.

Eine Veränderung der Retikulozytenzahl im peripheren Blut gibt Hinweise auf eine verstärkte oder verminderte Erythropoese. Auf erniedrigte Hb-Werte reagiert der Körper mit einer gesteigerten Erythropoese (siehe Diskussion). In diesem Zusammenhang waren von 58,7\% (210 von 358) der Patienten Retikulozytenwerte zum Diagnosezeitpunkt vorhanden, die alterskorreliert ausgewertet wurden.

Eine deutliche Häufung erhöhter Retikulozytenwerte zeigte sich besonders vom dritten bis 13 . Lebensjahr (43 Patienten), sowie weniger ausgeprägt vom sechsten Lebensmonat bis zweiten Lebensjahr (14 Patienten). In allen anderen Altersgruppen lag die Patientenanzahl mit erhöhten Retikulozytenwerten zwischen null und zwei (siehe Abb. 3.5). 


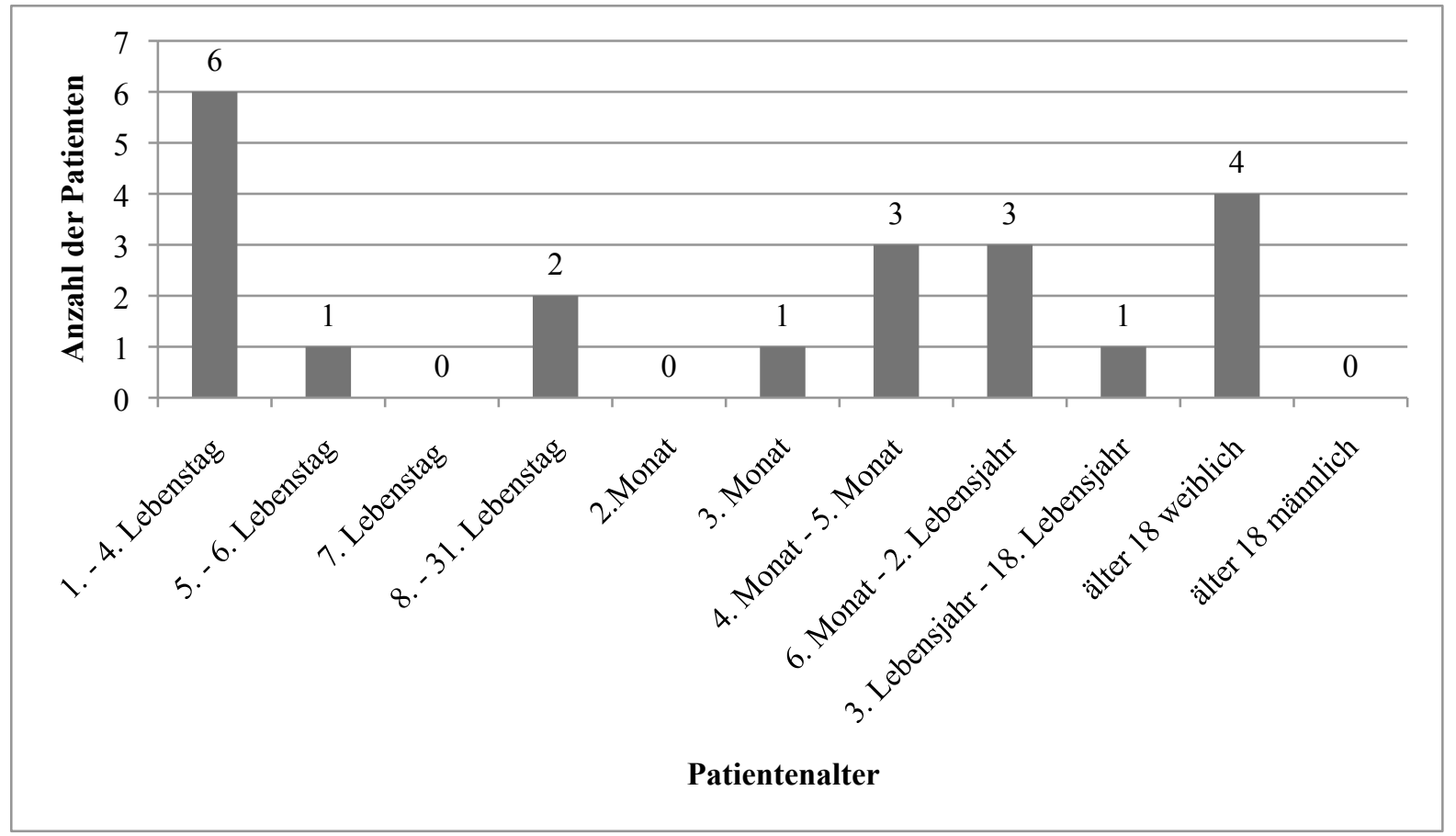

Abbildung 3.6 Erniedrigte alterskorrelierte Retikulozytenanzahl zum Diagnosezeitpunkt.

Eine Häufung an Patienten mit erniedrigten Retikulozytenwerten trat zum Diagnosezeitpunkt zwischen dem ersten und vierten Lebenstag auf.

Erniedrigte Retikulozytenwerte traten zum Diagnosezeitpunkt bei 10\% (21) der 210 Patienten auf. Die alterkorreliert ausgewerteten Ergebnisse zeigten eine Häufung der erniedrigten Werte bei Patienten, die vom ersten bis vierten Lebenstag diagnostiziert (6 von 21) wurden und bei Patientinnen (4 von 21) die zum Diagnosezeitpunkt älter als 18 Jahre alt waren. Die anderen Werte lagen unregelmäßig verteilt zwischen null und drei Patienten in Bezug auf ihr Diagnosealter (siehe Abb. 3.6).

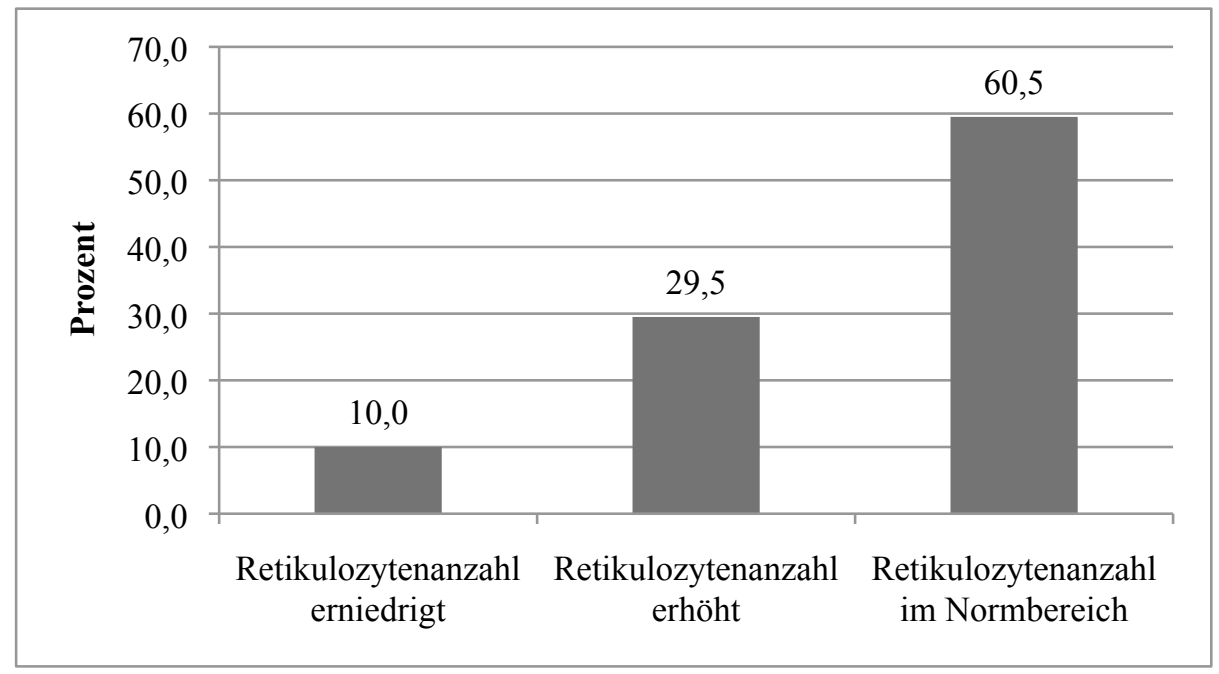
Abbildung 3.7
Übersicht alters- korrelierter Reti- kulozytenwerte zum Diagnose- zeitpunkt. Etwa 1/3 der Patienten wiesen zum Dia- gnosezeitpunkt er- höhte Retikulozy- tenwerte auf. 
Zusammenfassend zeigte sich, dass bei 29,5\% der Patienten die Retikulozytenwerte zum Diagnosezeitpunkt erhöht und bei 10\% erniedrigt waren. Bei 60,5\% der Patienten lagen die Retikulozytenwerte zum Diagnosezeitpunkt im Normbereich (siehe Abb. 3.7).

\subsection{Alterskorrelierte Bilirubinwerte (gesamt) zum Diagnosezeitpunkt}

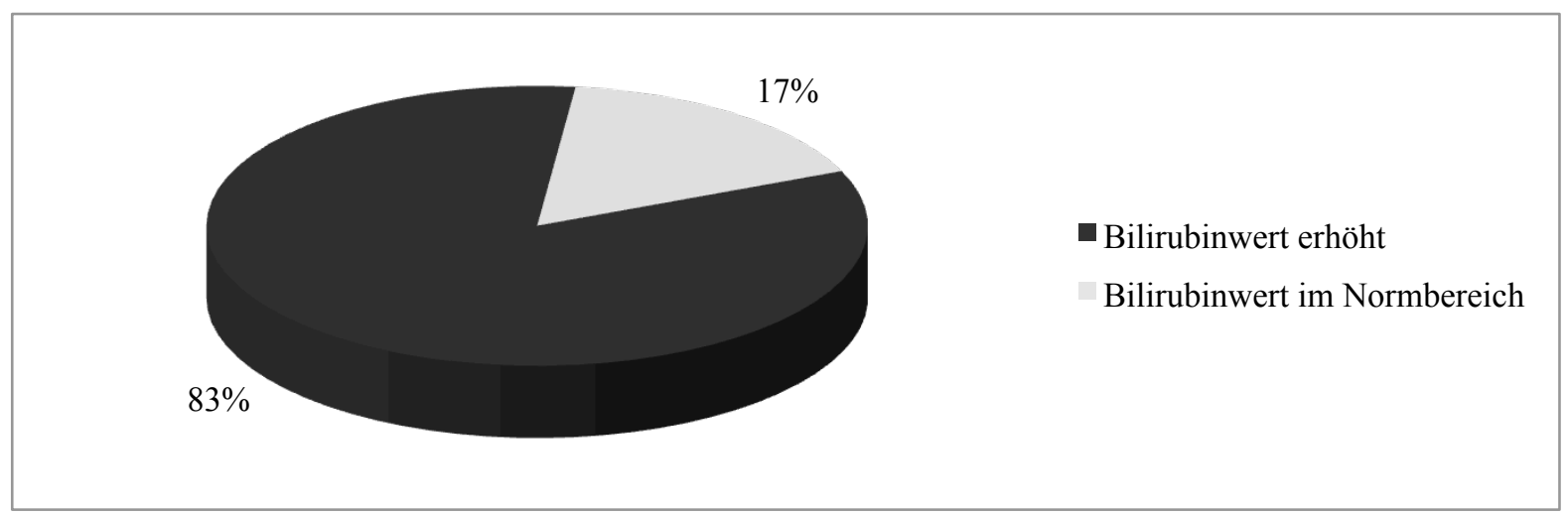

Abbildung 3.8 Alterskorrelierter Bilirubinwert (gesamt) zum Diagnosezeitpunkt. Bei den meisten Patienten (83\%) war der Bilirubinwert zum Diagnosezeitpunkt erhöht.

Von 57,1\% der Patienten (185 von 358) lagen Daten über den Gesamt-Bilirubinwert zum Diagnosezeitpunkt vor. Bei den alterskorreliert ausgewerteten Daten wurden nur Patienten bewertet, die älter als ein Monat waren. Zum Diagnosezeitpunkt wiesen die meisten Patienten (83\%, 154 von 185 Patienten) einen erhöhten Bilirubinwert auf, 17\% (31 von 185 Patienten) hatten Werte im Normbereich.

\subsection{Acylglycerol-Lysis-Test (AGLT) zum Diagnosezeitpunkt}

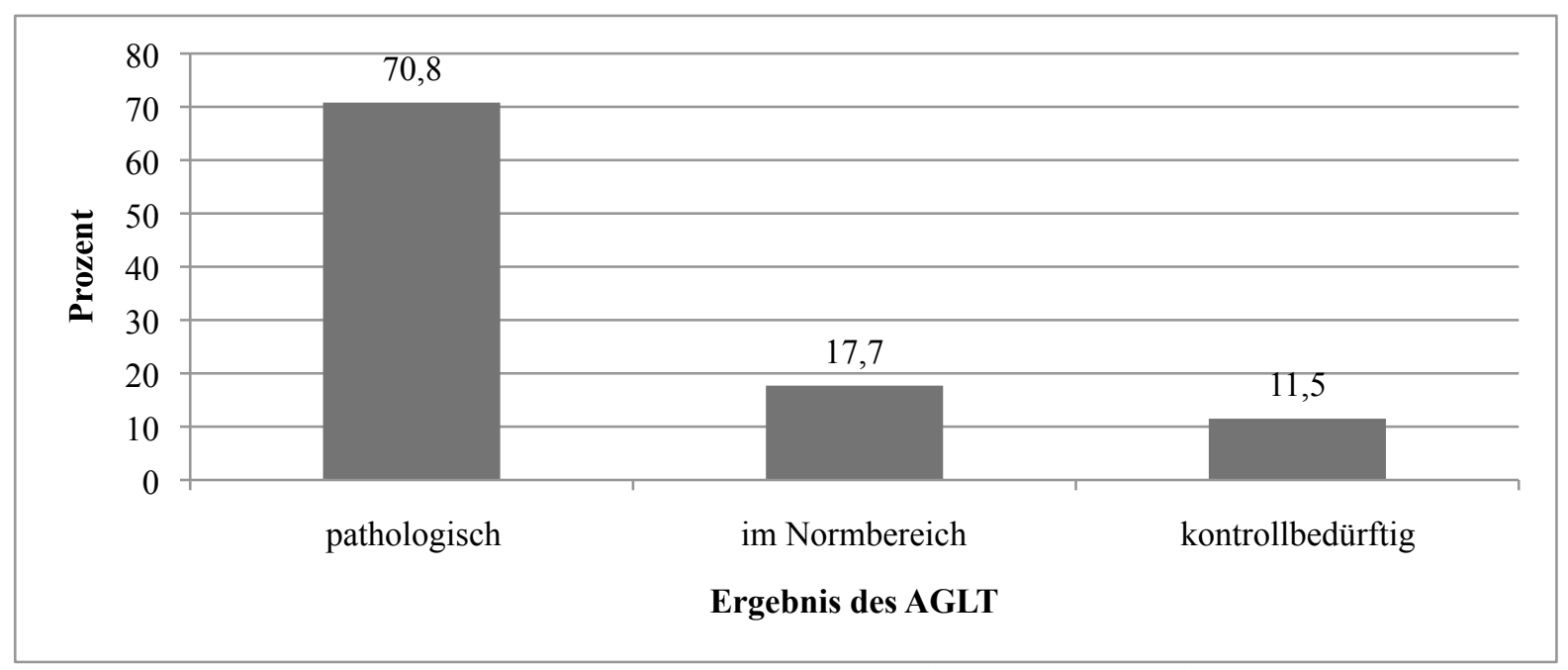

Abbildung 3.9 AGLT zum Diagnosezeitpunkt. Bei 70,8\% der Patienten war der AGLT zum Diagnosezeitpunkt pathologisch.

Von 26,8\% der an der Studie beteiligten Patienten (96 von 358) waren Daten über den Acylglycerol-Lysis-Test (AGLT) zum Diagnosezeitpunkt vorhanden. Bei 70,8\% der Patienten 
(68 von 96) waren die Testergebnisse mit einer Halbwertszeit unter zwei Minuten pathologisch, 17,7\% der Tests (17 von 96 Patienten) lagen mit einer Halbwertszeit von 30 Minuten im Normbereich. Die restlichen AGLT-Ergebnisse waren kontrollbedürftig (siehe Abb. 3.9).

\subsection{Kryohämolyse-Test zum Diagnosezeitpunkt}

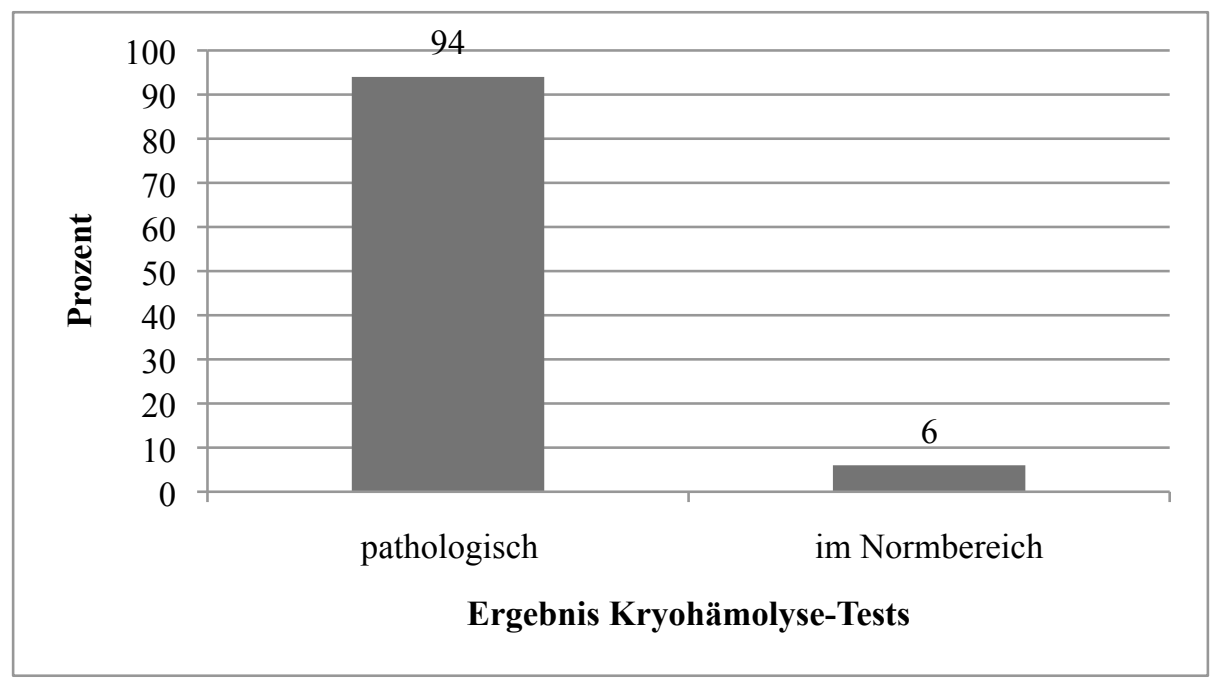

\author{
Abbildung 3.10 \\ Kryohämolyse- \\ Test zum \\ Diagnosezeit- \\ punkt. Bei $94 \%$ \\ der Patienten war \\ das Ergebnis des \\ Kryohämolyse- \\ Tests zum \\ Diagnosezeit- \\ punkt patholo- \\ gisch.
}

Von 18,7\% der Patienten (67 von 358) lagen Daten über den Kryohämolyse-Test zum Diagnosezeitpunkt vor. 94\% der Patienten (63 von 67) zeigten pathologische Testergebnisse, die restlichen 6\% (4 von 67) lagen im Normbereich (siehe Abb. 3.10).

\subsection{Osmotische Resistenz zum Diagnosezeitpunkt}

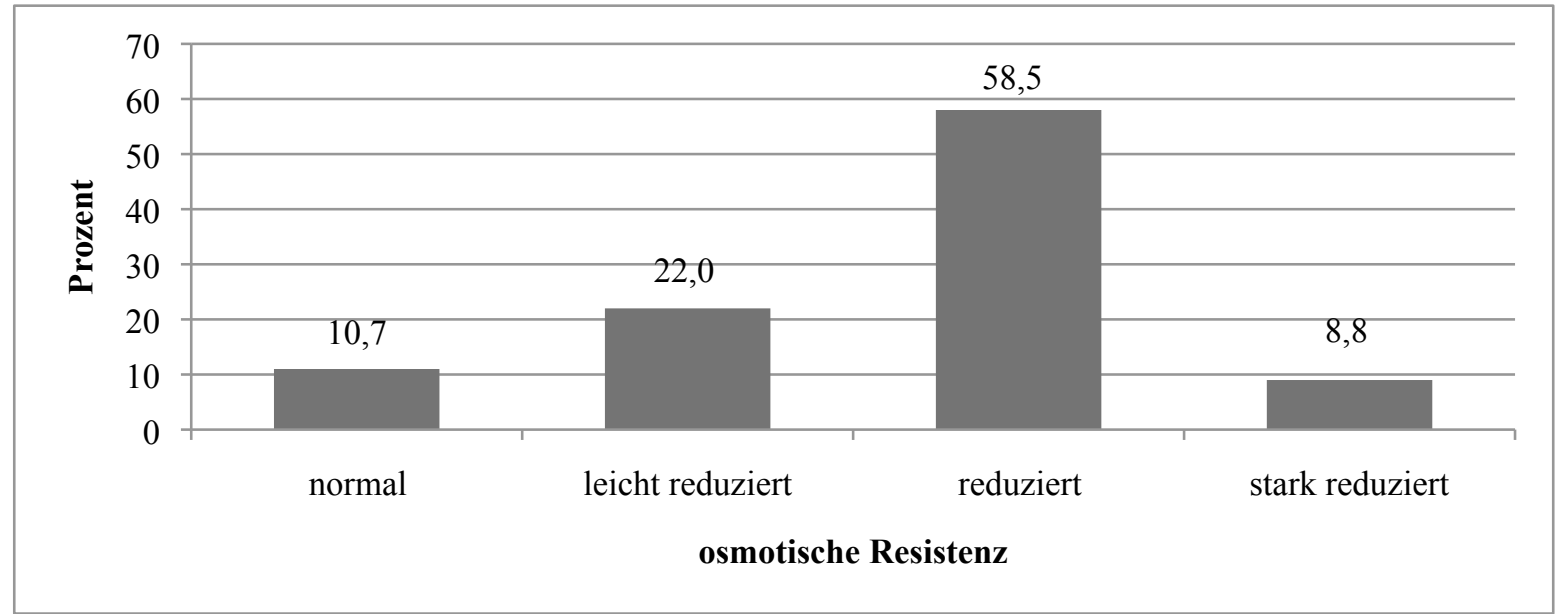

Abbildung 3.11 Osmotische Resistenz im Frischblut zum Diagnosezeitpunkt. Bei insgesamt 89\% der Patienten war die osmotische Resistenz im frischen Blut zum Diagnosezeitpunkt reduziert und damit pathologisch.

Da sich nicht alle Formen der Sphärozytose mittels AGLT und Kryohämolyse-Test diagnostizieren lassen, ist in ausgewählten Fällen die Bestimmung der osmotischen Resistenz 
und Autohämolyse notwendig. Von 44,4\% aller untersuchten Patienten (159 von 358) mit Sphärozytose standen Werte über die osmotische Resistenz der Erythrozyten im Frischblut zur Verfügung. Insgesamt war bei 89\% dieser Patienten (142 von 159) die osmotische Resistenz im frischen Blut zum Diagnosezeitpunkt pathologisch reduziert, wobei 22\% (35 von 159) leicht reduziert, 58,5\% (93 von 159) reduziert und 8,8\% (14 von 159) stark reduziert waren. Die restlichen 10,7\% der Testergebnisse (17 von 159) lagen im Normbereich (siehe Abb. 3.11).

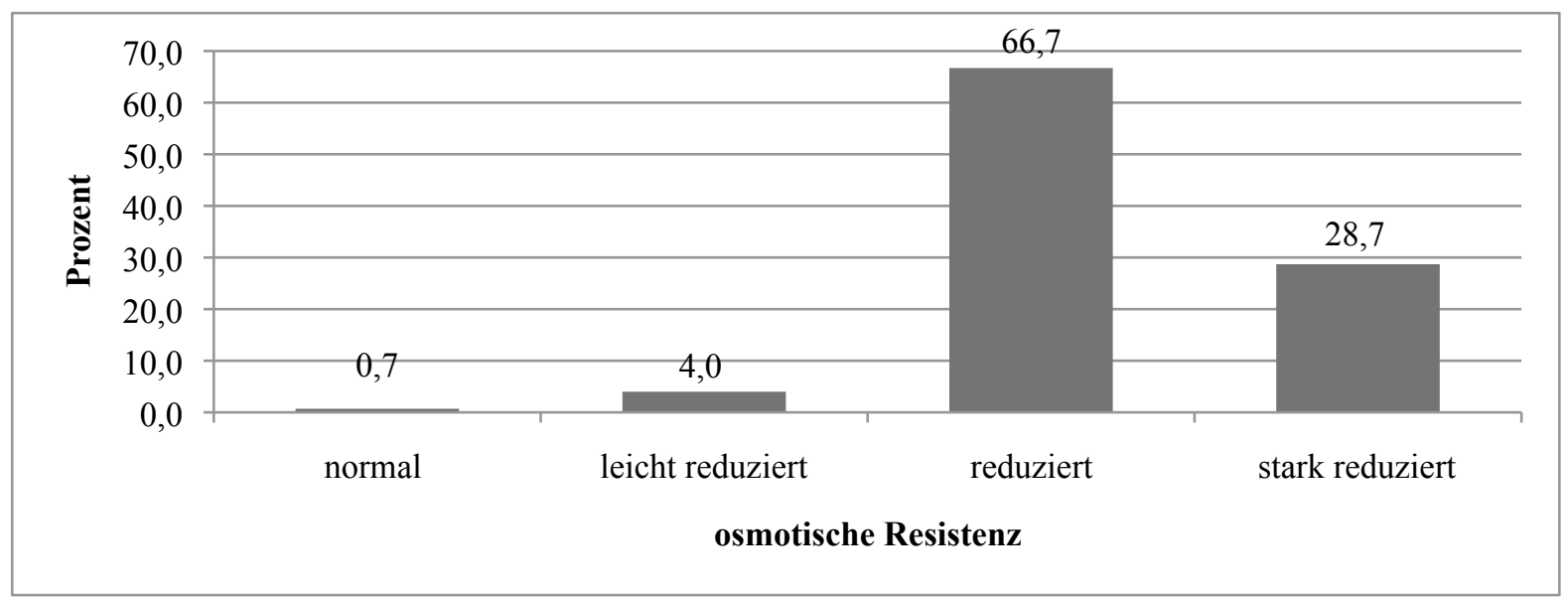

Abbildung 3.12 Osmotische Resistenz der Erythrozyten im inkubierten Blut zum Diagnosezeitpunkt. 99,3\% der zum Diagnosezeitpunkt untersuchten Erythrozytenproben wiesen eine pathologisch reduzierte osmotische Resistenz im 24 Stunden lang inkubierten Blut auf.

Für die Untersuchung der osmotischen Resistenz der Erythrozyten im 24 Stunden lang inkubierten Blut standen zum Diagnosezeitpunkt von 41,9\% aller Patienten (150 von 358) Daten zur Verfügung. Insgesamt 99,3\% dieser untersuchten Erythrozytenproben zeigten ein pathologisch reduziertes Ergebnis, wobei am häufigsten $(66,7 \%)$ eine reduzierte osmotische Resistenz vorlag (100 von 150 Patienten). Ein Drittel (43 und 6 von 150 Patienten) zeigte eine stark bzw. leicht reduzierte osmotische Resistenz und bei 0,7\% der Patienten (1 von 150) lagen Normwerte vor (siehe Abb. 3.12).

\subsection{Autohämolyse zum Diagnosezeitpunkt}

Neben der Bestimmung der osmotischen Resistenz wird auch die Autohämolyse der Erythrozyten bestimmt. Sie wird sowohl mit als auch ohne Glukosezusatz getestet. 


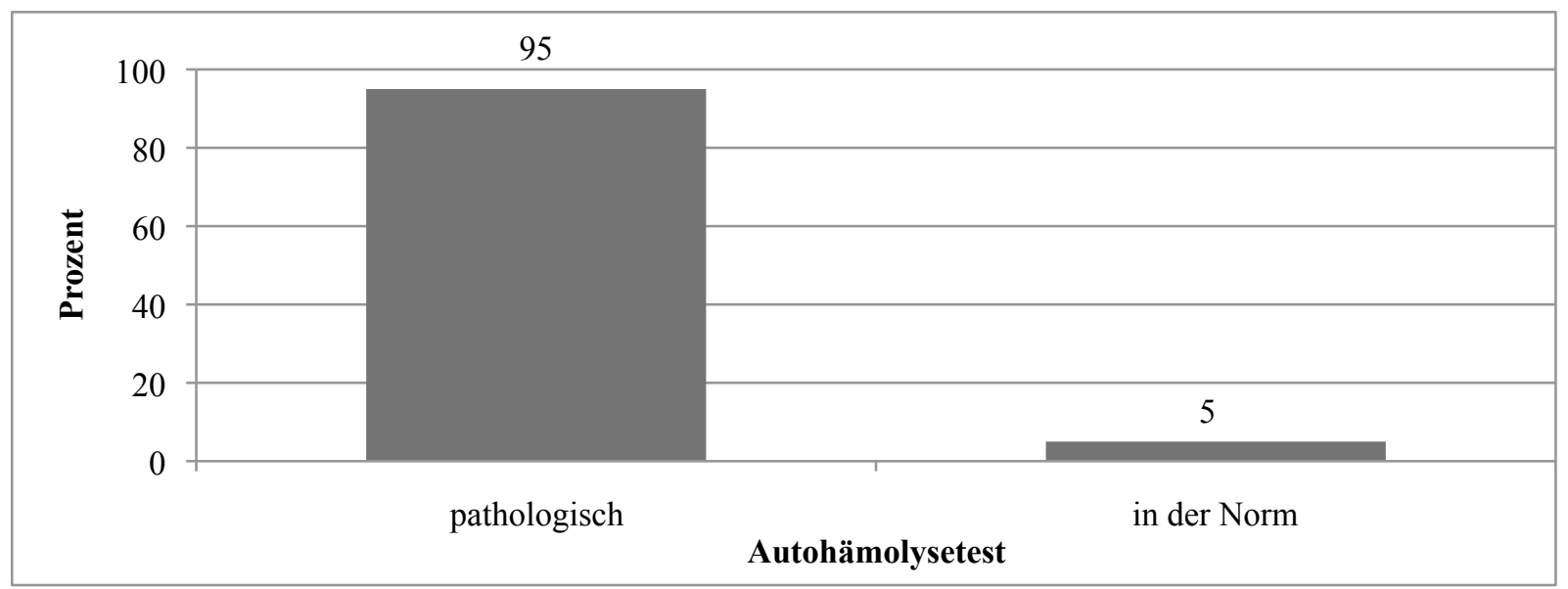

Abbildung 3.13 Autohämolyse ohne Zusätze zum Diagnosezeitpunkt. 95\% der untersuchten Blutproben zeigten ein pathologisches Ergebnis.

Von 39,4\% aller Patienten mit Sphärozytose (141 von 358) lagen Daten über die Autohämolyse ohne Zusätze vor. 95\% der Werte (134 von 141 Patienten) waren pathologisch und 5\% (7 von 141 Patienten) befanden sich mit einer Autohämolyse $<4 \%$ im Normbereich (siehe Abb. 3.13).

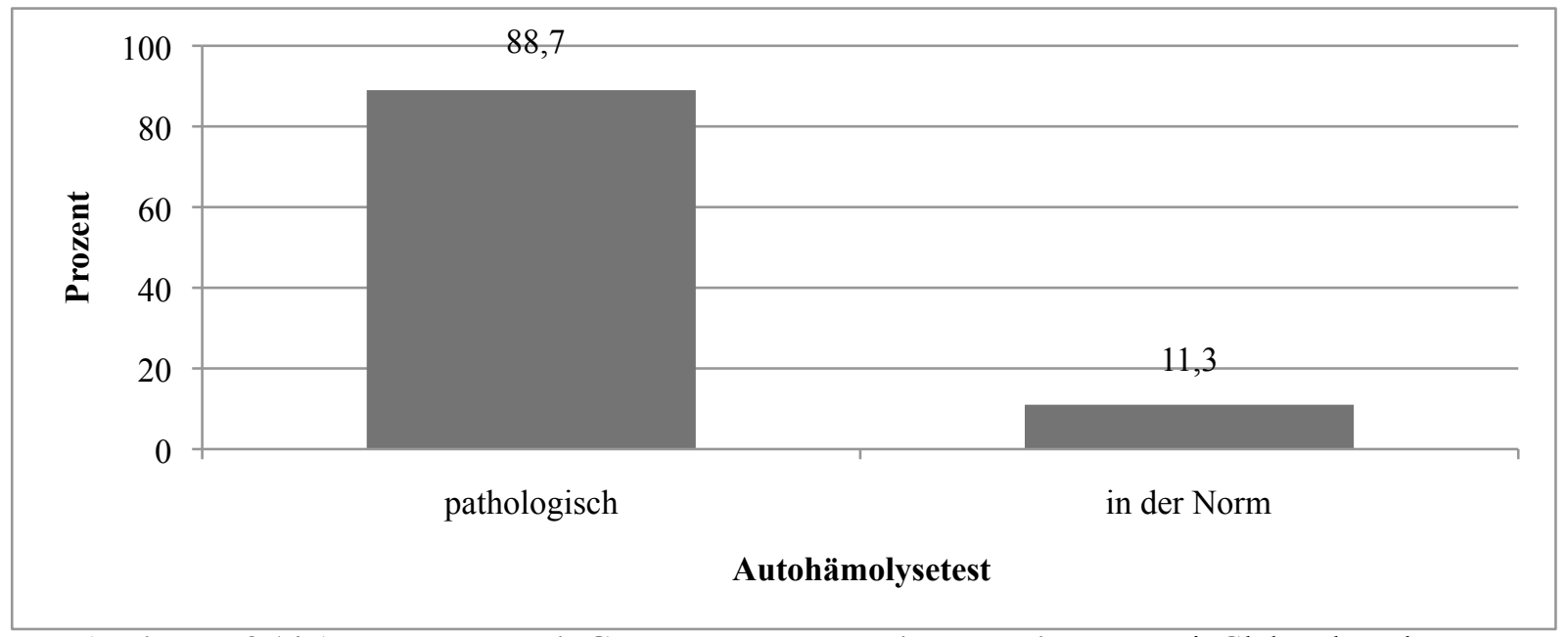

Abbildung 3.14 Autohämolyse mit Glukosezusatz zum Diagnosezeitpunkt. Mit Glukosekorrektur ergaben $88,7 \%$ der untersuchten Blutproben der Patienten mit Sphärozytose ein pathologisches Hämolyseergebnis.

Mit Glukosezusatzkorrektur waren 88,7\% der untersuchten Autohämolysewerte (126 von 142 Patienten) pathologisch und 11,3\% der Tests (16 von 142) lagen mit einer Autohämolyse $<1 \%$ im Normbereich (siehe Abb. 3.14). 


\subsection{Alterskorrelierte mittlere korpuskuläre Hämoglobinkonzentration (MCHC) zum Diagnosezeitpunkt}

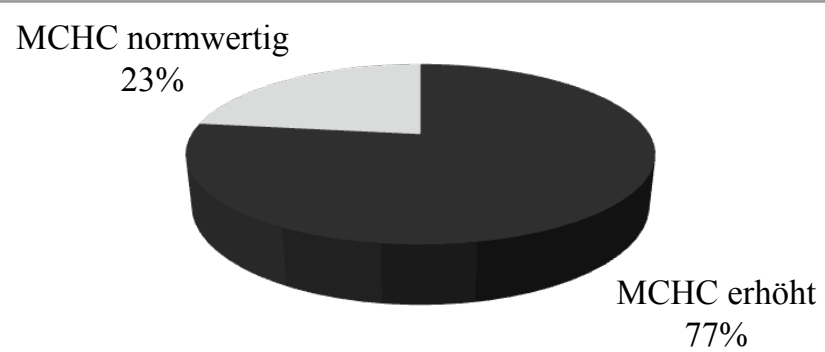

Abbildung 3.15 Alterskorrelierter MCHC -Wert zum Diagnosezeitpunkt. Bei 77\% der Patienten lag der MCHC-Wert pathologisch oberhalb des Normbereichs.

Von 52,2\% aller untersuchten Patienten (187 von 358) lagen Daten über die mittlere korpuskuläre Hämoglobinkonzentration $(\mathrm{MCHC})$ bei Diagnosestellung vor. Die alterskorreliert ausgewerteten Daten zeigten, dass bei den meisten Patienten (77\%, 144 von 187 Patienten) der MCHC-Wert zum Diagnosezeitpunkt erhöht war. Bei 23\% (43 von 187 Patienten) lag er im Normbereich (siehe Abb. 3.15).

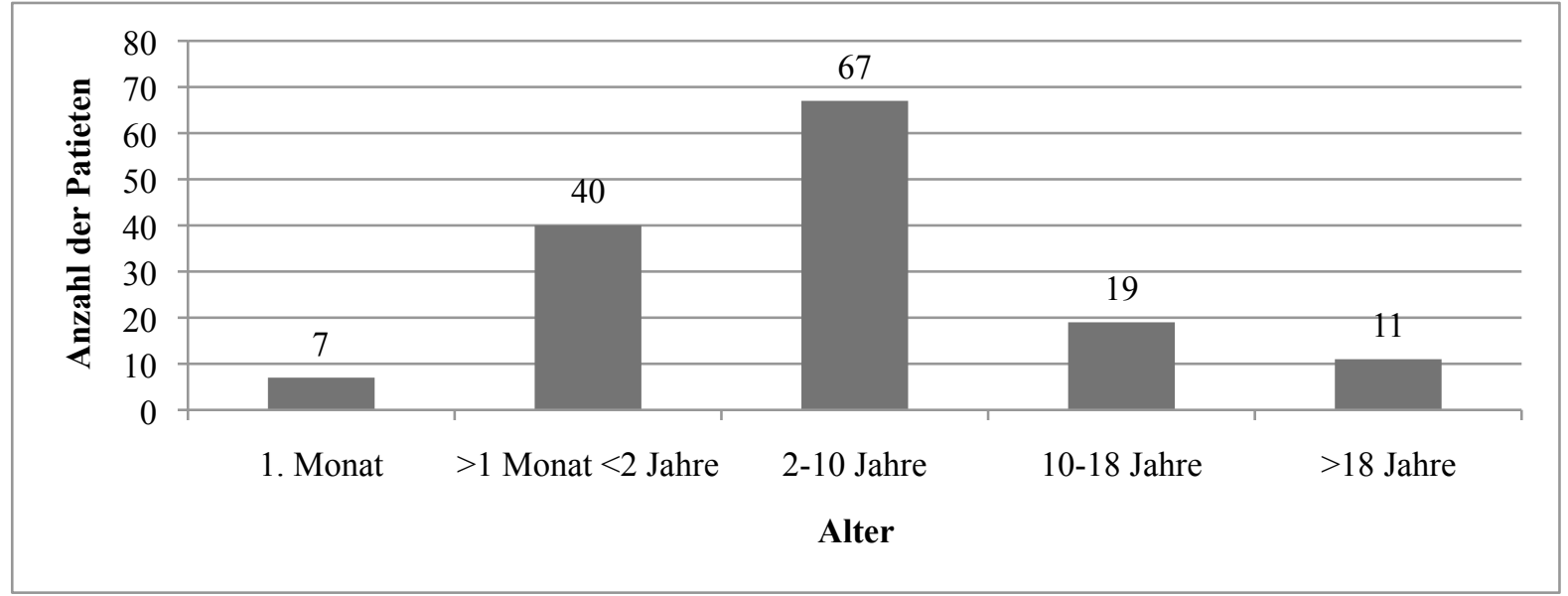

Abbildung 3.16 Alterskorrelierte MCHC-Wert-Erhöhung zum Diagnosezeitpunkt. Eine Häufung der Patientenanzahl mit einer Erhöhung des MCHC-Wertes trat in den Altersstufen zwei bis zehn Jahre (67 Patienten) und ein Monat bis zwei Jahre (40 Patienten) auf.

Die genaue Analyse zeigte, dass die Mehrheit der Patienten (67 von 144) mit einer MCHCWert-Erhöhung zum Diagnosezeitpunkt ein Alter zwischen zwei und zehn Jahren aufwies und etwas weniger Patienten (40) ein Alter zwischen einem Monat und zwei Jahren aufwiesen. Die restlichen Patienten verteilten sich auf die Altersstufen erster Lebensmonat und älter als zehn Jahre (siehe Abb. 3.16). 


\subsection{Laktatdehydrogenase zum Diagnosezeitpunkt}

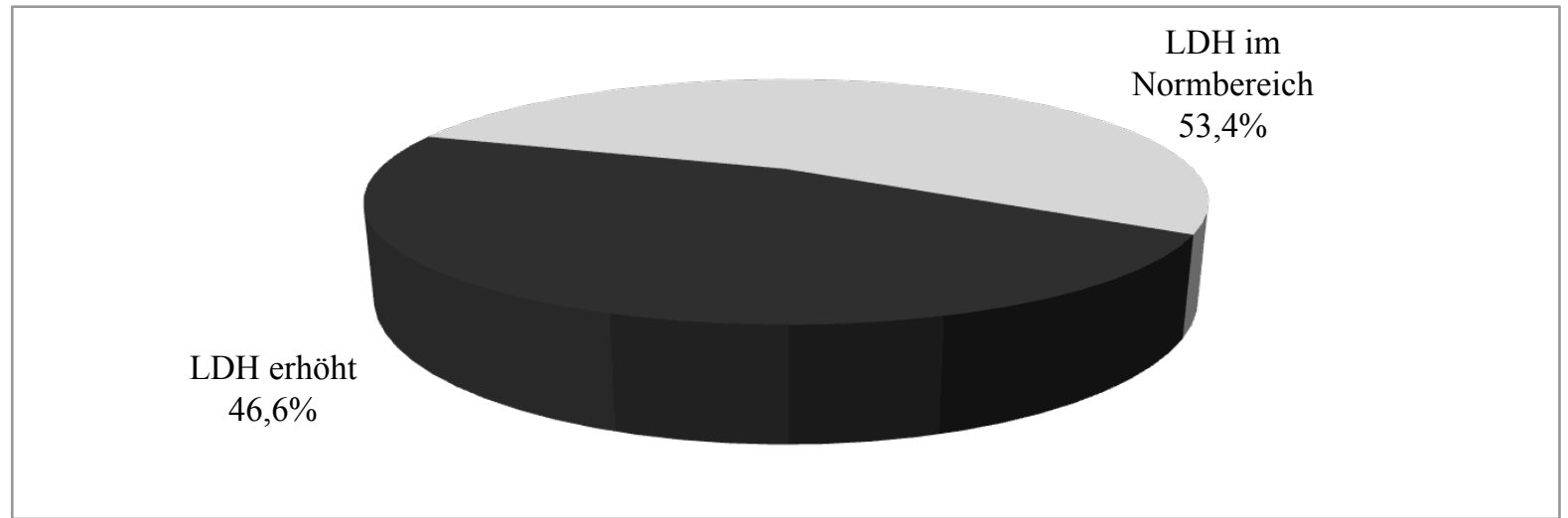

Abbildung 3.17 Übersicht über alterskorrelierte LDH-Werte zum Diagnosezeitpunkt. Bei nahezu der Hälfte der untersuchten Patienten war der LDH-Wert zum Diagnosezeitpunkt erhöht.

Die Laktatdehydrogenase (LDH) ist ein Enzym, das unter anderem in Erythrozyten/Sphärozyten enthalten ist. Durch den vorzeitigen Abbau von Sphärozyten in der Milz, wird die LDH freigesetzt und ist im peripheren Blut erhöht nachweisbar. In diesem Zusammenhang lagen von 49,7\% der Patienten (178 von 358) bei Diagnosestellung LDHDaten vor, die alterskorreliert ausgewertet wurden. Ein erhöhter LDH-Wert trat zum Diagnosezeitpunkt bei nahezu der Hälfte der Patienten (46,6\%, 83 von 178 Patienten) auf. Im Normbereich lagen 53,4\% (95 von 178) der Patienten (siehe Abb. 3.17).

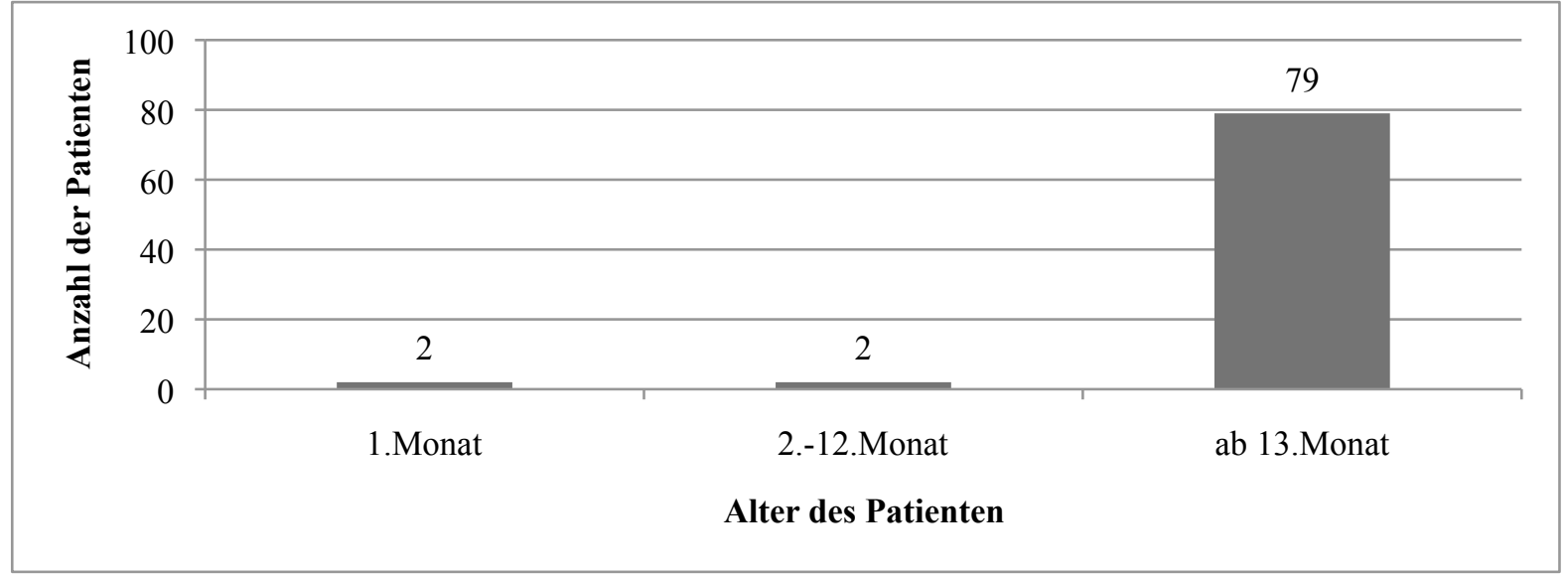

Abbildung 3.18 Auftreten eines erhöhten alterskorrelierten LDH-Wertes zum Diagnosezeitpunkt. Die Mehrheit der Patienten (79) mit erhöhtem LDH-Wert war zum Diagnosezeitpunkt älter als 13 Monate.

Die genaue Betrachtung der LDH-Werte zeigte, dass die Mehrheit der Patienten (79) mit erhöhtem LDH-Wert zum Diagnosezeitpunkt älter als 13 Monate waren, nur vier Patienten waren jünger als 13 Monate (siehe Abb. 3.18). 


\subsection{Thrombozyten zum Diagnosezeitpunkt}

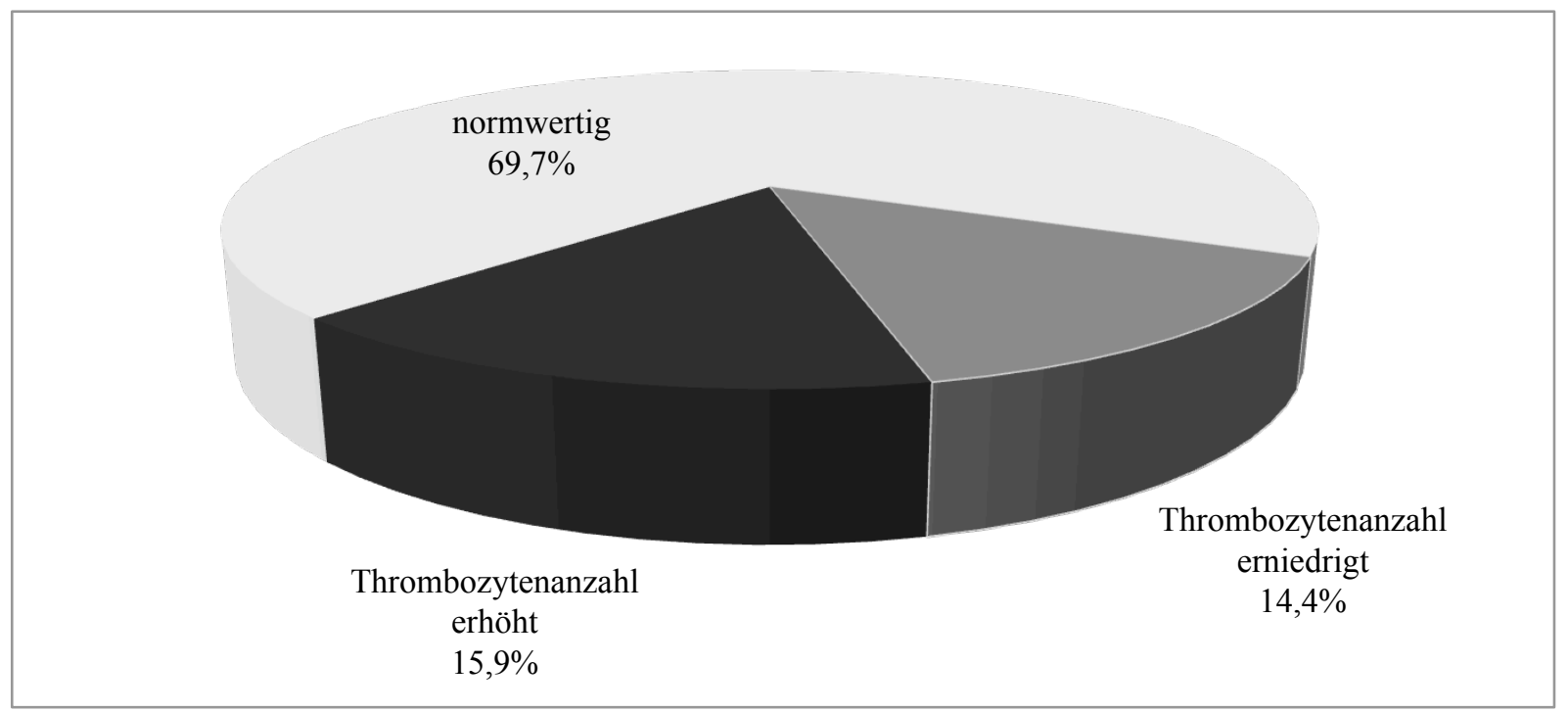

Abbildung 3.19 Alterskorrelierte Thrombozytenwerte zum Diagnosezeitpunkt. Bei knapp 1/6 der Patienten wurden erhöhte Thrombozytenwerte bei Diagnosestellung der HS festgestellt und bei etwa einem weiteren 1/6 war die Thrombozytenanzahl erniedrigt.

Von 58,1\% der Patienten (208 von 358) lagen Thrombozytenwerte zum Diagnosezeitpunkt vor. Alterskorreliert ausgewertet, wiesen fast 1/6 der Patienten (33 von 208) einen erhöhten Thrombozytenwert auf, bei etwa einem weiteren 1/6 (30 von 208) war der Thrombozytenwert zum Diagnosezeitpunkt erniedrigt. Die übrigen Thrombozytenwerte (69,7\%, 145 von 208 Patienten) lagen im Normbereich. Von den Patienten mit erhöhten Thrombozytenwerten waren 93,9\% (31 von 33) zum Zeitpunkt der Blutentnahme zwischen dem ersten Lebensmonat und zehn Jahren alt (54,5\%, 18 von 33 Patienten zwischen erstem Lebensmonat und zwei Jahren; 39,4\%, 13 von 33 Patienten zwischen zwei und zehn Jahren). Die verbleibenden 6,1\% der Patienten waren älter als zehn Jahre. Von den Patienten mit erniedrigten Thrombozytenwerten waren 43,3\% (13 von 30) im Alter zwischen zwei und zehn Jahren. Die übrigen Patienten verteilten sich auf andere Altersstufen. 


\subsection{Auftreten eines Icterus neonatorum bei Patienten mit Sphärozytose}

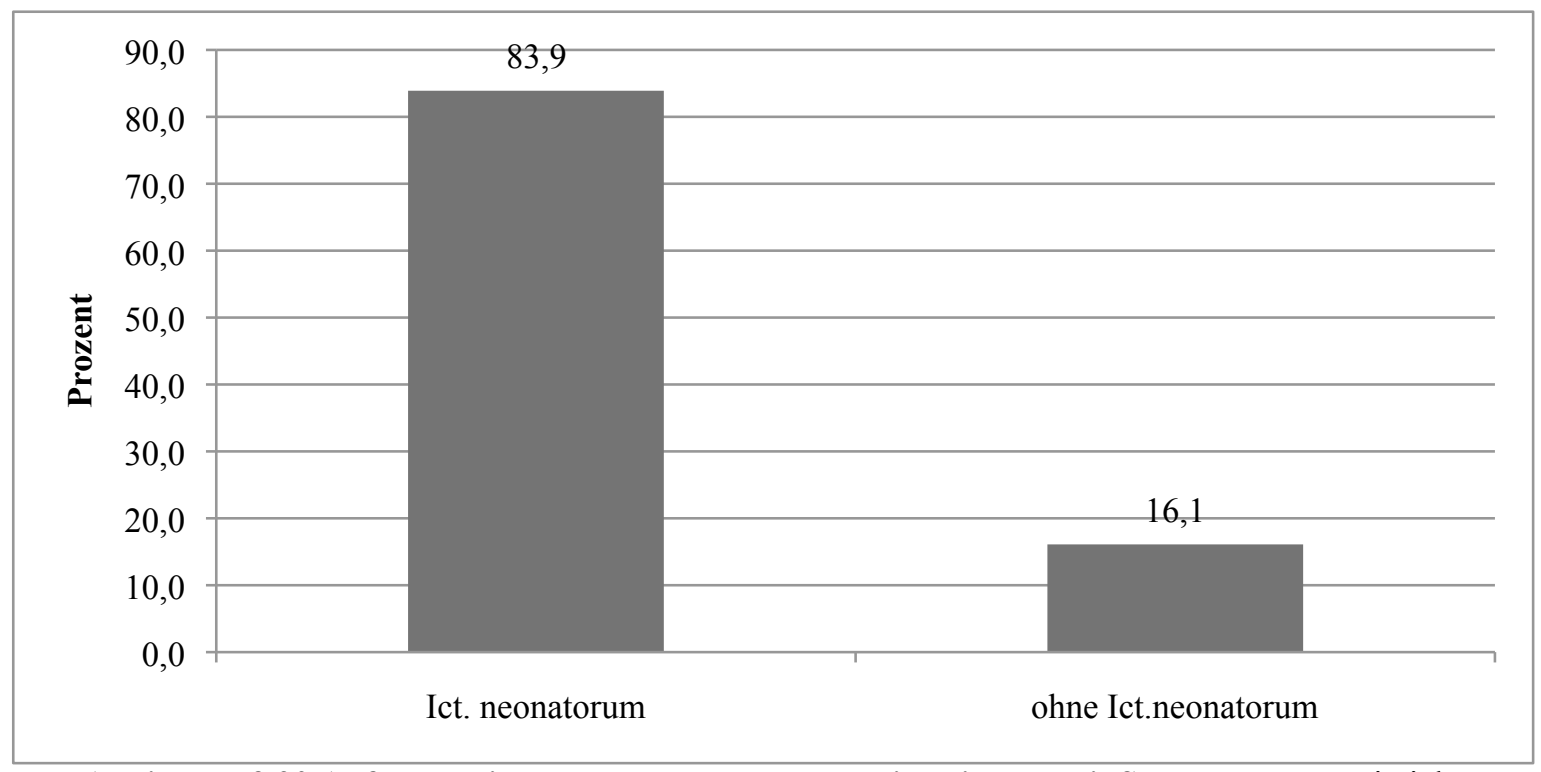

Abbildung 3.20 Auftreten eines Icterus neonatorum bei Patienten mit Sphärozytose. Bei vielen Patienten mit Sphärozytose $(83,9 \%)$ trat ein Icterus neonatorum auf.

Von 46,9\% (168 von 358) der Patienten lagen uns Daten über das Auftreten/Nichtauftreten eines Ikterus vor, wobei bei 83,9\% (141 von 168 Patienten) ein Icterus neonatorum beschrieben wurde. Wenige (16,1\%, 27 von 168 Patienten) zeigten keinen Icterus neonatorum.

\subsection{Durchführung einer Phototherapie bei Icterus neonatorum}

Ein erhöhter Bilirubinspiegel im Blut eines Neugeborenen kann einen Icterus neonatorum hervorrufen. Ab der Übersteigung eines bestimmten alterskorrelierten Bilirubingrenzwertes wird eine Phototherapie durchgeführt. In diesem Zusammenhang waren von 22,6\% der analysierten Patienten (81 von 358) Daten über eine Phototherapie zur Behandlung eines Icterus neonatorum vorhanden.

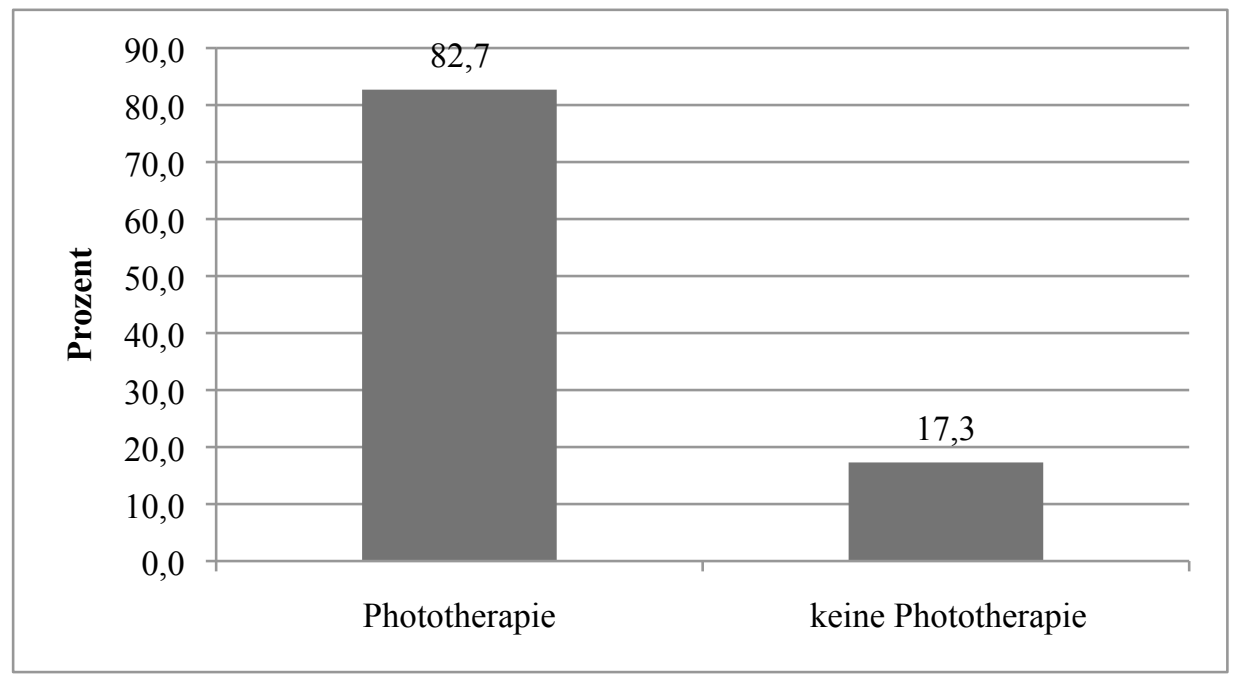

Abbildung 3.21 Phototherapiebehandlung bei Auftreten eines Icterus neonatorum. Mehr als 4/5 der Patienten mit Icterus neonatorum wurden phototherapiert. 
Mehr als 4/5 (82,7\%) dieser Patienten mit Icterus neonatorum (67 von 81) wurden phototherapiert, die übrigen $17,3 \%$ (14 von 81) benötigten keine Phototherapie (siehe Abb. 3.21).

\subsection{Austauschtransfusionsbehandlung bei Hyperbilirubinämie}

Bei weiterem Ansteigen des Bilirubinspiegels und/oder Nichtansprechen der Phototherapie wird wiederum alterskorreliert über die Durchführung einer Austauschtransfusion entschieden (siehe Abb. 3.22).

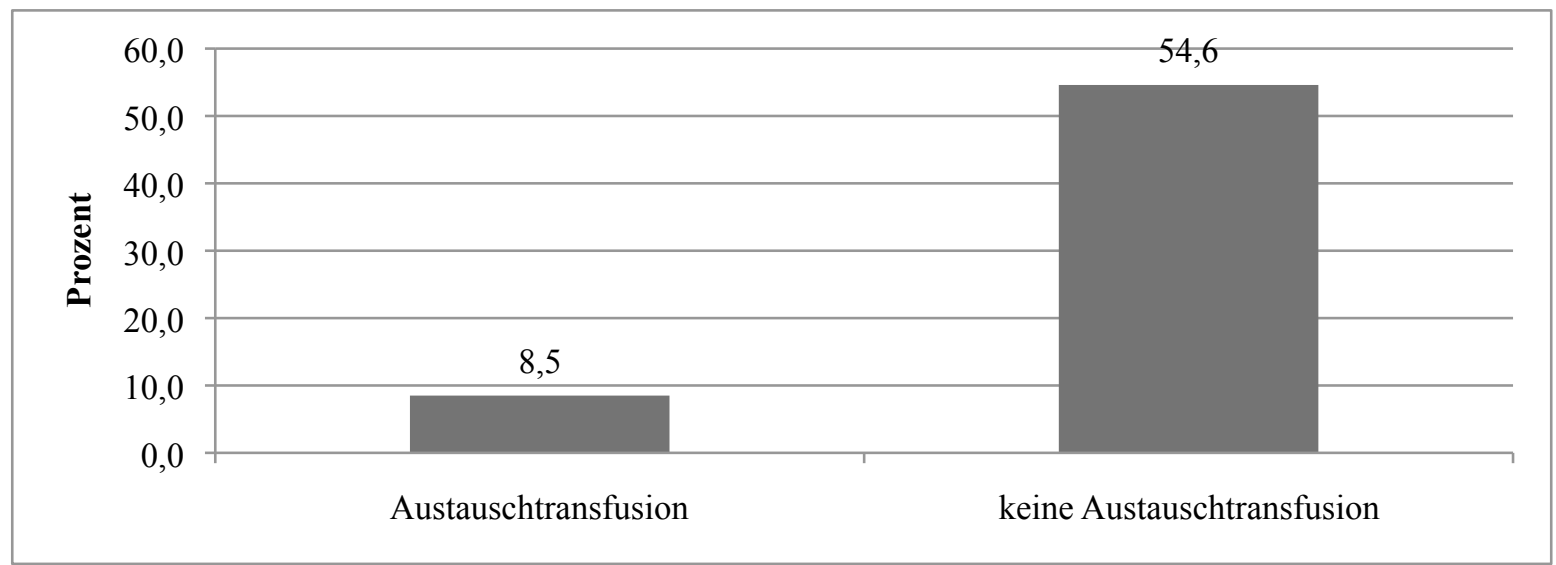

Abbildung 3.22 Durchführung einer Austauschtransfusion bei Hyperbilirubinämie. 8,5\% der Patienten mit pathologischer Hyperbilirubinämie wurden einer Austauschtransfusion unterzogen.

Von 63\% (89 von 141) der Patienten mit Ikterus lagen uns Daten über Austauschtransfusionen (AT) bei Hyperbilirubinämie vor, wobei 8,5\% (12 von 141 Patienten) eine AT und 54,6\% (77 von 141 Patienten) keine AT erhielten. Von den übrigen 36,9\% der 141 Patienten (52) lagen keine Daten über Austauschtransfusionen bei Hyperbilirubinämie vor. 


\subsection{Diagnosestellung innerhalb von vier Wochen nach Austauschtransfusion oder Icterus-praecox- und/oder Icterus-gravis-Diagnose}

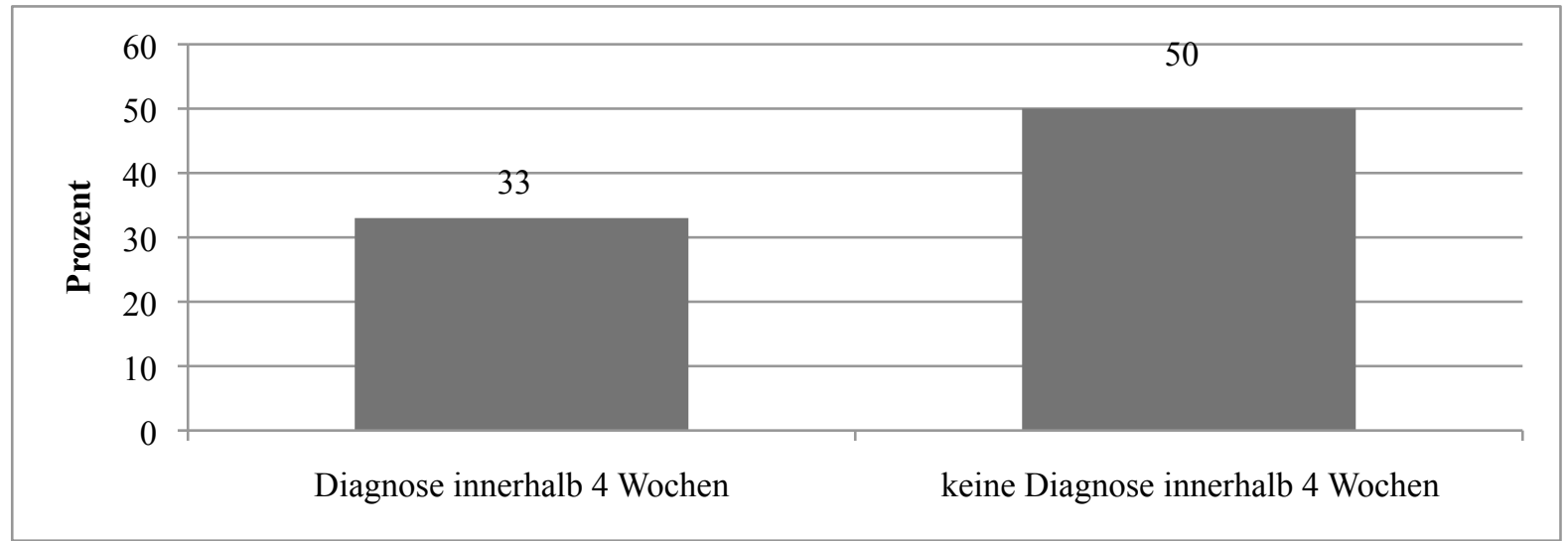

Abbildung 3.23 HS-Diagnosestellung innerhalb von vier Wochen nach Austauschtransfusion. Bei nur $1 / 3$ der Patienten wurde die HS innerhalb von vier Wochen nach Austauschtransfusion diagnostiziert.

In Korrelation dazu untersuchten wir, wie häufig die Diagnose hereditäre Sphärozytose innerhalb von vier Wochen nach Austauschtransfusionen gestellt wurde (siehe Abb. 3.23). Immerhin 50\% der Patienten (6 von 12) erhielten keine Diagnosestellung innerhalb von vier Wochen nach Austauschtransfusion und nur bei $1 / 3$ der Patienten (4 von 12) wurde die Diagnose hereditäre Sphärozytose innerhalb von vier Wochen gestellt. Von den übrigen 17\% der Patienten (2 von 12) lag kein Diagnosedatum vor.

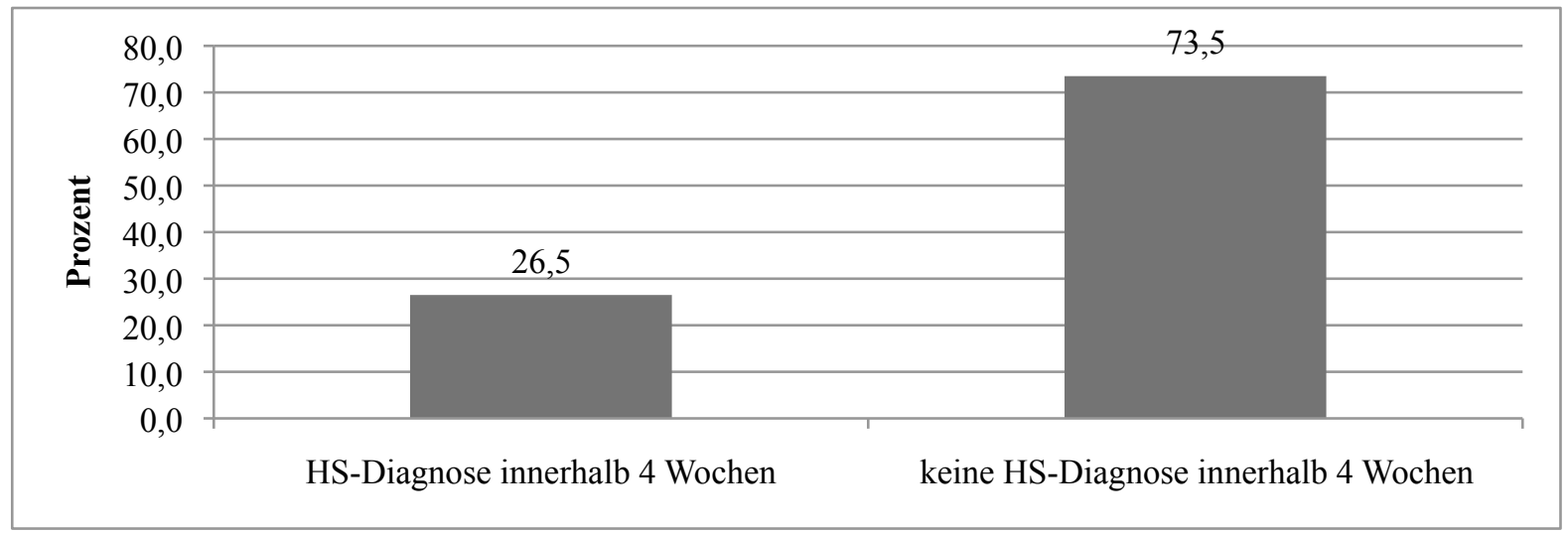

Abbildung 3.24 Diagnosestellung innerhalb von 4 Wochen bei festgestelltem Icterus praecox und/oder Icterus gravis. Bei nur etwas mehr als $1 / 4$ der Patienten wurde die Diagnose der hereditären Sphärozytose innerhalb von vier Wochen nach Feststellung eines Icterus praecox und/oder Icterus gravis gestellt.

Außerdem wurde analysiert, bei wie vielen Patienten die Diagnose der hereditären Sphärozytose innerhalb von vier Wochen gestellt wurde, wenn ein Icterus praecox und/oder Icterus gravis vorlag (siehe Abb. 3.24). Von 34 Patienten, die einen Icterus praecox und/oder Icterus gravis hatten, waren Daten vorhanden. Auch bei dieser Patientengruppe wurde die Diagnose der hereditären Sphärozytose bei den meisten Patienten (73,5\%, 25 von 34 Patienten) nicht 
innerhalb von vier Wochen gestellt. Nur $26,5 \%$ der Patienten (9 von 34 ) wurden innerhalb von vier Wochen diagnostiziert.

\subsection{Transfusionsbehandlungen im Zusammenhang mit der Sphärozytose- Erkrankung}

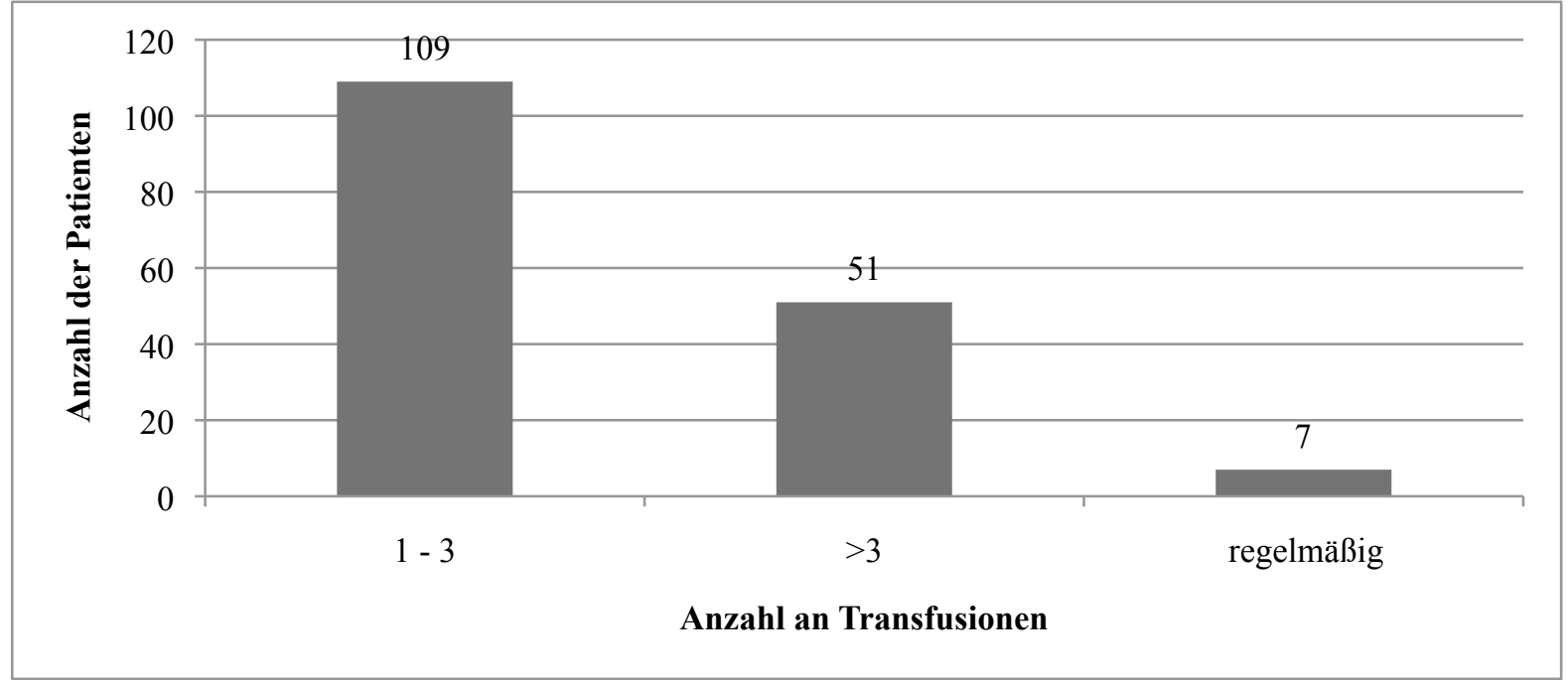

Abbildung 3.25 Übersicht über die Anzahl an Transfusionen bei Patienten mit Sphärozytose.

Der Großteil der Patienten mit Transfusionstherapie bei Sphärozytose wurde ein bis drei Mal transfundiert.

44,7\% (160 von 358) aller Patienten wurden im Laufe ihrer Sphärozytose-Erkrankung transfundiert. Der Großteil dieser Patienten $(68,1 \%, 109$ von 160) erhielt eine bis drei Transfusionen. Die übrigen 31,9\% (51 von 160) wurden mehr als drei Mal transfundiert, wovon sieben Patienten sogar regelmäßig (wöchentlich bis alle drei Monate) Transfusionen bekamen (siehe Abb. 3.25). 


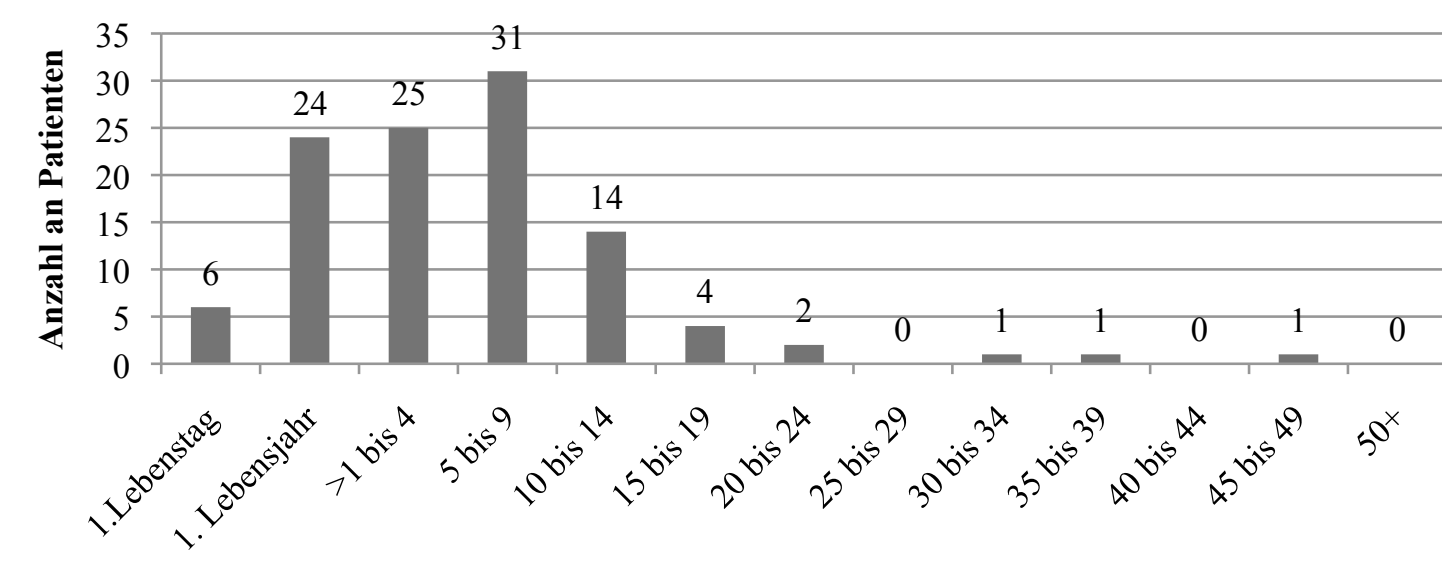

Alter in Jahren

Abbildung 3.26 Altersverteilung bei Patienten mit 1-3 Transfusionen. 91,7\% der Patienten, die ein bis drei Transfusionen erhielten, wurden bereits vor dem 15. Lebensjahr transfundiert.

Genauer analysiert, zeigte die Altersverteilung bei Patienten mit ein bis drei Transfusionen, dass 91,7\% (100 von 109) dieser Patienten bis zum 15. Lebensjahr bereits transfundiert wurden. Die meisten Patienten benötigten diese Transfusionen im Alter zwischen fünf und neun Jahren (28,4\%, 31 von 109 Patienten), der Bedarf an Transfusionen im ersten Lebensjahr und im Alter von eins bis vier Jahren war fast identisch bei 27,5\% (6+24 von 109) und 22,9\% (25 von 109) der Patienten. Die restlichen Patienten verteilten sich auf die anderen Altersstufen (siehe Abb. 3.26).

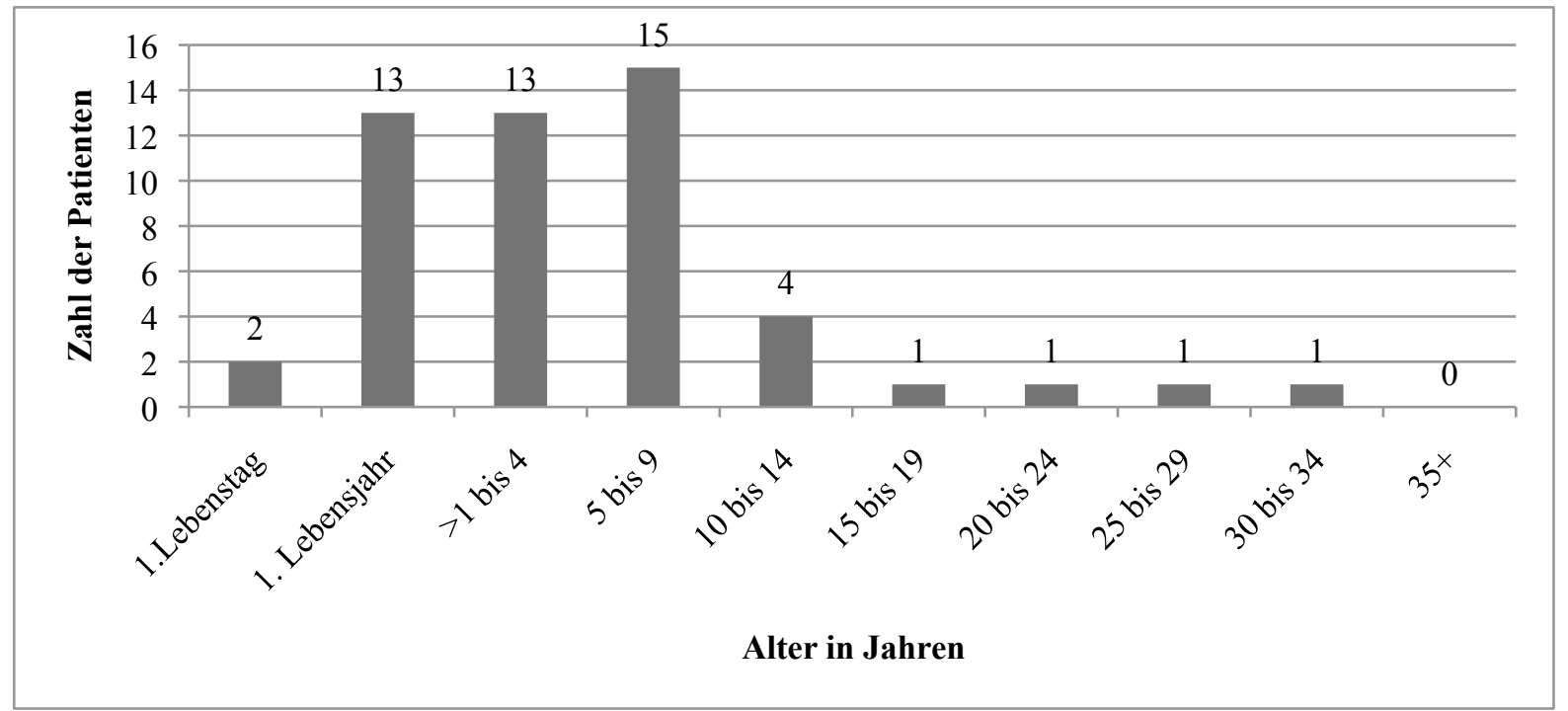

Abbildung 3.27 Altersverteilung bei Patienten mit mehr als 3 Transfusionen. 92,2\% der Patienten, die mehr als drei Transfusionen bekamen, wurden bereits vor dem 15. Lebensjahr transfundiert.

Auch die Altersverteilung bei Patienten mit mehr als 3 Transfusionen zeigte, dass ein hoher Transfusionsbedarf im Alter zwischen fünf und neun Jahren lag (29,4\%, 15 von 51 Patienten). Im ersten Lebensjahr benötigten ebenfalls $29,4 \%$ der Patienten (15 von 51) mehr als drei 
Transfusionen, knapp gefolgt von der Altersgruppe eins bis vier Jahre (25,5\%, 13 von 51

Patienten). Die übrigen Patienten verteilten sich auf andere Altersstufen (siehe Abb. 3.27).

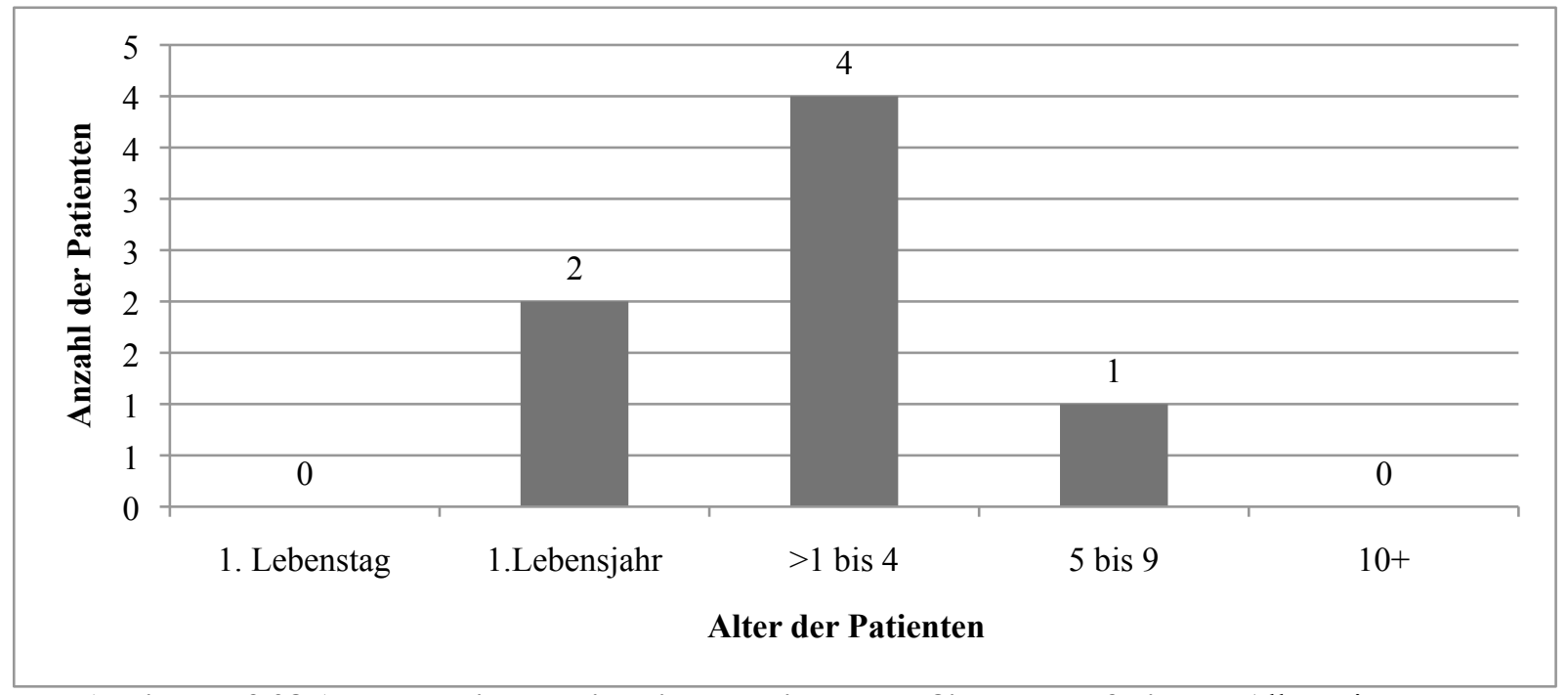

Abbildung 3.28 Altersverteilung bei Patienten mit regelmäßigen Transfusionen. Alle Patienten, die regelmäßig transfundiert wurden, waren unter zehn Jahre alt. Eine Häufung zeigte sich bei Patienten, die älter als ein und jünger als fünf Jahre alt waren.

Von den 51 Patienten, die mehr als drei Mal transfundiert wurden, bekamen sieben Patienten regelmäßig Transfusionen. Auch hier verteilten sich die Patientenzahlen auf die jüngeren Altersstufen, jedoch war kein Patient zehn Jahre alt oder älter, als er transfundiert wurde. Alle Patienten wurden zwischen dem ersten und neunten Lebensjahr transfundiert. Eine Häufung zeigte sich bei Patienten (vier von sieben), die älter als ein und jünger als fünf Jahre alt waren (siehe Abb. 3.28). 


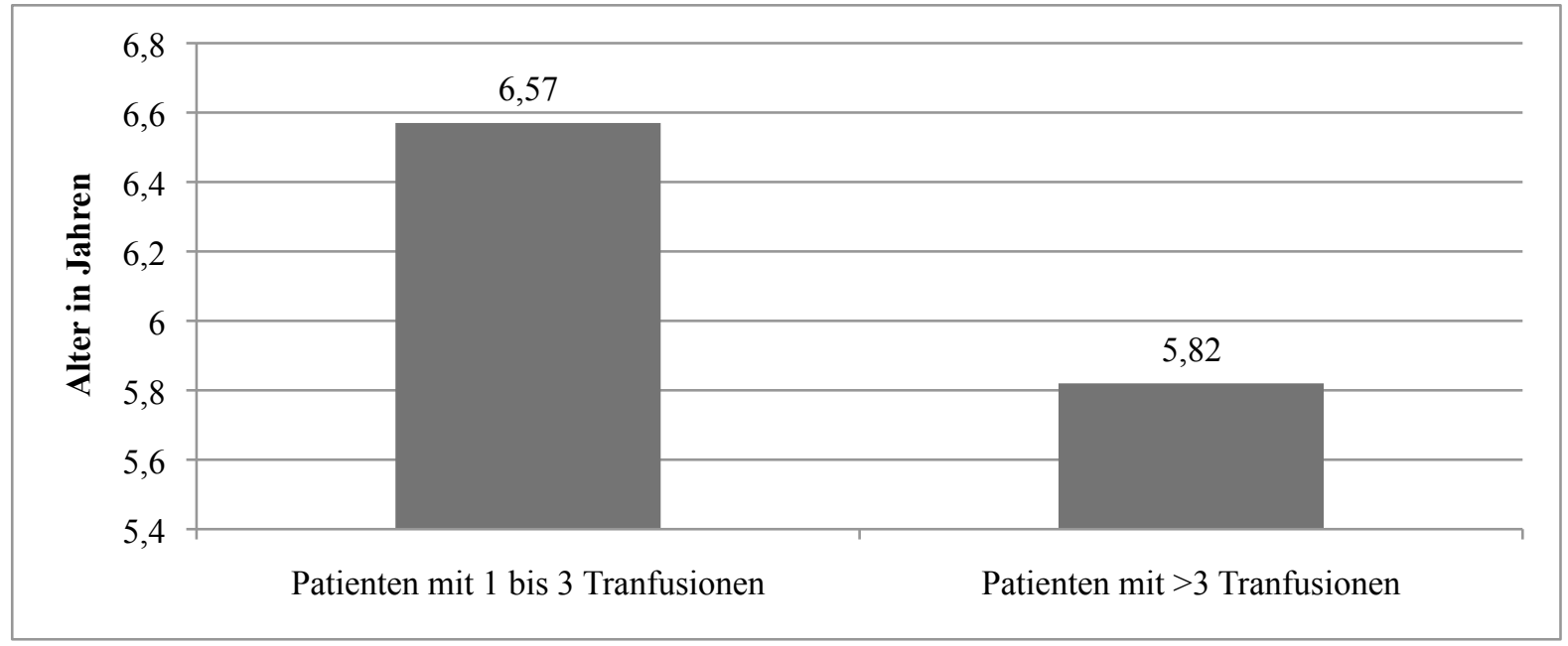

Abbildung 3.29 Altersdurchschnitt der Patienten mit hereditärer Sphärozytose in Korrelation mit der Transfusionsanzahl. Der Altersdurchschnitt liegt um das sechste Lebensjahr. Patienten mit ein bis drei Transfusionen sind im Durchschnitt etwas älter (6,57 Jahre) als Patienten, die häufiger als drei Mal transfundiert wurden (5,82 Jahre).

Der Altersdurchschnitt der Patienten mit hereditärer Sphärozytose, die mit Transfusionen therapiert wurden, liegt um das sechste Lebensjahr. Bei Patienten mit ein bis drei Transfusionen liegt der Altersdurchschnitt mit 6,57 Jahren über dem der Patienten mit mehr als drei Transfusionen (5,82 Jahren).

\subsection{Gallensteinauftreten bei Patienten mit Sphärozytose}

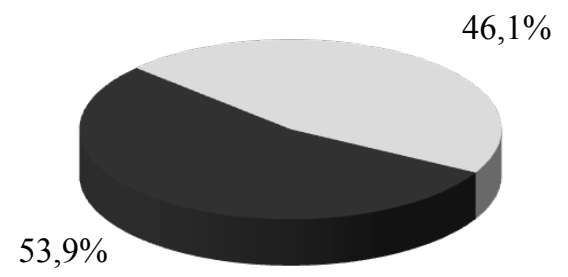

Patienten ohne Gallenstein

- Patienten mit Gallensteinen

Abbildung 3.30 Auftreten von Gallensteinen bei Patienten mit HS. Bei mehr als der Hälfte der Patienten $(53,9 \%)$ trat ein Gallensteinleiden auf.

Durch die gesteigerte Abbauleistung der Leber und die nachfolgende erhöhte Konzentration von Gallensäuren können Gallensteine entstehen, so dass das Auftreten von Gallensteinen im Rahmen der HS-Diagnostik untersucht wurde. Von 67,3\% aller untersuchten Patienten mit Sphärozytose (241 von 358) gab es Daten über das Auftreten/Nichtauftreten von Gallensteinen. Bei mehr als der Hälfte (53,9\%) der Patienten (130 von 241) traten Gallensteine auf, die übrigen Patienten hatten keine Gallensteine (siehe Abb. 3.30). 


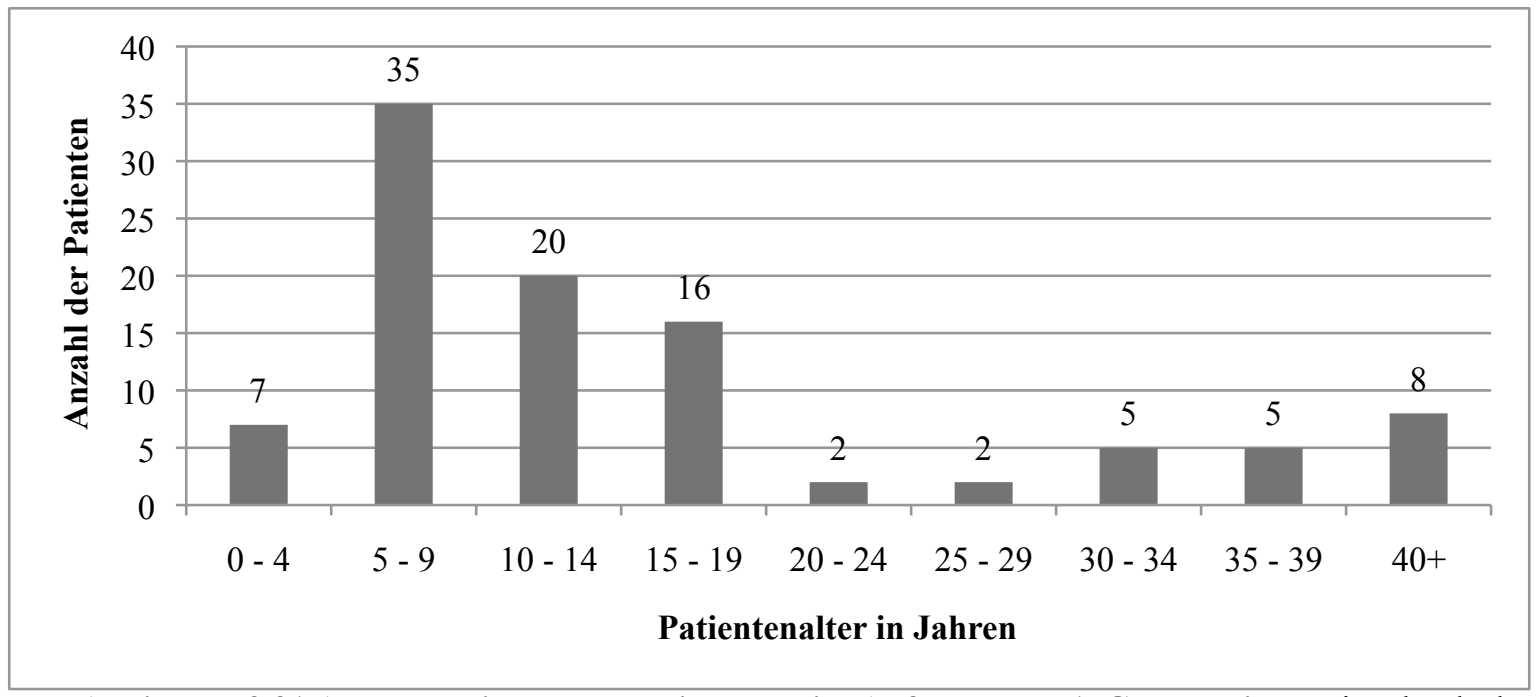

Abbildung 3.31 Altersverteilung von Patienten beim Auftreten des 1. Gallensteins. Bei mehr als der Hälfte der Patienten mit HS trat ein Gallensteinleiden bereits im Alter zwischen fünf und 19 Jahren auf.

Die genaue Analyse der Altersverteilung bei Auftreten eines ersten Gallensteins ergab, dass bei 71 von 130 Patienten (54,6\%) Gallensteine im Alter zwischen fünf und 19 Jahren diagnostiziert wurden. Die meisten Patienten dieser Gruppe (35) waren zwischen fünf und neun Jahre alt. Auf die restlichen Altersstufen verteilten sich Patientenzahlen zwischen zwei und acht Patienten, wobei ab dem 30. Lebensjahr die Gallensteindiagnosen wieder leicht anstiegen (siehe Abb. 3.31). Bei weiteren 30 Patienten traten Gallensteine auf, doch war das Diagnosealter nicht bekannt.

\subsection{Cholezystektomiebehandlung bei Patienten mit Sphärozytose}

Auf Grund des erhöhten Auftreten von Gallensteinen kann eine Cholezystektomie in Betracht gezogen werden. 70,6\% der Patienten mit HS (84 von 119) wurden cholezystektomiert, die übrigen 29,4\% (35 von 119 Patienten) benötigten keine Cholezystektomie. Insgesamt lagen darüber von 33,2\% aller Patienten mit HS (119 von 358) Daten vor. Von den cholezystektomierten Patienten waren 52,4\% (44 von 84) weiblich und 47,6\% (40 von 84) männlich. 


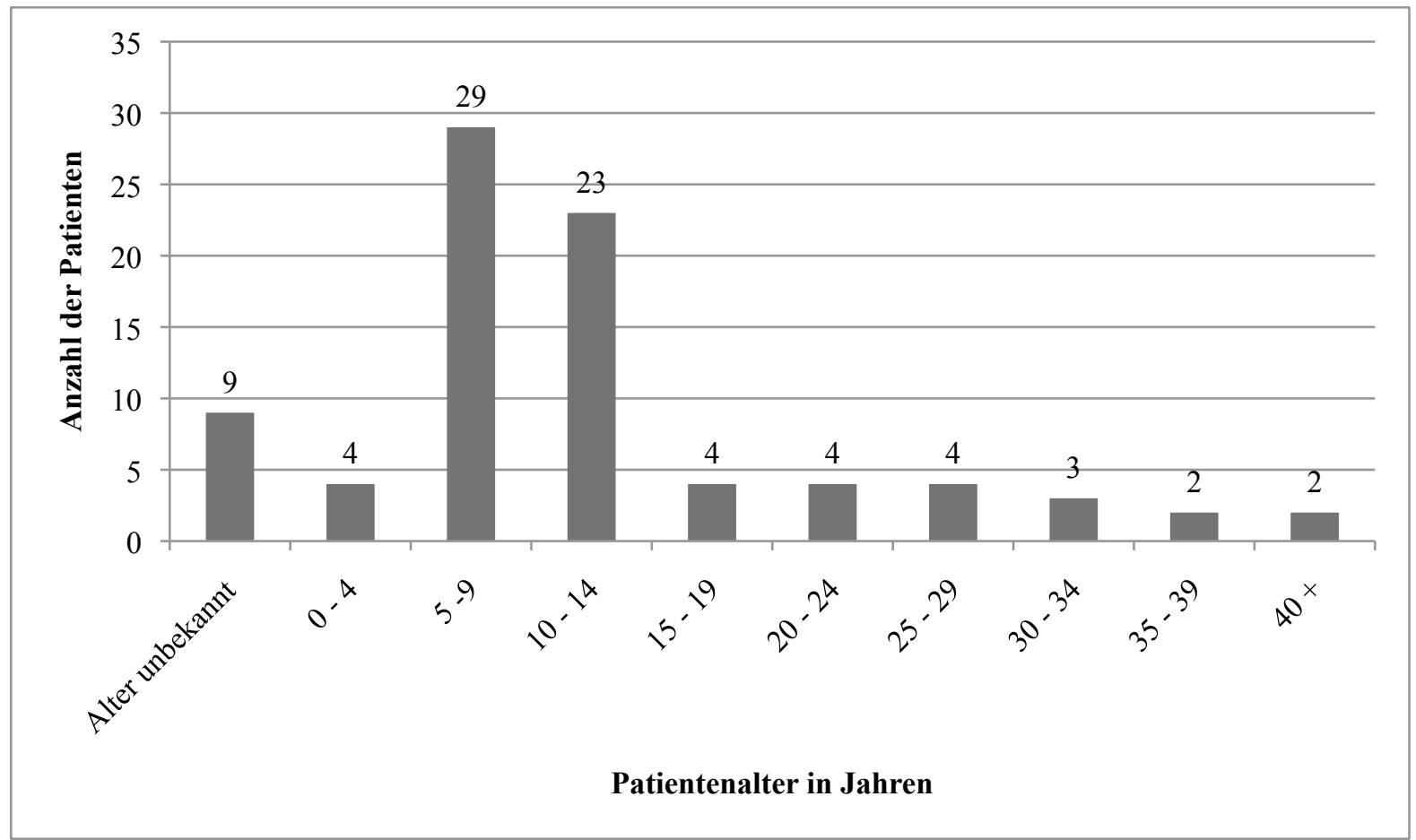

Abbildung 3.32 Altersverteilung bei Cholezystektomie von Patienten mit Sphärozytose. Ein Großteil der Patienten mit Cholezystektomie bei HS wurden im Alter zwischen fünf und 14 Jahren cholezystektomiert.

Genauer analysiert ergab sich, dass ein Großteil der Patienten (61,9\%, 52 von 84 Patienten) im Alter zwischen fünf und 14 Jahren cholezystektomiert wurde. In allen anderen Altersgruppen lag die Patientenzahl zwischen zwei und vier (siehe Abb. 3.32). Bei neun Patienten war das Cholezystektomiealter nicht bekannt. 


\subsection{Splenektomiebehandlung bei Patienten mit Sphärozytose}

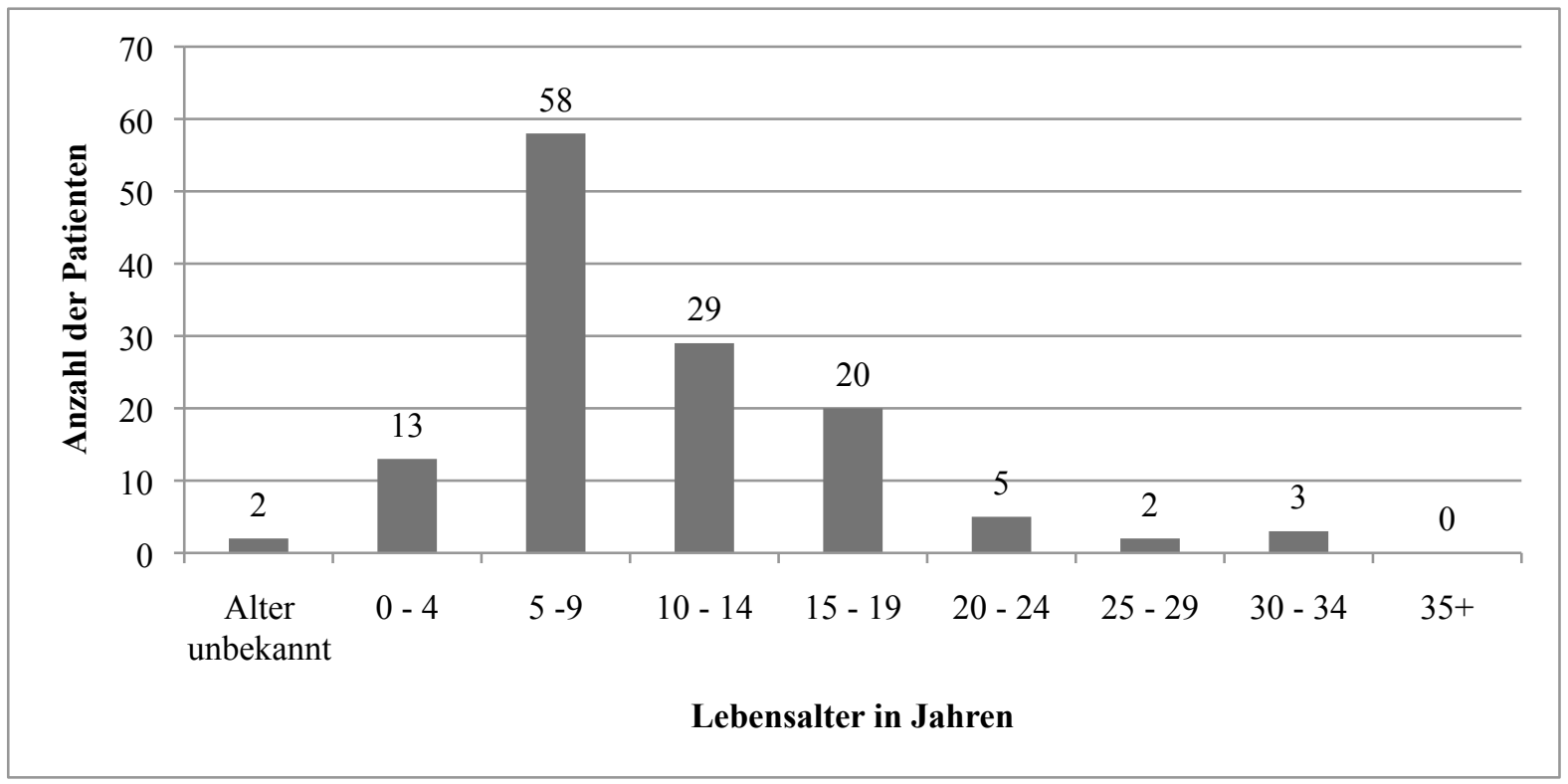

Abbildung 3.33 Altersverteilung bei Splenektomie von Patienten mit Sphärozytose. Die meisten Patienten mit HS wurden im Alter zwischen fünf und neun Jahren, etwas weniger im Alter zwischen zehn und 19 Jahren splenektomiert.

Von den 36,9\% der Patienten (132 von 358), von denen uns Daten über eine Splenektomie zur Verfügung standen, waren 48,5\% (64 von 132) weiblich und 51,5\% (68 von 132) männlich.

Wie bei der Cholezystektomie, wurde auch bei der Splenektomie das Operationsalter genauer analysiert. Die meisten Patienten mit HS (90,9\%, 120 von 132) wurden in den beiden ersten Lebensdekaden splenektomiert, wobei der Großteil (43,9\%, 58 Patienten) zwischen fünf und neun Jahren und weitere 29 (22\%) bzw. 20 Patienten (15,2\%) zwischen zehn und 14 bzw. 15 und 19 Jahren splenektomiert wurde. Die restlichen Patienten verteilten sich auf die anderen Altersgruppen (siehe Abb. 3.33). Bei zwei Patienten war das Splenektomiealter unbekannt. Der Altersmittelwert der Patienten mit HS bei Splenektomie lag bei 11,05 Jahren. 


\subsection{Antibiotikaprophylaxe nach Splenektomie}

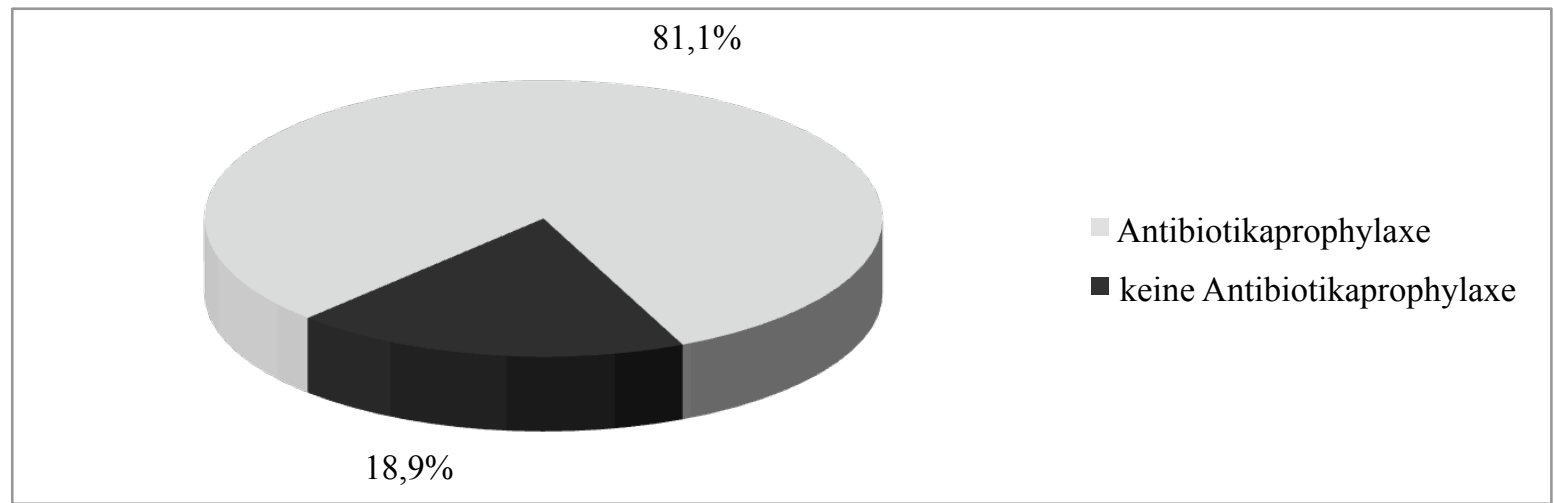

Abbildung 3.34 Durchführung einer Antibiotikaprophylaxe bei Patienten mit Sphärozytose nach Splenektomie. Bei nahezu 1/5 der splenektomierten Patienten fand keine Antibiotikaprophylaxe statt.

Von den insgesamt 132 (von 358) splenektomierten Patienten (siehe Kapitel 3.19) lagen von 72\% (95 von 132) Daten über die Durchführung einer Antibiotikaprophylaxe vor. Die Prophylaxe wurde bei $81,1 \%$ der Patienten (77 von 95) durchgeführt, nahezu 1/5 der splenektomierten Patienten (18 von 95) erhielt keine Postsplenektomieprophylaxe, jedoch wurde auch bei keinem Patienten das Auftreten eines Overwhelming postsplenectomy infection (OPSI) syndrome registriert.

\subsection{Analyse hämolytischer/aplastischer Krisen bei Patienten mit HS}

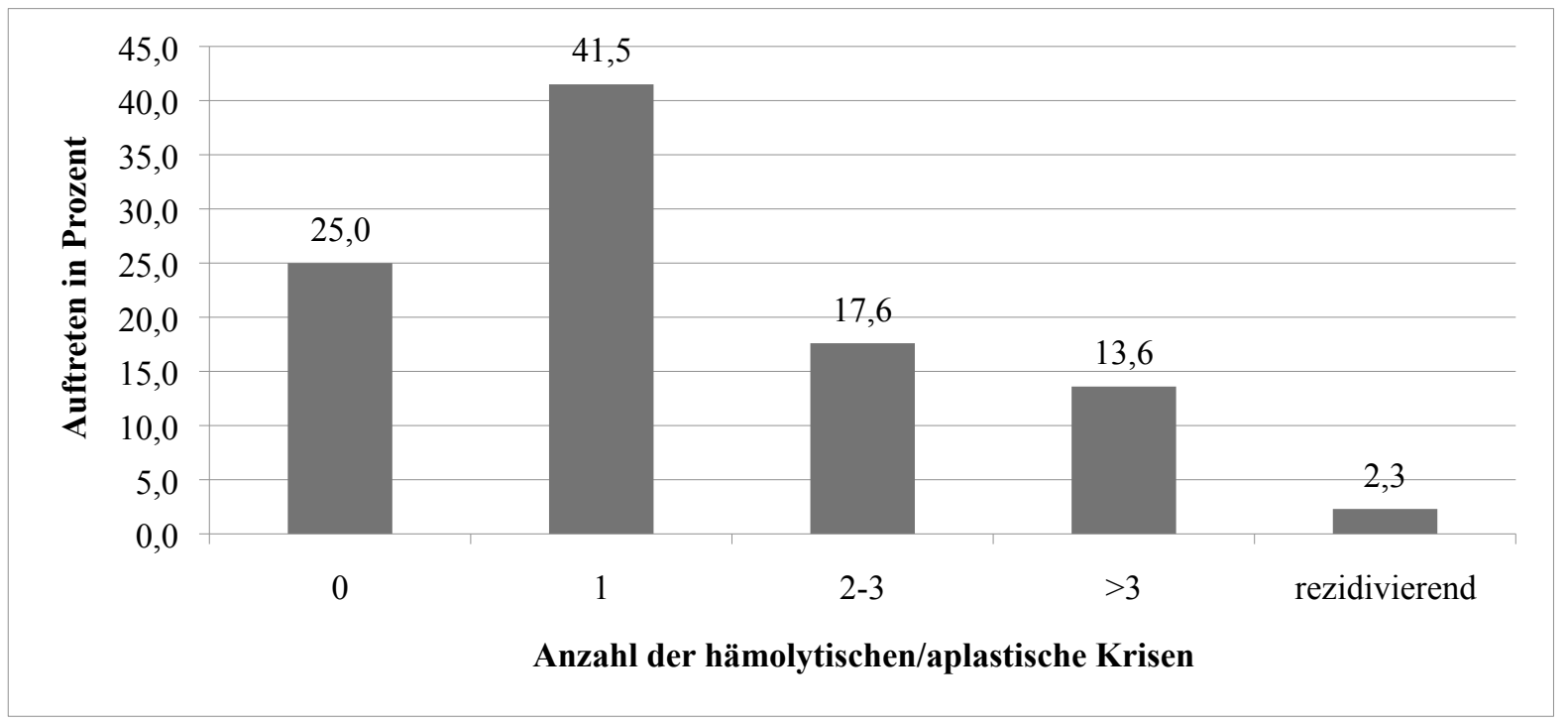

\footnotetext{
Abbildung 3.35 Analyse des Auftretens hämolytischer/aplastischer Krisen bei Patienten mit Sphärozytose. Bei $75 \%$ der Patienten traten hämolytische/aplastische Krisen auf, von denen die meisten (41,5\%) eine Krise im Verlauf der Erkrankung hatte.
}

Die Erkrankung der HS geht gehäuft mit hämolytischen/aplastischen Krisen einher. Von 49,2\% aller untersuchten Patienten (176 von 358) standen uns Daten über das Auftreten/Nichtauftreten solcher Krisen zur Verfügung. 75\% der Patienten (134 von 176) wiesen 
hämolytische/aplastische Krisen auf, von denen der Großteil (41,5\%, 73 von 176 Patienten) eine Krise und insgesamt 33,5\% der Patienten (59 von 176) bereits mehr als eine hämolytische/aplastische Krise im Krankheitsverlauf durchgemacht hatten. Nur 1/4 der Patienten (44 von 176) gaben an, bis jetzt keine Krise gehabt zu haben (siehe Abb. 3.35).

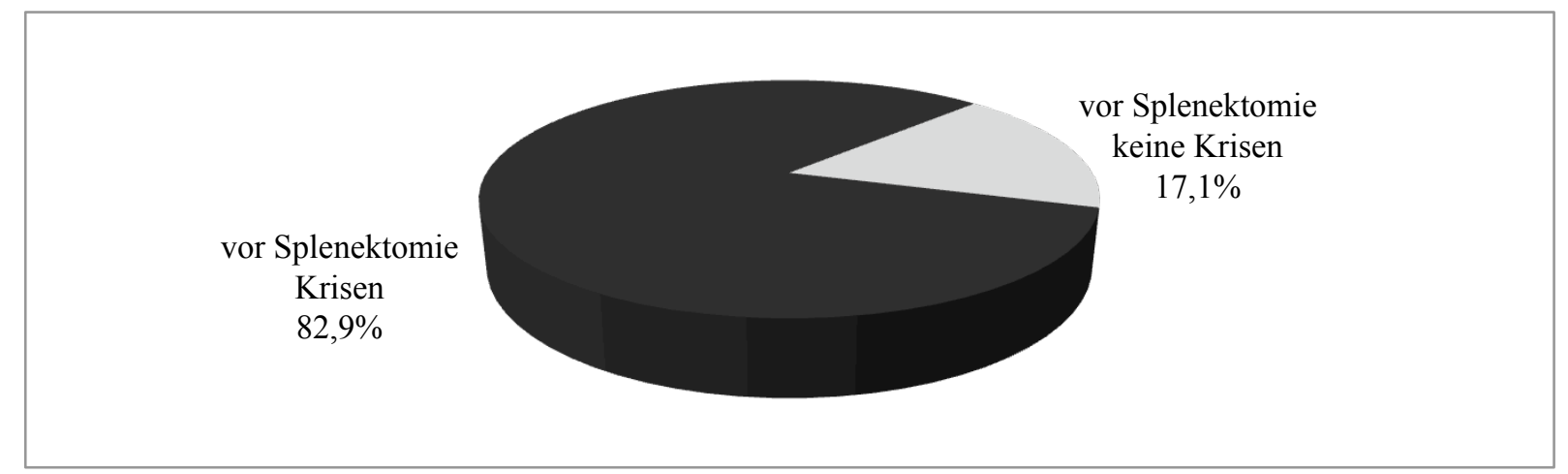

Abbildung 3.36 Auftreten hämolytischer/aplastischer Krisen vor Splenektomie bei Patienten mit hereditärer Sphärozytose. Bei den meisten Patienten mit HS (82,9\%) traten vor Splenektomie hämolytische/aplastische Krisen auf.

In Korrelation dazu wurde das Auftreten bzw. Nichtauftreten hämolytischer/aplastischer Krisen vor und nach Splenektomie analysiert. Von den 19,6\% der Patienten (70 von 358) mit Daten darüber, hatten $82,9 \%$ (58 von 70 Patienten) vor der Splenektomie Krisen, bei den übrigen $17,1 \%$ der Patienten (12 von 70 ) traten keine hämolytischen/aplastischen Krisen auf (siehe Abb. 3.36). 


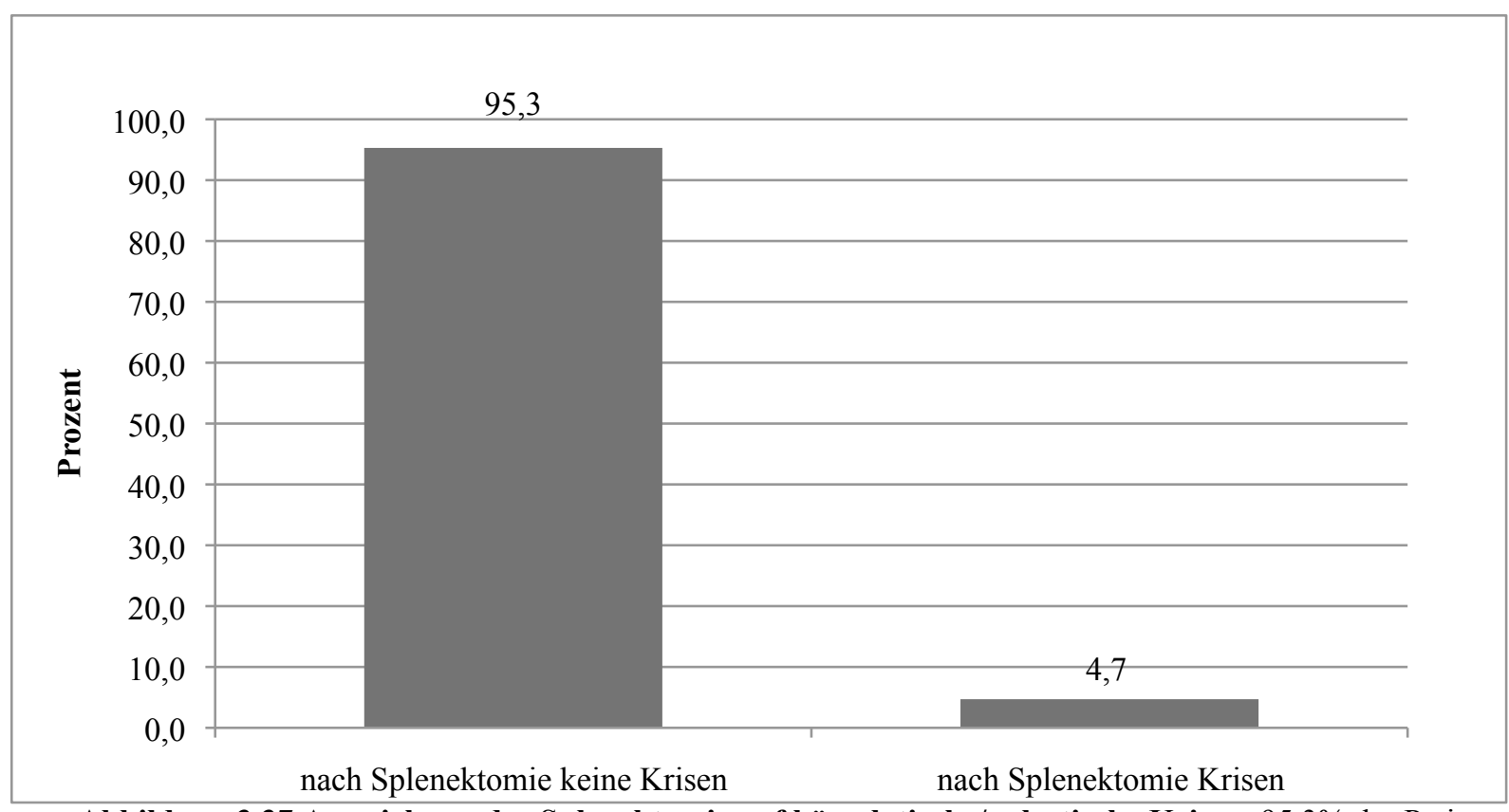

Abbildung 3.37 Auswirkung der Splenektomie auf hämolytische/aplastische Krisen. 95,3\% der Patienten, die vor Splenektomie hämolytische/aplastische Krisen hatten, wiesen nach der Operation keine Krisen mehr auf.

Die Patienten (58), die vor Splenektomie hämolytische/aplastische Krisen aufwiesen (siehe Abb. 3.37), wurden auf das Auftreten solcher Krisen nach Splenektomie untersucht, um die Effektivität der Behandlung darzustellen. Von 74,1\% der Patienten (43 von 58), die vor Splenektomie hämolytische/aplastische Krisen hatten, lagen nach Splenektomie Daten über den weiteren Krisenverlauf vor. 95,3\% von diesen Patienten (41 von 43) hatten nach Splenektomie keine Krisen mehr und 4,7\% (2 von 43) hatten sowohl vor als auch nach Splenektomie hämolytische Krisen. Von den übrigen 15 Patienten mit Krisen vor Splenektomie gab es keine Daten über Krisen nach Splenektomie. 


\section{Diskussion}

Durch einen Defekt von Zellmembranbestandteilen der Erythrozyten kommt es bei der Erkrankung der hereditären Sphärozytose (HS) zu einem Verlust der bikonkaven Form der Erythrozyten. Sie nehmen eine Kugelform an (Sphärozyt), sind weniger verformbar und werden von der Milz frühzeitig abgebaut. Es resultiert eine hämolytische Anämie mit Ikterus und einer Splenomegalie (Dacie 1985). Durch den erhöhten Bilirubinspiegel können bereits im Kindesalter Gallensteine zu Beschwerden führen. Das häufige Auftreten der HS -in Deutschland mit einer Häufigkeit von 1:2500- macht sie zu der bedeutendsten angeborenen hämolytischen Anämie (Eber 2006).

Unsere Untersuchung von 358 Patientinnen und Patienten wurde als retrospektiv-deskriptive Untersuchung angelegt, wie sie in diesem Umfang bis jetzt noch in keiner früheren Untersuchung dargestellt wurde. Die meisten Patientinnen und Patienten waren zwischen einem Tag und 64 Jahre, der älteste Patient sogar 84 Jahre alt. Ähnliche Altersverteilungen findet man in anderen Studien, wie z.B. der von Jonte et al. (1995), bei der die Patienten zwischen einem Tag und 64 Jahre alt waren. Der Altersmittelwert bei Diagnosestellung lag allerdings in der Studie von Jonte et al. bei 13 Jahren und in unserer Untersuchung bei 7,27 Jahren. Das mag daran liegen, dass Jontes Untersuchungen im Jahr 1995 stattfanden und die Diagnostik heute früher erfolgreich ist. Die meisten Patienten (77,6\%) unserer Untersuchung waren bei Diagnosestellung jünger als neun Jahre, und am häufigsten wurden Patienten im ersten Lebensjahr diagnostiziert. Friedman et al. berichteten 1988 über die HS-Diagnostik bei fünf Patienten in der siebten bis neunten Lebensdekade. Nicht zuletzt wegen der nur milden oder gar fehlenden Klinik solcher Patienten mag die Diagnose erst in dem späten Alter gestellt worden sein. Auch kann die Erkrankung der HS übersehen werden, wenn behandelnde Ärzte z.B. durch eine Anämie bei Eisenmangel zur falschen Diagnosestellung verleitet werden. Kutter und Gulbis gingen 2005 aus diesem Grunde sogar von einer höheren Inzidenz der HS als beschrieben aus.

Häufig ist eine Anämie mit Symptomen wie Müdigkeit, Abgeschlagenheit, mangelnder Leistungsfähigkeit und Belastbarkeit, Blässe, Kopfschmerzen, Dyspnoe, Konzentrationsschwierigkeiten und/oder Tachykardie die erste Auffälligkeit vor der Diagnostik. So hatten auch bei unserer Untersuchung mehr als die Hälfte der Patienten $(58,5 \%)$ einen erniedrigten Hämoglobinwert (Hb-Wert). Unsere Ergebnisse zeigten eine Häufung der Patientenanzahl mit erniedrigten Hb-Werten bei Diagnosezeitpunkten im Alter zwischen 12 
Wochen und 10 Jahren. Das passt zu unserer Altersverteilung des Diagnosealters, bei der 77,6\% der Patienten unter neun Jahre alt waren. Patienten mit Anämie zum Diagnosezeitpunkt innerhalb der ersten drei bis vier Lebenswochen fanden sich seltener. In der Literatur variieren die Zahlen der Patienten mit erniedrigten Hb-Werten. Jonte et al. beschrieben 1995 erniedrigte Werte bei mehr als 60\% ihrer 61 Patienten bei Diagnosestellung und Nathan et al. (2003) beschrieben eine Anämie bei Geburt bei 43\% ihrer Patienten. Nathan et al. betonten aber, dass ernsthafte Anämien mit Transfusionsbedarf bei Geburt selten waren. Delhommeau et al. (2000) berichteten über Patienten mit HS, die bei Geburt einen normalen Hb-Wert aufwiesen, bei denen aber innerhalb von 20 Tagen eine Anämie auftrat. Bei Betrachtung dieser Ergebnisse fällt auf, dass viele Patienten auch ohne offensichtliche Anämie an HS erkrankt sein können. Es sollte also bei der Diagnostik auch ohne vorliegende Anämie an die Differentialdiagnose HS gedacht werden.

Bei der Sphärozytose ist die Überlebenszeit der Erythrozyten verkürzt. Auch nach einer Splenektomie tritt keine Überlebenszeitverlängerung der Erythrozyten auf. Chapman und McDonald (1968) verglichen 11 Patienten mit HS nach Splenektomie mit einer gesunden Kontrollgruppe (12 Personen). Die Überlebenszeit der Erythrozyten nach Splenektomie lag bei $96 \pm 13$ Tagen, die der gesunden Personen bei $123 \pm 14$ Tagen. Diese verkürzte Überlebenszeit der Erythrozyten führt zur Anämie und zur gesteigerten Retikulozytenproduktion. Erhöhte Retikulozytenwerte zum Diagnosezeitpunkt traten bei unserer Untersuchung vor allem bei Patienten im Alter zwischen dem dritten und 13. Lebensjahr auf. Bei den meisten unserer Patienten (60,5\%) lag die Retikulozytenanzahl zum Diagnosezeitpunkt im Normbereich, bei 29,5\% war sie erhöht. In anderen Untersuchungen beschrieben die Autoren ein wesentlich häufigeres Auftreten von erhöhten Retikulozytenwerten, z.B. Jonte et al. (1995) bei $91 \%$ von 61 Patienten. Bei unserer Untersuchung gab es keine Patienten mit erhöhten Retikulozytenwerten, die älter als 18 Jahre waren, obwohl 10,5\% der Patienten älter als 20 Jahre waren, als sie diagnostiziert wurden. Allerdings ist zu beachten, dass von den 260 Patienten, von denen Altersangaben zum Diagnosezeitpunkt vorlagen, nur von 210 Patienten Retikulozytenwerte bekannt waren. Von den übrigen 50 Patienten waren bei Diagnosestellung jedoch nur acht $(3,1 \%)$ älter als 18 Jahre. Demnach konnte dies nicht der Grund für das Nichtauftreten erhöhter Retikulozytenwerte bei Patienten, die älter als 18 Jahre waren sein. Bei hämolytischen Krisen sind die Retikulozytenwerte erhöht. Wenn Patienten erst nach dem 18. Lebensjahr diagnostiziert wurden, könnte es durchaus sein, dass nur eine leichte Form der HS vorlag und/oder die HS-Erkrankung zum Zeitpunkt der Untersuchung nicht in einem 
akuten Stadium war. In diesen Fällen ist es möglich, dass keine erhöhten Retikulozytenwerte festzustellen sind.

Delhommeau et al. (2000) beschrieben bei 16 von 18 Patienten mit HS (88,9\%) bei Geburt zunächst einen erhöhten Retikulozytenspiegel, wie es bei Neugeborenen üblich ist. Der Spiegel fiel daraufhin ab und blieb mehrere Wochen bis Monate im Normbereich, um ab dem ersten Lebensjahr erneut in den pathologischen Bereich anzusteigen. Auch bei unserer Untersuchung waren die Patientenzahlen mit erhöhtem Retikulozytenspiegel ab dem sechsten Lebensmonat höher als bei jüngeren Patienten. Erhöhte Werte direkt nach Geburt konnten wir in unserer Untersuchung nicht bestätigen. Vielmehr registrierten wir insgesamt 21 Patienten mit erniedrigten Retikulozytenwerten (10\% der 210 Patienten mit Retikulozytendaten), von denen neun erniedrigte Werte innerhalb der ersten 30 Lebenstage zeigten.

Aus dem bei der HS vorliegenden gesteigerten Erythrozytenabbau resultiert häufig eine Hyperbilirubinämie. Bei unserer Untersuchung wiesen die meisten Patienten zum Diagnosezeitpunkt (83\% von 185 Patienten mit Bilirubinspiegeldaten) einen erhöhten Bilirubinwert auf. Da bei Patienten, die im ersten Lebensmonat diagnostiziert werden, generell ein erhöhter Bilirubinwert besteht, wurden diese nicht berücksichtigt. Es wäre retrospektiv schwer nachzuweisen gewesen, dass der registrierte Wert HS-bedingt und nicht auf Grund des erhöhten HbF-Abbaus bestand. In der Literatur variieren die Patientenzahlen mit Hyperbilirubinämie. Bei einer Studie in Indien wurde bei $89,1 \%$ der 70 Patienten mit HS eine Hyperbilirubinämie beschrieben (Kar et al. 2009), bei einer spanischen Studie trat bei 72\% der 61 Patienten ein erhöhter Bilirubinwert auf (Jonte et al. 1995). Auch die unterschiedlich hohen Patientenzahlen bei Hyperbilirubinämie sind wohl mit den verschieden starken Krankheitsphasen zu begründen. In einer Phase mit erhöhtem Erythrozytenabbau durch Infekt und/oder einer hämolytischen Krise wird der Bilirubinspiegel bei Patienten mit HS höher als gewöhnlich sein. Zudem lag der alterskorrelierte Bilirubinwert zum Diagnosezeitpunkt bei immerhin 17\% der Patienten im Normbereich. Im Hinblick auf die Diagnostik kann demnach auch ein normaler Bilirubinwert eine Erkrankung an HS nicht ausschließen.

Als diagnostische Mittel werden, neben der Beobachtung der klinischen Symptomatik, Bluttests durchgeführt. Vor allem haben der Acylglycerol-Lysis-Test (AGLT), KryohämolyseTest, die Überprüfung der osmotischen Resistenz der Erythrozyten und der AutohämolyseTest diagnostische Relevanz. In unserer Untersuchung war bei 70,8\% der Patienten mit HS der AGLT zum Diagnosezeitpunkt pathologisch und bei 11,5\% kontrollbedürftig. Der 
Kryohämolyse-Test war sogar bei $94 \%$ der Patienten pathologisch. Unsere Testergebnisse passen gut zu einigen der bisher veröffentlichten Daten. Diese variieren allerdings stark und zeigen in ihren Ergebnissen auch die Entwicklung und Weiterentwicklung der Tests. Der AGLT wurde 1980 von Zanella et al. beschrieben und damals schon als einfach, schnell und kostengünstig, wenig Blut benötigend und deutliche Ergebnisse liefernd bezeichnet. Die beschriebene 100\%ige Sensitivität und Spezifität konnte allerdings von z.B. Rutherford et al. (1986) nicht bestätigt werden. 1992 wurde der Test von den Göttingern Eber et al. modifiziert und dadurch spezifischer. Ihre Ergebnisse deuteten auf ein höheres HS-Auftreten in der Bevölkerung als bisher angenommen hin. Sie vermuteten 1992 ein Auftreten der HS-Genfrequenz von bis zu 0,05\% in der deutschen Gesamtbevölkerung. Im Jahr 2008 veröffentlichten die Italiener Mariani et al. eine Untersuchung von 300 Patienten und bestätigten eine 99\%ige Sensitivität des AGLT. Der Kryohämolyse-Test wurde von ihnen wiederum nur als 53\%ig sensibel beschrieben. Eine viel höhere Sensitivität (94\%-100\%) des KryohämolyseTests für HS mit einer 94\%igen Spezifität für normale, gesunde Patienten schilderten Nathan et al. (2003). Romero et al. (1997) verglichen den Kryohämolyse-Test, der bei all ihren Patienten mit Sphärozytose positiv und bei allen Patienten ohne HS negativ ausfiel, mit dem Test der osmotischen Resistenz und der Autohämolyse, die auch bei allen Patienten mit HS positiv waren. Der Kryohämolyse-Test wurde deshalb von ihnen als schneller und einfacher bewertet. Von einer Göttinger Forschungsgruppe wurde der Kryohämolyse-Test wiederum als gleichwertig mit dem Test der osmotischen Resistenz angesehen (Iglauer et al. 1999). Sie beschrieben bei 61 Patienten mit HS eine signifikant höhere Kryohämolyserate als bei den gesunden Personen und allen anderen anämischen Patienten.

Unser Göttinger Speziallabor der Pädiatrie I hat bei der HS-Diagnostik sehr gute Erfahrungen mit der Untersuchung der osmotischen Resistenz der Erythrozyten (OR) und der Autohämolyse gemacht. Wir haben den Vorteil, dass alle Tests (auch die Kryohämolyse und der AGLT) seit Jahren von ein und derselben Person unter konstanten Bedingungen durchgeführt werden und deshalb die Fehlerrate, die durch unterschiedliche Handhabungen verschiedener Personen an unterschiedlichen Geräten entstehen kann, sehr gering ist. So lieferte die Untersuchung der osmotischen Resistenz im Frischblut zum Diagnosezeitpunkt bei 89,3\% der Patienten mit HS (22\% OR leicht reduziert, 58,5\% OR reduziert, 8,8\% OR stark reduziert) und im 24-Stunden inkubierten Blut sogar bei 99,3\% der Patienten mit HS (4\% OR leicht reduziert, 66,7\% OR reduziert, 28,7\% OR stark reduziert) ein reduziertes, pathologisches Ergebnis. Die Autohämolyse ohne Zusatz von Glukose war zum Diagnosezeitpunkt bei 95\% der Patienten 
pathologisch und damit als Untersuchungsinstrument ähnlich gut geeignet wie die osmotische Resistenzüberprüfung. Bei 88,7\% der Patienten ergab die Autohämolyse nach Glukosekorrektur ein pathologisches Ergebnis. Nach Nathan et al. (2003) weisen die Erythrozyten im Frischblut bei ungefähr einem viertel der Patienten mit HS eine normale osmotische Resistenz auf. Nach 24-stündiger Inkubation mit Kochsalzlösungen verschiedener Konzentrationen bei $37^{\circ} \mathrm{C}$ verlieren die HS-Erythrozyten schneller als normale Erythrozyten Teile ihrer Membranoberfläche, weil sie durchlässiger und instabiler sind. Die Inkubation mit Kochsalzlösungen zeigt den Defekt der HS-Erythrozyten auf und macht nach der Beschreibung von Nathan et al. den Test der osmotischen Resistenz zum sensitivsten Routinetest, den es für die HS-Diagnostik gibt. Verglichen mit weiteren Untersuchungen lagen unsere Ergebnisse häufig über dem Durchschnitt anderer. So beschrieben die Italiener Mariani et al. (2008) bei ihrer 300-Patienten-Untersuchung den Test der osmotischen Resistenz mit einer Sensitivität, die zwischen $48 \%$ und $95 \%$ lag. Kar et al. (2009) stellten bei 88,2\% von 70 Patienten mit HS eine verminderte osmotische Resistenz im inkubierten Blut fest. Nur Jonte et al. (1995) fanden bei ihren Untersuchungen von 61 Patienten mit HS eine verminderte osmotische Resistenz im Frischblut bei $86 \%$ und im inkubierten Blut bei $97 \%$ ihrer Patienten und somit ähnliche Daten wie in unserer Untersuchung. Über die Anwendung der osmotischen Resistenztestung in der Neugeborenen- und pränatalen Diagnostik der HS wird diskutiert. Einige Autoren rieten von einer pränatalen Diagnostik mit Hilfe der osmotischen Resistenz ab und bemängelten die nicht gut definierten Kriterien für die HS-Diagnostik bei Geburt (Celkan und Alhaj 2008), andere hoben die gute Anwendbarkeit des Tests unter Beachtung spezieller neonataler Auswertungskurven hervor. Diese speziellen Auswertungskurven sind notwendig, da neonatale Erythrozyten eine größere osmotische Resistenz als die der Erwachsenen aufweisen (Steiner und Gallagher 2007).

Auch die israelische Forschungsgruppe Streichman und Gescheidt (1998) bewerteten den Test der OR besser als den Test der Autohämolyse. Die Testung der OR hatte bei ihnen nur in zwei von 55 Fällen die Diagnose verfehlt. Zudem korrelierte der Autohämolysetest mit dem Kryohämolyse-Test schlecht, wobei der Kryohämolyse-Test eine 100\%ige Sensitivität und eine 87 bis 90\%ige Spezifität vorwies. Eine deutsche Gruppe aus Jena (Thornburg und Ware 2003) sah nur begrenzten Nutzen in der Autohämolyse, da sie nur in zwei von 52 Fällen hilfreich und des Weiteren laborintensiver und häufig ungenauer war. Letztendlich reichte einer anderen deutschen Gruppe (Hermann und Hetzinger 1989) für die HS-Diagnostik die Familienanamnese, Hämolysezeichen wie Ikterus und Retikulozytose, osmotische Resistenz 
und AGLT aus. Nach ihrer Aussage gab es keinen Grund, den teuren Autohämolysetest durchzuführen. In der pädiatrischen Abteilung unserer Klinik wird die Diagnostik ähnlich gehandhabt. Neben den klinischen Auffälligkeiten der Patienten werden AGLT und der Kryohämolyse-Test stets gemeinsam analysiert. Nur bei nicht eindeutigem Ergebnis wird der aufwendigere und teurere Test der osmotischen Resistenz hinzugezogen, der, wie oben beschrieben, die deutlichsten Ergebnisse lieferte.

Neben Blutwerten wie erhöhtem Bilirubin und einer Retikulozytose, untersuchten wir auch Werte wie die mittlere korpuskuläre Hämoglobinkonzentration (MCHC), die Laktatdehydrogenase (LDH) und die Anzahl der Thrombozyten im Blut zum Diagnosezeitpunkt. Die MCHC war bei 77\% unserer Patienten pathologisch erhöht. Alterskorreliert ausgewertet, trat eine Häufung der Patienten mit erhöhtem MCHC-Wert in der Altersgruppe ein Monat bis zwei Jahre bei 40 (von 144 Patienten) und in der Gruppe zwei bis zehn Jahre bei sogar 67 Patienten (von 144) auf. Auch in anderen Untersuchungen wurde bei Patienten mit HS ein erhöhter MCHC-Wert festgestellt. Eine griechische Forschungsgruppe beschrieb 1999 eine Untersuchung an 73 Patienten mit HS, bei denen sowohl bei allen splenektomierten, als auch bei allen nicht splenektomierten Patienten der MCHC-Wert signifikant höher als in der Kontrollgruppe war (Premetis et al. 1999). Zwei Jahre zuvor beschrieben auch Michaelis et al. bei allen ihrer 112 Patienten mit HS signifikant höhere MCHC-Werte (Michaels et al. 1997). Sie beschrieben die MCHC-Untersuchung in Kombination mit der Erythrozytenverteilungsbreite (RDW) als exzellenten Test zur Diagnosefindung der HS. Im Jahr 2010 vermuteten die Amerikaner Christensen et al., dass die HS bei neonatalem Ikterus zu selten erkannt würde. Sie wiesen darauf hin, dass eine MCHC von $\geq 36 \mathrm{~g} / \mathrm{dl}$ Ärzte veranlassen sollte, die Neugeborenen auf eine HS zu untersuchen. Laut ihrer Untersuchung war der MCHC-Wert von $\geq 36 \mathrm{~g} / \mathrm{dl}$ zu $82 \%$ sensibel und zu 98\% spezifisch für die HS.

Die LDH ist ein Enzym, das in vielen Geweben vorkommt, unter anderem in Erythrozyten. Wenn diese zerstört werden, wird LDH freigesetzt und ist bei der Blutuntersuchung erhöht nachweisbar. Bei unserer Untersuchung wurde zum Diagnosezeitpunkt bei 46,6\% der Patienten ein erhöhter LDH-Wert festgestellt. Die Mehrheit dieser Patienten (79 von 83) war älter als 13 Monate. Bei einer Untersuchung von Jonte et al. wurde, ohne Berücksichtigung des Alters, bei einer größeren Anzahl der Patienten (58\% der 61 Patienten) ein erhöhter LDHWert festgestellt (Jonte et al. 1995). Da die LDH auch in vielen anderen Geweben vorkommt, wie z.B. der Herz- und Skelettmuskulatur, ist davon auszugehen, dass die Spezifität für die HS-Diagnostik nicht ausreichend ist. Im Blut können erhöhte LDH-Werte unter anderem 
sowohl bei einem Herzinfarkt, Skelettmuskelverletzungen, Lebererkrankungen als auch bei Tumoren oder Untergang von Erythrozyten festgestellt werden (Neumeister et al. 2009). Aus diesem Grund kann bei der HS zwar ein erhöhter LDH-Wert gemessen werden, doch können starke Schwankungen in der Höhe der registrierten Werte entstehen und auch nicht spezifisch auf die HS-Erkrankung zurückgeführt werden.

Bei den Thrombozytenwerten lagen viele unserer Patienten im Normbereich (69,7\%). Ungefähr 1/6 der Patienten hatte erhöhte, ein weiteres 1/6 hatte erniedrigte Thrombozytenwerte bei Diagnosestellung. Der größte Teil der Patienten mit erhöhten Thrombozytenwerten (93,9\% von 33 Patienten) war zum Zeitpunkt der Blutentnahme zwischen einem Monat und zehn Jahre alt. Keiner der Patienten mit erhöhten Werten war zum Diagnosezeitpunkt splenektomiert. Erhöhte Thrombozytenwerte bei der HS werden vor allem nach Splenektomie beschrieben (Hanel und Cohn 1975, Perkins et al. 2009), doch auch von einigen Autoren vor Splenektomie erwähnt (Troendle et al. 2007). Eine Thrombozytose vor Splenektomie kann durch entzündliche Prozesse, die zu einer Steigerung der Thrombozytenproduktion führen würden, erklärt werden. Da die Thrombozyten (normale Überlebenszeit ca. sieben Tage) von Milz und Leber abgebaut werden, kann bei Splenomegalie sowohl ein Thrombozytenanstieg nach Splenektomie, als auch ein erniedrigter Thrombozytenspiegel vor Splenektomie vorhanden sein. Eine Splenomegalie, die bei der HS durchaus existieren kann, führt zu gesteigertem Thrombozytenabbau (Kemkes-Matthes und Oehler 2001). So kann auch der erniedrigte Thrombozytenspiegel einiger unserer Patienten erklärt werden.

Sowohl der MCHC-Wert, als auch der LDH- und Thrombozytenwert sind für die Erkrankung der HS keine spezifischen Parameter. Alle drei werden durch zu viele andere Parameter beeinflusst, so dass sie nicht nur bei der HS auffällige Werte zeigen. Dennoch können Werte, die nicht im Normbereich liegen, ein Hinweis auf die HS sein. Häufig treten im Zusammenhang mit der HS weitere Symptome, z.B. ein Ikterus, auf. Durch die gesteigerte Hämolyse der Sphärozyten steigt der Bilirubinspiegel im Blut an und tritt in der Regel ab einer Konzentration von 5mg/dl als Ikterus in Erscheinung. Nach Koletzko (2007) tritt bei mehr als der Hälfte der Neugeborenen ein Icterus neonatorum physiologischerweise auf. Reinhardt (2007) beschreibt bis zu 60\% aller reifen Neugeborenen innerhalb der ersten Lebenswoche als ikterisch, und Niessen (2001) berichtet einige Jahre zuvor über das Auftreten eines physiologischen Icterus neonatorum bei bis zu 50\% aller reifen Neugeborenen. Der physiologische Ikterus entsteht zwei bis drei Tage nach der Geburt und hat sein Maximum ungefähr am vierten bis fünften Lebenstag, um daraufhin langsam abzuklingen. Eine Therapie ist meist nicht 
notwendig (Koletzko 2007). Dennoch vermuten manche Autoren, die HS würde bei neonatalem Ikterus zu selten erkannt werden (Christensen und Henry 2010). In unserer Untersuchung wurde bei vielen Patienten mit HS (83,9\%) ein Icterus neonatorum diagnostiziert. Verglichen mit den in der Literatur beschriebenen Prozentwerten des Auftretens eines physiologischen Icterus neonatorum unterscheidet sich unser Wert je nach Literaturangabe um ungefähr $20 \%$ bis $30 \%$. Bei einem Patienten mit Icterus neonatorum sollte demnach die HS als Differentialdiagnose bedacht werden, da der Icterus neonatorum bei Patienten mit HS häufiger als bei Patienten ohne HS aufzutreten scheint.

Es erhielten mehr als 4/5 (82,7\%) unserer Patienten mit HS, bei denen ein Icterus neonatorum diagnostiziert wurde, eine Phototherapie, und mindestens $8,5 \%$ benötigten eine Austauschtransfusion. Nur bei $16,1 \%$ unserer Patienten wurde kein Icterus neonatorum diagnostiziert. Eine Austauschtransfusion erhielten bei einer Studie in Kanada 22,1\% aller 258 Patienten mit schwerer neonataler Hyperbilirubinämie. Allerdings waren darunter nur 93 Kinder mit bekannten Gründen für die Hyperbilirubinämie und darunter wiederum nur sieben Patienten mit hereditärer Sphärozytose (Sgro et al. 2006).

Einige Autoren bemängelten bei Hyperbilirubinämie eine zu geringe Durchführung von Labordiagnostik nach der Entlassung der Patienten aus der Klinik. In Bezug auf die Erkennung der Ursachen einer neonatalen Hyperbilirubinämie vermuteten sie einen Zusammenhang zwischen der Unterschätzung der Risikofaktoren, die zu einer Hyperbilirubinämie führen, und einer zu frühen Durchführung der Phototherapie (Petrova et al. 2006). Iolascon und Avvisati berichteten 2008 von einer Untersuchung in Italien, bei der fast alle Neugeborenen mit HS einen Ikterus aufwiesen und daraufhin phototherapiert wurden, manchmal auch Austauschtransfusionen bekamen (Iolascon und Avvisati 2008). Bei einem übermäßigen Anstieg von Bilirubin im Blut kann das unkonjugierte Bilirubin die Blut-Hirn-Schranke passieren und sich in den Kernen des Gehirns ansammeln (Reinhardt 2007). Die frühe Durchführung einer Phototherapie kann das Auftreten eines Kernikterus verhindern. So sahen das auch Watchko und Maisels, die vermuteten, dass ein Kernikterus bei Frühgeborenen häufiger auftreten würde, wenn die Phototherapie nicht frühzeitig aggressiv eingesetzt werden würde (Watchko und Maisels 2003). Dennoch stellten sowohl wir als auch andere Gruppen ein erhöhtes Auftreten eines Ikterus bei Patienten mit HS fest; bei Kar et al. (2009) waren es $82,9 \%$ der 70 Patienten mit HS, bei Mehta et al. (1992) waren es 66,9\% von 145 Patienten mit HS. In diesem Zusammenhang ist es interessant zu erkennen, dass der Wissensstand über den neonatalen Ikterus unterschiedlich ist. In Nigeria z.B. kennen nur 51,5\% von 66 Mitarbeitern 
des Gesundheitswesens die korrekte Definition des neonatalen Ikterus (Ogunfowora und Daniel 2006). Auch kann die HS-Diagnose durch andere Erkrankungen, wie z.B. Morbus Gilbert-Meulengracht, Blutgruppeninkompatibilität, neonatale Infektionen oder unzureichende Ernährung verschleiert werden (Garg et al. 2008, Koletzko 2007). Eine indirekte Hyperbilirubinämie mit Ikterus kann auch durch Enzymdefekte wie Glukose-6-PhosphatDehydrogenase-Mangel oder Pyruvatkinase-Mangel hervorgerufen werden (Koletzko 2007). So scheint die Zahl der Differentialdiagnosen gar nicht so klein zu sein, dessen ungeachtet sollte bei einem Ikterus nicht zuletzt an die hereditäre Sphärozytose gedacht werden. Bei unseren Patienten wurde die Diagnose HS nach Austauschtransfusion nur bei 33\% innerhalb von vier Wochen gestellt. Dabei ist zu beachten, dass uns von $17 \%$ der Patienten mit Austauschtransfusion kein Diagnosedatum vorlag. Doch selbst wenn auch bei diesen 17\% die Diagnose frühzeitig gestellt worden wäre, wären noch immer 50\% der Patienten nach vier Wochen nicht diagnostiziert worden. Bei festgestelltem Icterus praecox und/oder gravis wurde die HS-Diagnose sogar nur bei $26,5 \%$ der Patienten innerhalb von vier Wochen gestellt. Diese Zahlen lassen staunen, wenn bedacht wird, dass die hereditäre Sphärozytose in Mitteleuropa bei weitem die häufigste angeborene hämolytische Anämie ist (Eber 2006).

Die Symptome der HS (Anämie, Ikterus) werden in der Regel nicht behandelt. Eine Ausnahme stellt die Gabe von Erythrozytentransfusionen bei stabiler Anämie dar, die bei einigen Patienten in den ersten beiden Lebensjahren aufgrund einer verzögert einsetzenden erythropoetischen Regeneration und/oder zur symptomatischen Behandlung im Verlauf hämolytischer und aplastischer Krisen notwendig sein kann. Ab einem Hb-Abfall von unter 50-60g/l und/oder entsprechender klinischer Symptomatik wird von den AWMF-Leitlinien zur Diagnostik und Therapie der HS eine Behandlung mit Erythrozytentransfusionen empfohlen, wobei für Neu-/Frühgeborene gesonderte Transfusionsgrenzen gelten (Eber 2006). Von unseren Patienten wurden 44,7\% im Laufe ihrer Sphärozytoseerkrankung transfundiert. Der Großteil $(68,1 \%)$ erhielt eine bis drei Transfusionen, 31,9\% wurden mehr als drei Mal transfundiert, von diesen 31,9\% wiederum bekamen 13,7\% regelmäßig Transfusionen. Es wurden mehr als 90\% der Patienten vor dem 15. Lebensjahr transfundiert mit einem besonders hohen Transfusionsbedarf in der Altersgruppe zwischen fünf und neun Jahren. Auch bei den Patienten, die regelmäßig transfundiert wurden, verteilten sich die Zahlen auf die jüngeren Altersstufen. Kein Patient war älter als neun Jahre. In Bezug auf die Anzahl der transfundierten Patienten unterscheiden sich die Daten in der Literatur erheblich; sie reichen von $16 \%$ der 61 Patienten einer spanischen Studie (Jonte et al. 1995), über 35,7\% der 70 
Patienten einer indischen (Kar et al. 2009) und 66\% der Patienten einer italienischen Untersuchung (Iolascon und Avvisati 2008) bis zu 76\% der 34 Patienten einer amerikanischen Studie (Delhommeau et al. 2000). Von diesen eben beschriebenen $76 \%$ der 34 Patienten mit HS bekamen 46,2\% eine und 53,8\% mehr als eine Transfusion, 92\% bekamen die Transfusion(en) innerhalb der ersten beiden Lebensmonate. Die Italiener wiederum beschrieben, dass viele Ihrer Patienten die Transfusionen innerhalb des ersten Lebensjahres bekamen und danach weniger als 20\% regelmäßig transfundiert wurden. Auf Grund der unterschiedlichen Einteilungen sind die Daten der Transfusionsanzahl und der Altersverteilung leider schwer vergleichbar. Dennoch lässt sich feststellen, dass die Zahl der Transfusionsbedürftigen Patienten mit HS in unserer Untersuchung ungefähr in der Mitte der in der Literatur beschriebenen Zahlen anzusiedeln ist und vor allem, dass bei uns ein deutlich geringerer Transfusionsbedarf innerhalb des ersten Lebensjahres der Patienten bestand (27,5\% bei ein bis drei Transfusionen bzw. 29,4\% bei mehr als drei Transfusionen im ersten Lebensjahr, verglichen mit 92\%, die innerhalb der ersten beiden Lebensmonate und „viele“, die innerhalb des ersten Jahres transfundiert wurden). Da der Altersdurchschnitt der Patienten, die mehr als drei Transfusionen bekamen (5,82 Jahre), unter dem der Patienten, die ein bis drei Mal transfundiert wurden (6,57 Jahre) lag, konnte ausgeschlossen werden, dass die Patientenzahl der mehr als drei Mal transfundierten nur deshalb höher war, weil die Patienten älter gewesen wären, als die Datenerfassung erfolgte, und sie dadurch theoretisch mehr Transfusionen hätten bekommen können. Das Alter schien hier eine untergeordnete Rolle zu spielen, eher sollte die Schwere der Erkrankung in Betracht gezogen werden. Diese hängt wiederum von vielen weiteren Parametern ab, so dass die Verteilung der Schweregrade in dieser retrospektiven Untersuchung nicht analysiert werden konnte.

Die häufigste Komplikation bei Patienten mit HS, ist das frühzeitige Auftreten von Gallensteinen, das auf den hämolysebedingten hohen Bilirubinspiegel zurückzuführen ist (Iolascon et al. 2003, Johns-Hopkins-University 2010). Bei unserer Untersuchung traten bei mehr als der Hälfte der Patienten (53,9\%, 130 von 241 Patienten) Gallensteine auf. Viele Patienten (54,6\%, 71 von 130 Patienten) waren zwischen fünf und 19 Jahre alt, die meisten dieser Gruppe (49,3\% von 71 Patienten) waren im Alter zwischen fünf und neun. Bei Patienten, die älter als 19 Jahre waren, wurden viel seltener Gallensteine diagnostiziert. Erst ab dem Alter von 30 bis 40 Jahren stiegen die Gallensteindiagnosen wieder an. Das wird aber wohl nicht auf die HS zurückzuführen sein, sondern eher auf das in unseren Breitengraden auftretende „Wohlstandsgallensteinleiden“. In den meisten anderen Studien wurde ein 
Auftreten von Gallensteinen bei ungefähr 25\% bis $40 \%$ der Patienten mit HS beschrieben (Iolascon et al. 2003, Croom et al. 1986, Kar et al. 2009). Nathan et al. (2003) schilderten einen dramatischen Anstieg des Gallensteinauftretens ab einem Alter von zehn Jahren, also etwas später als in unserer Untersuchung. Bogue et al. (2010) berichteten, dass es durch einen Mehrgebrauch der Sonographie zum Anstieg der Gallensteinbefunde kam. Vor allem bei Kindern würden nun auch symptomlose Gallensteine diagnostiziert. Zum Diagnosezeitpunkt von 382 Kindern mit Gallensteinen (bei unterschiedlichen Krankheitsbildern) waren bei ihrer Untersuchung 50,5\% der Patienten symptomlos. Der Altersdurchschnitt lag bei 8,23 Jahren. Über die Handhabung der symptomlosen Diagnosen und deren Weiterbehandlung wurde viel diskutiert. Bogue et al. (2010) empfahlen auf Grund der geringen Komplikationsrate eine konservative Therapie, bis Komplikationen auftreten würden. Doch gaben die Autoren auch an, dass bei ihren Patienten mit HS eine hohe Komplikationsrate vorhanden war. Es wurden mehr Operationen als bei Patienten mit Gallensteinen ohne HS-Erkrankung nötig gewesen wären, durchgeführt. Holcomb und Holcomb (1990) empfahlen eine Cholezystektomie aller symptomatischen Patienten mit HS, egal welchen Alters. In unserer Untersuchung wurden $70,6 \%$ der Patienten cholezystektomiert. Allerdings ist zu beachten, dass nur von 1/3 unserer Patienten Informationen über die Durchführung/Nichtdurchführung einer Cholezystektomie vorlagen. Die Altersanalyse ergab, dass 61,9\% dieser Patienten im Alter zwischen fünf und 14 Jahren cholezystektomiert wurden. Verglichen mit dem Alter bei Auftreten des ersten Gallensteins (54,6\% zwischen fünf und 19 Jahren, 42,3\% zwischen fünf und 14 Jahren) korrelieren die Zahlen gut, obwohl auch noch ein erhöhtes, wenn auch geringeres, Gallensteinauftreten bei Patienten im Alter zwischen 15 und 19 Jahren registriert wurde.

Bei vermehrtem Auftreten von Gallensteinen kann über eine Cholezystektomie ggf. in Kombination mit einer Splenektomie diskutiert werden. Schilling (2009) erläuterte, dass bei Patienten mit HS keine Splenektomie aus Gründen der Gallensteinprophylaxe erfolgen sollte, aber wenn Steine vorhanden sind, die Splenektomie durchaus angebracht ist. Und Abdulla et al. beschrieben 2009 in einer chirurgischen Studie mit 1657 Patienten mit HS, dass die Kombinationsoperation der Splenektomie mit einer Cholezystektomie und/oder einer Appendektomie komplikationslos zu sein scheint. Die erste erfolgreiche Splenektomie bei HS erfolgte vor ungefähr 30 Jahren in England. Eine Splenektomie bei HS eliminiert sowohl die Anämie, als auch die Hyperbilirubinämie, führt zur Retikulozytenreduktion und heilt fast alle Patienten mit HS. Die Erythrozytenüberlebensrate wird wieder normal oder bleibt nur leicht vermindert, jedoch bleiben die Sphärozyten im Blut und ihre verminderte osmotische 
Resistenz weiterhin nachweisbar, wobei der klinische Befund der Patienten aber besser ist (Nathan et al. 2003). Nathan et al. (2003) beschrieben, dass die Splenektomie möglichst bis zum Alter zwischen fünf und neun Jahren hinausgezögert werden sollte, ab zehn Jahren steige das Gallensteinrisiko dann dramatisch. In unserer Untersuchung wurden 36,9\% der Patienten mit HS im Verlauf der Erkrankung splenektomiert. Bei einer Altersspanne von einem Tag bis 34 Jahre lag der Altersmittelwert der Patienten bei Splenektomie bei 11,05 Jahren. Bei zwei Patienten lag kein Splenektomiedatum vor. Der Großteil der Patienten $(43,9 \%)$ war zwischen fünf und neun Jahre alt, gefolgt von 22\%, die zwischen zehn und 14 Jahre alt waren. Insgesamt wurden 90,9\% der operierten Patienten innerhalb der ersten beiden Lebensdekaden splenektomiert. Bei anderen Untersuchungen wurden Splenektomieraten zwischen 17\% (Kar et al. 2009) und 27,3\% (Tamary et al. 2003) angegeben. Tamarys Patienten (27,3\% von 44 Patienten) wurden im Alter zwischen vier und 19 Jahren splenektomiert. Ihr Altersdurchschnitt lag bei 13 Jahren. Croom et al. (1986) sprachen sogar von einer Splenektomieindikation bei allen ihrer Patienten. Von ihren sieben Monate bis 64 Jahre alten Patienten waren 52,2\% (12 von 23 Patienten) bei Splenektomie unter zehn Jahre alt. Zusammenfassend sind auch diese Werte nicht eindeutig miteinander vergleichbar, doch zeigen sie, dass viele Patienten innerhalb der ersten beiden Lebensdekaden splenektomiert wurden, heute aber nicht mehr jeder Patient mit HS in jungen Jahren operiert wird. Bei einer HS-Diagnose im fortgeschrittenen Alter empfahlen Friedmann et al. (1988) sogar keine Splenektomie mehr. Wie oben bereits beschrieben, untersuchten sie fünf Patienten zwischen der siebten und neunten Lebensdekade mit nur milden oder keinen Symptomen und blieben bei einer konservativen Therapie.

In Bezug auf die Erythrozytenüberlebenszeit berichtete Chapman im Gegensatz zur bereits beschriebenen Untersuchung von Nathan et al. (2003), dass bei seiner Untersuchung die Splenektomie nicht zu einer Lebenszeitverlängerung der Erythrozyten führte. Bei ihm betrug die Überlebenszeit der Erythrozyten bei normalisiertem $\mathrm{Hb}$ und leicht erhöhten Retikulozytenwerten $96 \pm 13$ Tage (Chapman und McDonald 1968). Demgegenüber verbesserte sich der Hb-Wert durch die Splenektomie bei 25 von 26 Patienten mit HS im Alter zwischen fünf und 11 Jahren bei einer anderen Untersuchung (Durakbasa et al. 2006) von $8 \pm 1 \mathrm{~g} / \mathrm{dl}$ auf $13 \pm 1 \mathrm{~g} / \mathrm{dl}$, und die operierten Patienten gaben eine Lebensqualitätsverbesserung an. Doch wiesen die Autoren auf das OPSI-Syndrom (overwhelming postsplenectomy infection syndrome) hin, das bei ihrer Studie unter allen splenektomierten Patienten (mit verschiedenen Krankheitsursachen) mit einer Mortalität von 2\% auftrat (Durakbasa et al. 2006). Auf eine andere Komplikation weist eine von Jonte et al. (1995) publizierte 
Untersuchung hin, bei der 50\% der Patienten vor dem 14. Lebensjahr (Altersbereich: vier bis 64 Jahre) splenektomiert wurden. Die Operation korrigierte die Anämien und die Retikulozytenwerte, allerdings waren postoperativ die Thrombozytenwerte erhöht. Durch die erhöhten Thrombozytenwerte entsteht eine vergrößerte Thrombose- und Emboliegefahr. Hafsia et al. (2009) befürworteten die Splenektomie bei Patienten mit hereditären Anämien, um Transfusionen zu verringern oder ganz zu vermeiden. Doch beschrieben auch sie Postsplenektomiekomplikationen, wie eine Thrombozytose mit Thrombosen oder eine erhöhte Infektionsgefahr. Aus diesem Grund wurde in den letzten Jahren vermehrt die near total splenectomy empfohlen. Zum Beispiel beschrieb eine Göttinger Forschungsgruppe, dass ein radikalerer Ansatz bei der near total splenectomy mit einem postoperativen Milzrest von $10 \mathrm{~cm}^{3}$ zur Abnahme der Hämolyse, bei Wahrung der Immunfunktion, führte. Die neue Technik wurde als sicher, effektiv und sekundäre Spätfolgen minimierend beschrieben (Stoehr et al. 2005). Als Alternative zur Splenektomie oder Teilsplenektomie bei Patienten mit HS stellten Kimura et al. (2003) die Milz-Teilembolisation dar, die von ihnen als sicher und effektiv geschildert wurde. Allerdings umfasste ihre Untersuchung nur fünf Patienten.

Um die Infektionsgefahr nach Splenektomie so gering wie möglich zu halten, muss auch auf die postoperative Antibiotikaprophylaxe eingegangen werden. Von unseren splenektomierten Patienten erhielten $81,1 \%$ eine postoperative Antibiotikaprophylaxe. Es muss aber erwähnt werden, dass wir von 37 der 132 splenektomierten Patienten keine Angaben über die Durchführung/Nichtdurchführung der Prophylaxe vorliegen hatten. Wenn diese 37 Patienten keine Antibiotikaprophylaxe bekommen haben sollten, würde die Prozentzahl der prophylaktisch betreuten Patienten von 81,1\% auf 58,3\% fallen. Davon abgesehen bleiben auch bei den vorliegenden Zahlen noch 1/5 der Patienten ohne postoperative Antibiotikaprophylaxe. Ein Overwhelming postsplenectomy infection (OPSI) syndrome wurde dennoch bei keinem unserer Patienten registriert. Schätzungen über das Auftreten eines OPSI-Syndroms variieren. Die Inzidenz wurde zwischen 3,8 und 4,3\% mit einer Mortalität zwischen 1,7 und 2,4\% beschrieben. In einer italienischen HS-Register-Studie wurden 180 von 460 Patienten splenektomiert, ein Patient entwickelte eine Sepsis, aber keiner verstarb (Iolascon et al. 2003). Das entsprach einer Inzidenz von 0,6\%. Durch das OPSI-Syndrom verursacht, verstarben in einer Untersuchung von Durakbasa et al. (2006) zwei von 119 splenektomierten Patienten (mit unterschiedlichen Krankheitsursachen als Ausgang für die Splenektomieindikation). Das entsprach einer Inzidenz von 1,7\%. Durakbasa et al. wiesen auf die unterschiedliche Compliance der Patienten bei der Medikamenteneinnahme hin und die bei Non-Compliance 
wahrscheinliche höhere Sepsisrate. Bei einer amerikanischen Untersuchung beschrieben sogar nur 26\% der splenektomierten Patienten, die empfohlenen Medikamente bekommen und genommen zu haben (Grace et al. 2009). Leider wurde in dieser Untersuchung nicht auf die eventuell entstandenen Sepsisfälle eingegangen. Da bei unserer Untersuchung kein Sepsisfall registriert wurde, können wir die beschriebenen Werte nicht bestätigen. Allerdings ist unser Splenektomiepatienten-Kollektiv von 132 Fällen bei einem Auftreten einer Sepsis zwischen 0,6 und 4,3\% trotz seiner Größe vielleicht nicht groß genug, um eine Sepsis zu erfassen.

Die Erkrankung der HS fällt bei vielen asymptomatischen Patienten erst beim Auftreten von aplastischen Krisen auf. Bevor sich der Körper von einer aplastischen Krise erholt, fällt der Hämoglobinspiegel in etwa auf die Hälfte des Normwertes. Meist aber sind die hämolytischen Krisen, die häufig im Zusammenhang mit viralen Infekten auftreten, milde (Nathan et al. 2003). Bei unserer Untersuchung wiesen 75\% der Patienten hämolytische/aplastische Krisen auf, von denen die meisten (41,5\%) eine Krise und 33,5\% bereits mehr als eine Krise im Krankheitsverlauf durchgemacht hatten. Wir unterschieden auf Grund unserer retrospektiven Untersuchung nicht zwischen hämolytischer und aplastischer Krise. Weniger Patienten mit hämolytischen/aplastischen Krisen beschrieben Jonte et al. (1995) in ihrer Untersuchung. Insgesamt hatten 52\% ihrer 61 Patienten mit HS solche Krisen. Es wurde aber nicht auf die Anzahl der Krisen eingegangen. Aplastische Krisen werden meist durch das Parvovirus B19 ausgelöst und dauern ungefähr zehn bis 14 Tage an (Nathan et al. 2003). In Mortimers (1983) Untersuchung wurde bei 89\% der Patienten mit aplastischer Krise eine Parvovirus B19-Infektion nachgewiesen. Er schilderte, dass bis dahin nie ein anderer Grund für eine aplastische Krise beschrieben wurde. Auch sollten Patienten während der aplastischen Krise isoliert werden, da die Infektion mit dem Parvovirus B19 höchst ansteckend ist und eine Übertragungsmöglichkeit auf Risikopatienten minimiert werden soll (McLellan und Rutter 1987, Servey et al. 2007). Nach Green et al. (1984) konnten bei $60 \%$ aller Blutspender Antikörper gegen das Parvovirus B19 nachgewiesen werden. Sie stellten die Hypothese auf, dass es auch bei Gesunden (Nicht-HS-Patienten) zu hämolytischen Krisen kommt, dass diese jedoch unerkannt bleiben, da die normale Überlebenszeit der Erythrozyten länger ist, als die der Patienten mit HS. Bei gesunden Menschen, sind die Auswirkungen der Infektion demnach als verhältnismäßig harmlos zu beschreiben.

Interessant ist nun noch die Betrachtung des Auftretens von hämolytischen/aplastischen Krisen vor und nach Splenektomie. Von unseren Patienten, die splenektomiert wurden, hatten $82,9 \%$ vor dem operativen Eingriff hämolytische/aplastische Krisen. Nach der Splenektomie 
wiesen mehr als 95\% dieser Patienten keine Krisen mehr auf. So kann behauptet werden, dass die Splenektomie durchaus einen großen Einfluss auf das Auftreten von hämolytischen/aplastischen Krisen bei Patienten mit HS hat. Leider lagen von 15 splenektomierten Patienten mit Krisen vor der Operation keine Daten über das Auftreten von postoperativen Krisen vor. Wenn es bei keinem dieser 15 Patienten zu postoperativen Krisen gekommen wäre, hätten 96,6\% der splenektomierten Patienten (56 von 58 Patienten) nach der Operation keine Krisen mehr, wenn es bei allen von ihnen zu postoperativen Komplikationen gekommen wäre, hätten nur 70,7\% (43 von 58 Patienten) nach der Operation keine Krisen mehr. Selbst in diesem pessimistischen Falle wären aber 70,7\% ein großer Erfolg, der für die Splenektomie sprechen würde. In einer indischen Studie (12 Patienten) benötigten 91\% der Patienten nach der Splenektomie keine Transfusionen mehr (Kar et al. 2009). Demnach kann man wohl eher von einer hohen Prozentzahl für den Erfolg und das resultierende Nichtauftreten von Krisen nach Splenektomie ausgehen.

Unsere retrospektive Untersuchung war relativ umfangreich und konzentrierte sich nicht speziell auf einen Parameter oder eine Parametergruppe. So konnte einerseits aufgezeigt werden, dass ein tendenzieller Zusammenhang zwischen einigen Parametern existiert (z.B. erniedrigte $\mathrm{Hb}$-Werte zum Diagnosezeitpunkt in Korrelation zur Altersverteilung zum Diagnosezeitpunkt oder dem Bilirubinspiegel), anderseits wurden Aspekte, wie z.B. eine genauere Betrachtung der Retikulozytenwerte im Zusammenhang mit der Krankheitsphase zum Zeitpunkt der Blutentnahme, nicht untersucht.

Wie bei einigen beschriebenen Parametern bereits erwähnt, muss angeführt werden, dass die meisten Daten aus unserem Routinelabor in Göttingen stammten, so dass die einzelnen Krankheitsphasen der Patienten unter Umständen unterschiedlich waren. Zum Diagnosezeitpunkt stimmte die Tendenz der Zahl der Patienten mit erniedrigten Hb-Werten (58,5\%) mit der Tendenz der Zahl der Patienten mit erhöhten Bilirubinspiegeln (83\%) überein, allerdings mit einem Unterschied von fast 25\%. Die Prozentzahlen der Patienten mit erhöhtem Bilirubinspiegel (83\%) und die der Patienten mit Icterus neonatorum $(83,9 \%)$ waren dagegen nahezu identisch, jedoch nicht vergleichbar, da das Auftreten eines Icterus neonatorum nicht zeitlich an die zum späteren Diagnosezeitpunkt der HS durchgeführte Blutentnahme gebunden war. Es konnten daher in diesem Fall diese scheinbar zusammenhängenden Parameter nicht miteinander verglichen werden. 
Aus der Gesamtheit der diskutierten Ergebnisse ist ersichtlich, dass für die Diagnosefindung der hereditären Sphärozytose zahlreiche Parameter gemeinsam in Betracht gezogen werden sollten. Es gibt viele unterschiedliche Werte, wie z.B. die Blutparameter LDH, MCHC und die Thrombozytenkonzentration, die auf die Krankheit aufmerksam machen können, die aber nicht allein und spezifisch für die Diagnostik angewendet werden können. Parameter wie ein erniedrigter $\mathrm{Hb}$ mit erhöhter Retikulozytenkonzentration und erhöhter Bilirubinkonzentration im Zusammenhang mit einem Ikterus, der phototherapiert oder gar mit Austauschtransfusionen behandelt werden muss, das frühzeitige Auftreten von Gallensteinen und/oder hämolytischen Krisen im Rahmen von viralen Infekten (vor allem Parvovirus B19) sollte den behandelnden Arzt jedoch auch an die hereditäre Sphärozytose denken lassen. Leider ist dies noch zu selten gegeben. Wie die Ergebnisse unserer Untersuchung zeigen, ist die Diagnosestellung, sowohl was den Zeitpunkt als auch die Sicherheit der Diagnostik anbelangt, verbesserungswürdig. 


\section{Zusammenfassung}

Die vorliegende Untersuchung erfasst detailliert die Erkrankung der hereditären Sphärozytose mit ihren Besonderheiten und Komplikationen. Sie stellt dar, dass es viele diagnostische Parameter für die Krankheitserkennung der Sphärozytose gibt, die in der Praxis leider noch nicht oft genug zur frühzeitigen Diagnose führen. Unsere Untersuchung ist die bis jetzt größte deutsche Untersuchung in der 358 Patientinnen und Patienten retrospektiv-deskriptiv analysiert wurden. Dabei konzentrierten wir uns auf diagnostische Mittel wie Blutuntersuchungen, differenzierten aber auch allgemeine Daten und relevante krankheitsspezifische Ereignisse wie Zeitpunkte und Anzahl von hämolytischen Krisen, Transfusionen oder Phototherapien, das Auftreten von Gallensteinen und die Durchführung einer Splenektomie bei den Patienten.

Die meisten Patienten in unserer Untersuchung wurden im ersten Lebensjahr diagnostiziert. Der Altersmittelwert lag mit 7,27 Jahren unter dem älterer Studien (z.B. 13 Jahre bei Jonte et al. 1995). $\mathrm{Zu}$ bemerken ist, dass nur bei $58,5 \%$ der Patienten ein erniedrigter $\mathrm{Hb}-\mathrm{Wert}$ bei Diagnosestellung vorlag. Eine Hyperbilirubinämie bestand zwar bei 83\% der Patienten, doch lag auch bei 17\% der Patienten der alterskorrelierte Bilirubinwert im Normbereich. So sollte also bei der Abklärung einer hämolytischen Anämie auch ohne vorliegende Anämie und ohne erhöhten Bilirubinwert die Differentialdiagnose der HS bedacht werden.

Die meisten Patienten mit HS konnten durch den Kryohämolyse-Test (94\% der Patienten positiv) und den AGLT (70,8\% positiv und 11,5\% kontrollbedürftig) diagnostiziert werden. Die Überprüfung der osmotischen Resistenz der Erythrozyten lieferte die besten diagnostischen Ergebnisse (nach 24-h-Inkubation bei 99,3\% positiv) und sollte bei nicht eindeutigem Ergebnis von AGLT und Kryohämolyse-Test trotz des höheren Aufwandes und des hohen Preises durchgeführt werden.

In der Praxis gibt es Blutwerte (z.B. MCHC, LDH, Thrombozytenkonzentration), die häufig bei der Erkrankung auffällig, aber für die Diagnostik nicht spezifisch genug sind. Sie sollten im Zusammenhang mit anderen Parametern aber an die Diagnose der hereditären Sphärozytose denken lassen.

Ein Icterus neonatorum der Patienten mit HS (83,9\%) wurde in unserer Untersuchung 20 bis $30 \%$ (je nach Literaturquelle) häufiger registriert, als er in der Literatur als physiologisch beschrieben wird. Von den ikterischen Patienten erhielten 82,7\% eine Phototherapie, und 
mindestens 8,5\% benötigten eine Austauschtransfusion. Beunruhigend ist, dass die Diagnose der HS nach Austauschtransfusion nur bei 33\% und bei vorliegendem Icterus praecox und/oder gravis sogar nur bei $26,5 \%$ innerhalb von vier Wochen gestellt wurde.

Bei unseren Patienten traten hämolytische Krisen im Laufe der Erkrankung gehäuft auf, und mehr als 90\% der bluttransfundierten Patienten wurden noch vor dem 15. Lebensjahr transfundiert. Gallensteine wurden häufiger $(53,9 \%)$ als in anderen HS-Studien $(25 \%$ bis $40 \%$ ) beschrieben registriert.

Die Therapie der HS ist die Splenektomie, die bei nahezu allen unserer Patienten zum Sistieren der hämolytischen/aplastischen Krisen führte. Die Untersuchung zeigt, dass viele Patienten innerhalb der ersten beiden Lebensdekaden splenektomiert wurden, aber heute nicht mehr jeder Patient in jungen Jahren operiert wird. Der Altersmittelwert bei Splenektomie lag bei 11,05 Jahren. Postoperativ ist eine Antibiotikaprophylaxe zur Verhinderung einer Sepsis notwendig, die bei mindestens 1/5 der Patienten nicht eingehalten wurde. Dies führte allerdings nicht zu einer erhöhten Sepsisrate unserer Patienten.

Die hereditäre Sphärozytose ist die bedeutendste angeborene hämolytische Anämie in Mitteleuropa (Eber 2006). Trotz auffälliger Klinik (Ikterus, Anämie) wird die Diagnose der Sphärozytose jedoch zu selten in Betracht gezogen. Für eine frühzeitigere Diagnosestellung der hereditären Sphärozytose ist es notwendig, bewusster an die HS im Rahmen der Differentialdiagnosen bei Ikterus zu denken, um so den Patienten eine optimale Behandlung zukommen zu lassen. 


\section{Anhang}

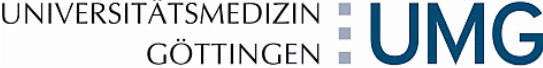

\section{Einwilligungserklärung zur Weitergabe und Verarbeitung personenbezogener Daten entspre- chend der Zielsetzungen des}

ENERCA-Projekts

Betrifft

geb.

(Patient: Name, Vorname)

Wir bitten Sie sich damit einverstanden zu erklären, dass von Ihnen / Ihrer Tochter / Ihrem Sohn personenbezogene Daten (Name, Geburtsdatum, Wohnort, Diagnose mit Befunderhebung, Therapieform und -verlauf sowie andere medizinisch relevante Daten) verarbeitet werden (Speicherung, Übermittlung, Veränderung, Auswertung, Löschen).

Die Daten werden an die Abteilung Pädiatrie I der Universitätskinderklinik Göttingen übermittelt.

Von dort werden Ihre Daten in anonymisierter Form im Rahmen des ENERCA-Projekts (European Network for Rare and Congenital Anemias) einem europäischen Netzwerk für seltene Anämien zur medizinischen Dokumentation zur Verfügung gestellt, um europaweit eine Verbesserung der Diagnose und Überwachung der Therapie durch den behandelnden Arzt zu erreichen. Eine solche Dokumentation ist daher als wichtiges Hilfsmittel einer zeitgemäßen Behandlung anzusehen.

Alle Personen, die Einblick in die gespeicherten Daten haben, unterliegen der ärztlichen Schweigepflicht bzw. dem Datenschutzgesetz. Ihr Einverständnis zur Datenverarbeitung und -weitergabe ist freiwillig. Für den Fall, dass Sie es nicht geben, entstehen Ihnen keine Nachteile. Sie können Ihr Einverständnis jederzeit widerrufen.

Detaillierte Informationen über die Arbeit von ENERCA finden Sie im Internet unter www.enerca.org.

Ich erkläre mich / Wir erklären uns mit der Verarbeitung der personenbezogenen Daten im oben beschriebenen Umfang und ausschließlich für die vorgenannten Zwecke einverstanden: 


\section{Fragebogen zu Hereditärer Sphärozytose und Pyruvatkinase-Mangel}

Füllen Sie den Fragebogen bitte möglichst vollständig aus.

Bei Fragen wenden Sie sich bitte an Ihren zuständigen Arzt oder uns. Im Arztbrief stehen auch Angaben zu den Blutwerten.

Persönliche Angaben:

\begin{tabular}{|l|l|}
\hline Patientennummer in der UMG & \\
\hline Vorname & \\
\hline Nachname & \\
\hline Geburtsname & \\
\hline Titel & \\
\hline Tel-Nummer & \\
\hline
\end{tabular}

\begin{tabular}{|l|l|}
\hline $\begin{array}{l}\text { Krankenhaus, } \\
\text { vollständige Adresse }\end{array}$ & \\
\hline Patientennummer & \\
\hline Abteilung & \\
\hline behandelnder Arzt/ Ärztin & \\
\hline
\end{tabular}

\begin{tabular}{|l|l|}
\hline Hausarzt/ Hausärztin & \\
\hline Straße & \\
\hline Postleitzahl & \\
\hline Ort & \\
\hline Tel-Nummer & \\
\hline
\end{tabular}

\begin{tabular}{|l|l|l|l|l|l|l|l|}
\hline Geschlecht (bitte ankreuzen) & männlich & weiblich & & unbekannt & \multicolumn{5}{l|}{} \\
\hline Geburtsdatum (TT/MM/JJJ) & \multicolumn{5}{|l|}{} \\
\hline Todesdatum (TT/MM/JJJ) & \multicolumn{5}{|l|}{} \\
\hline Geburtsland/ ethnische Abstammung & & & & Ja & \\
\hline $\begin{array}{l}\text { Gibt es in Ihrer Familie eine oder mehrere } \\
\text { blutsverwandte Ehen? }\end{array}$ & Nein & & Unbekannt & & Ja \\
\hline
\end{tabular}

Nur wenn „Ja“ bitte hier angeben, wer mit wem blutsverwandt ist. (sonst diese Frage überspringen)

\begin{tabular}{|l|l|}
\hline Diagnose & \\
\hline $\begin{array}{l}\text { Diagnosedatum falls bekannt, sonst bitte Alter bei Diagnose } \\
\text { (falls auch nicht bekannt bitte, ,unbekannt“ eintragen) }\end{array}$ & \\
\hline Größe in cm & \\
\hline
\end{tabular}




\section{Gewicht in $\mathrm{kg}$}

\begin{tabular}{|l|l|}
\hline Vererbung & \\
\hline angeboren & \\
\hline erworben & \\
\hline Status & \\
\hline $\begin{array}{l}\text { Platz für An- } \\
\text { merkungen } \\
\text { und Fragen }\end{array}$ & \\
& \\
\hline
\end{tabular}

Blutarmut in Familie und Verwandtschaft

Welche Familienmitglieder oder Verwandten sind außerdem davon betroffen?

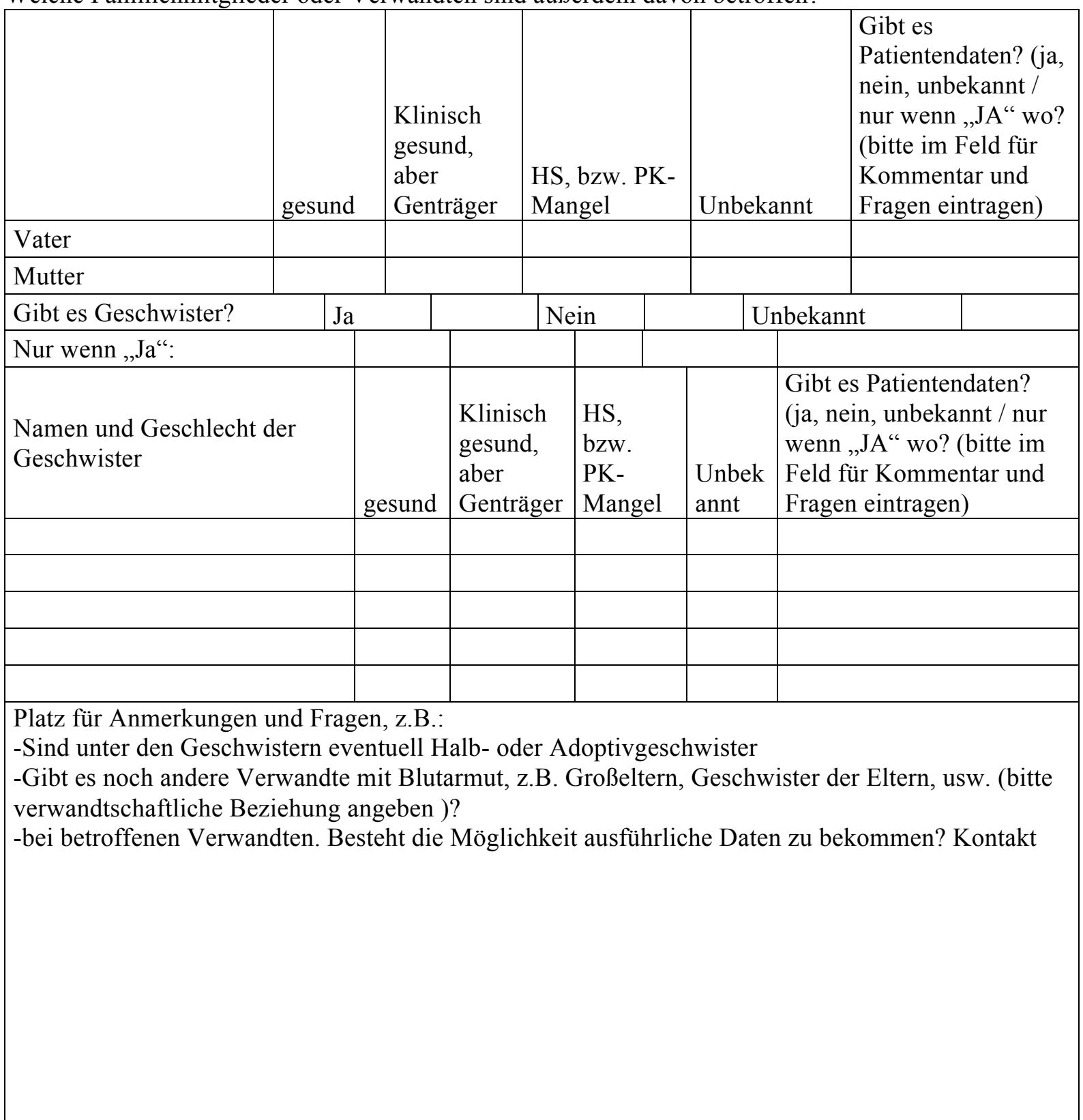




\section{Untersuchungsergebnisse}

Falls die Einheiten der Messergebnisse von den hier genannten abweichen oder hier keine angeben sind, bitte beim jeweiligen Wert Einheit eintragen.

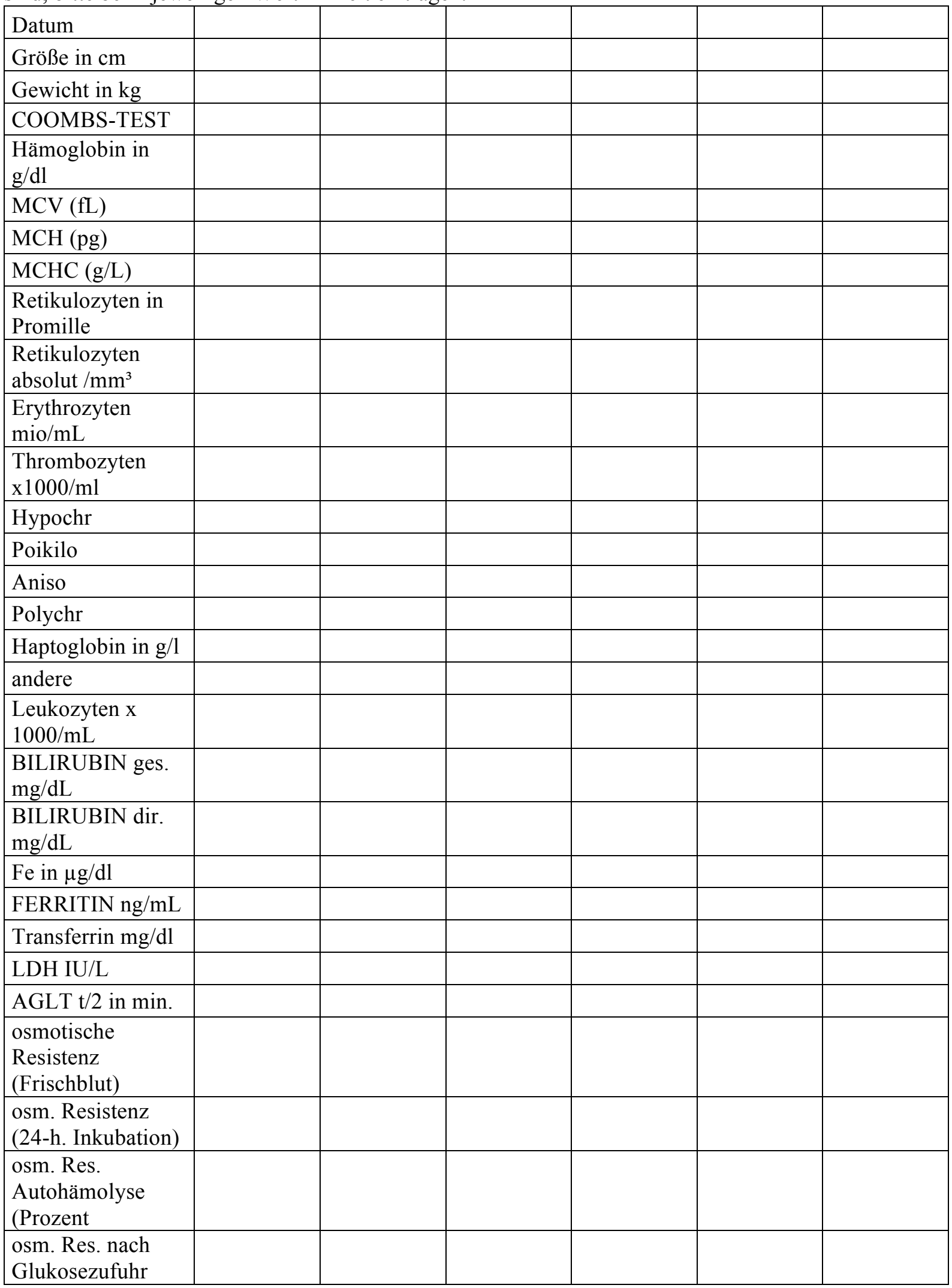




\begin{tabular}{|l|l|l|l|l|l|l|}
\hline (Prozent) & & & & & & \\
\hline $\begin{array}{l}\text { Kryohämolyse in } \\
\text { Prozent }\end{array}$ & & & & & & \\
\hline $\begin{array}{l}\text { intraerythrocyteric } \\
\text { Elektrolyte }\end{array}$ & & & & & & \\
\hline $\begin{array}{l}\text { Spektrin-Dimer- } \\
\text { Konzentration in } \\
\text { Prozent }\end{array}$ & & & & & & \\
\hline Enzymaktivität & & & & & & \\
\hline $\begin{array}{l}\text { Enzymaktivität in } \\
\text { Prozent von } \\
\text { normal und Name } \\
\text { des Enzyms }\end{array}$ & & & & & & \\
\hline Knochenmark & & & & & & \\
\hline
\end{tabular}

\section{Splenektomie}

\begin{tabular}{|l|l|l|l|l|l|}
\hline Datum & & & & & \\
\hline Milzgröße in ml & & & & & \\
\hline
\end{tabular}

\begin{tabular}{|c|c|c|c|c|c|c|}
\hline & \multicolumn{3}{|c|}{$\begin{array}{l}\text { Ja (bitte Datum oder Alter } \\
\text { eintragen soweit bekannt) }\end{array}$} & Nein & \multicolumn{2}{|c|}{$\begin{array}{l}\text { unbekan } \\
\text { nt }\end{array}$} \\
\hline \multicolumn{7}{|l|}{ Splenektomie, total } \\
\hline \multicolumn{7}{|l|}{ Splenektomie, near total } \\
\hline \multicolumn{7}{|l|}{ Splenektomie, subtotal } \\
\hline \multicolumn{7}{|l|}{ Splenektomie, Typ unbekannt } \\
\hline \multirow{2}{*}{\multicolumn{2}{|c|}{$\begin{array}{l}\text { Wurde die Splenektomie laparoskopisch durchgeführt? } \\
\text { Krankenhausaufenthalt nach Splenektomie in Tagen }\end{array}$}} & $\mathrm{Ja}$ & nein & unbek & & \\
\hline & & \multicolumn{2}{|c|}{ Anzahl Tage } & \multicolumn{3}{|c|}{ unbekannt } \\
\hline
\end{tabular}

Milzwachstum nach Splenektomie

\begin{tabular}{|l|l|l|l|l|l|}
\hline Datum & & & & & \\
\hline Milzgröße in ml & & & & & \\
\hline
\end{tabular}

\section{Thrombose nach Splenektomie}

Bitte zutreffendes ankreuzen oder ausfüllen

\begin{tabular}{|c|c|c|c|c|c|}
\hline \multirow[t]{3}{*}{ Thrombose } & \multicolumn{2}{|l|}{ Nein } & & & \\
\hline & \multicolumn{2}{|l|}{$\mathrm{Ja}$} & \multicolumn{2}{|c|}{ Datum der Thrombose } & \\
\hline & \multicolumn{2}{|l|}{ unbekannt } & & & \\
\hline \multirow{3}{*}{\multicolumn{2}{|c|}{ Thrombosevorbeugung }} & \multicolumn{3}{|c|}{ Nein } & \\
\hline & & \multicolumn{3}{|c|}{ Unbekannt } & \\
\hline & & \multicolumn{3}{|c|}{ Ja (Anfangsdatum, wenn bekannt) } & \\
\hline \multicolumn{2}{|c|}{$\begin{array}{l}\text { Nur wenn bei } \\
\text { Thrombosevorbeugung“Ja" }\end{array}$} & \multicolumn{3}{|c|}{ Medikament zur Thrombosevorbeugung } & \\
\hline & & \multicolumn{3}{|c|}{$\begin{array}{l}\text { Ende der Thrombosevorbeugung, Datum } \\
\text { Oder falls nicht bekannt, bitte die Dauer } \\
\text { in Monaten }\end{array}$} & \\
\hline \multicolumn{2}{|l|}{ OPSI } & $\mathrm{Ja}$ & & Nein & unbekannt \\
\hline
\end{tabular}




\begin{tabular}{|l|l|}
\hline PSP Dauer in Monaten & \\
\hline PSP DOSIS & \\
\hline
\end{tabular}

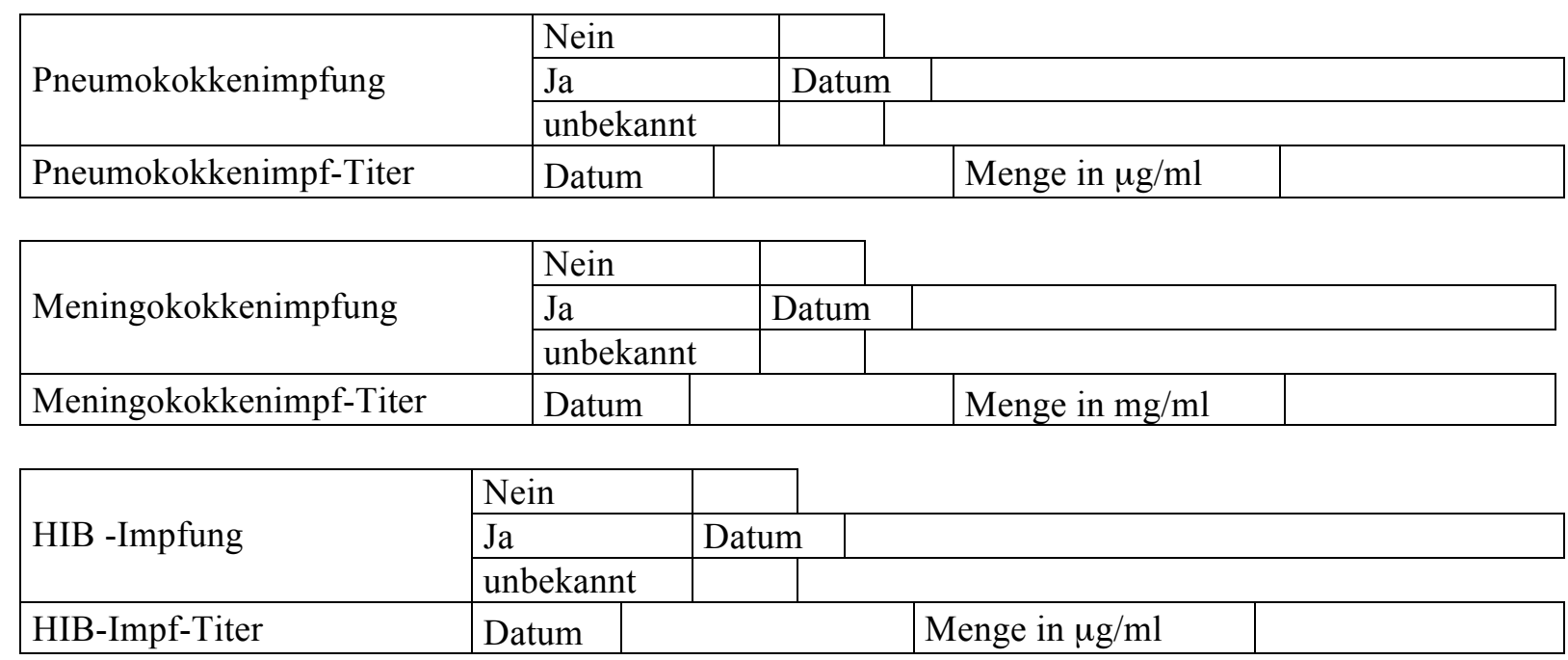

\section{Gallensteine und Cholezystektomie}

\begin{tabular}{|c|c|c|c|c|}
\hline Gallensteine & $\mathrm{Ja}$ & Nein & unbekannt & \\
\hline \multicolumn{5}{|c|}{$\begin{array}{l}\text { Nur wenn mit "ja” beantwortet zutreffendes bitte ankreuzen oder falls bekannt bitte genaues Datum } \\
\text { oder Alter eintragen }\end{array}$} \\
\hline \multicolumn{5}{|c|}{ Erster Gallenstein, Alter unbekannt } \\
\hline \multicolumn{5}{|c|}{ Erster Gallenstein, Alter 0 - 4} \\
\hline \multicolumn{5}{|c|}{ Erster Gallenstein, Alter 5 - 9} \\
\hline \multicolumn{5}{|c|}{ Erster Gallenstein, Alter 10 -14 } \\
\hline \multicolumn{5}{|c|}{ Erster Gallenstein, Alter 15 - 19} \\
\hline \multicolumn{5}{|c|}{ Erster Gallenstein, Alter 20 - 24} \\
\hline \multicolumn{5}{|c|}{\begin{tabular}{|l|} 
Erster Gallenstein, Alter 25 - 29 \\
\end{tabular}} \\
\hline \multicolumn{5}{|c|}{ Erster Gallenstein, Alter 30 - 34} \\
\hline \multicolumn{5}{|c|}{ Erster Gallenstein, Alter 35 - 39} \\
\hline Erster Gallens & tein, Alter ab 40 & & & \\
\hline
\end{tabular}

\begin{tabular}{|c|c|c|c|}
\hline Cholezystektomie & Ja & Nein & unbekannt \\
\hline \multicolumn{4}{|l|}{ Cholezystektomie, Alter unbekannt } \\
\hline \multicolumn{4}{|l|}{ Cholezystektomie, Alter 0 - 4} \\
\hline \multicolumn{4}{|l|}{ Cholezystektomie, Alter 5 - 9} \\
\hline \multicolumn{4}{|l|}{ Cholezystektomie, Alter $10-14$} \\
\hline \multicolumn{4}{|l|}{ Cholezystektomie, Alter 15 - 19} \\
\hline \multicolumn{4}{|l|}{ Cholezystektomie, Alter 20 - 24} \\
\hline \multicolumn{4}{|l|}{ Cholezystektomie, Alter 25 - 29} \\
\hline \multicolumn{4}{|l|}{ Cholezystektomie, Alter 30 - 34} \\
\hline \multicolumn{4}{|l|}{ Cholezystektomie, Alter 35 - 39} \\
\hline Cholezystektomie, Alter ab 40 & & & \\
\hline
\end{tabular}




\begin{tabular}{|l|l|l|l|l|l|l|}
\hline Wurde die Cholezystektomie laparoskopisch durchgeführt? & Ja & & nein & & unbekannt & \\
\hline
\end{tabular}

\section{Aplastische / hämolytische Krise}

\begin{tabular}{|l|l|l|l|l|l|l|}
\hline aplastische / hämolytische Krise & Ja & & Nein & & unbekannt & \\
\hline
\end{tabular}

Nur wenn mit "ja" beantwortet zutreffendes bitte ankreuzen oder falls bekannt bitte genaues Datum oder Alter eintragen

\begin{tabular}{|l|l|}
\hline Datum der ersten aplastischen Krise & \\
\hline Anzahl der aplastischen Krisen & \\
\hline Art der Virusinfektion & \\
\hline
\end{tabular}

\begin{tabular}{|l|l|l|l|l|l|l|}
\hline Bein Ulcera & Ja & & Nein & & unbekannt & \\
\hline
\end{tabular}

Platz für Anmerkungen und Fragen:

\section{Transfusionen}

\begin{tabular}{|l|l|l|l|l|l|}
\hline \multirow{2}{*}{$\begin{array}{l}\text { AustauschTRANSFUSION nach der } \\
\text { Geburt }\end{array}$} & Nein & \multicolumn{4}{|c|}{} \\
\cline { 2 - 6 } & Ja & wann & & wie viele & \\
\cline { 2 - 5 } & unbekannt & & &
\end{tabular}

\begin{tabular}{|l|l|l|l|l|l|l|}
\hline Transfusionen & Ja & & Nein & & unbekannt & \\
\hline
\end{tabular}

Nur wenn mit "ja" beantwortet zutreffendes bitte ankreuzen oder falls bekannt bitte genaues Datum oder Anzahl eintragen

\begin{tabular}{|l|l|}
\hline $1-3$ Transfusionen & \\
\hline Mehr als 3 T Transfusionen & \\
\hline Transfusionen regelmäßig & \\
\hline
\end{tabular}

\begin{tabular}{|l|l|l|l|l|l|l|}
\hline Gelbsucht & Ja & & Nein & & unbekannt & \\
\hline
\end{tabular}
Nur wenn mit "ja" beantwortet zutreffendes bitte die Fragen zur Gelbsucht beantworten.

\begin{tabular}{|l|l|l|l|}
\hline \multirow{4}{*}{ Permanente Gelbsucht } & Nein & \multicolumn{1}{|l|}{} \\
\cline { 2 - 4 } & Ja & Seit & \\
\cline { 2 - 3 } & unbekannt & & \multicolumn{2}{|c|}{} \\
\hline \multirow{2}{*}{ Temporäre Gelbsucht } & Nein & & \multicolumn{2}{|c|}{} \\
\cline { 2 - 3 } & Ja & Wann? & \\
\hline
\end{tabular}




\begin{tabular}{|c|c|c|c|}
\hline \multirow{4}{*}{$\begin{array}{l}\text { Temporäre Gelbsucht im } \\
\text { Zusammenhang mit } \\
\text { Infektionen }\end{array}$} & \multirow{2}{*}{$\begin{array}{l}\text { unbekannt } \\
\text { Nein }\end{array}$} & & \\
\hline & & & \\
\hline & \multirow{2}{*}{$\begin{array}{l}\text { Ja } \\
\text { unbekannt }\end{array}$} & \multicolumn{2}{|l|}{ Wann? } \\
\hline & & & \\
\hline \multicolumn{4}{|l|}{ Art der Gelbsucht } \\
\hline $\begin{array}{l}\text { Behandlung der } \\
\text { Gelbsucht }\end{array}$ & & & \\
\hline
\end{tabular}

\begin{tabular}{|c|c|c|c|}
\hline Phototherapie & Nein & & \\
\hline & $\mathrm{Ja}$ & wann & Dauer in Tagen \\
\hline & unbek & nnt & \\
\hline
\end{tabular}

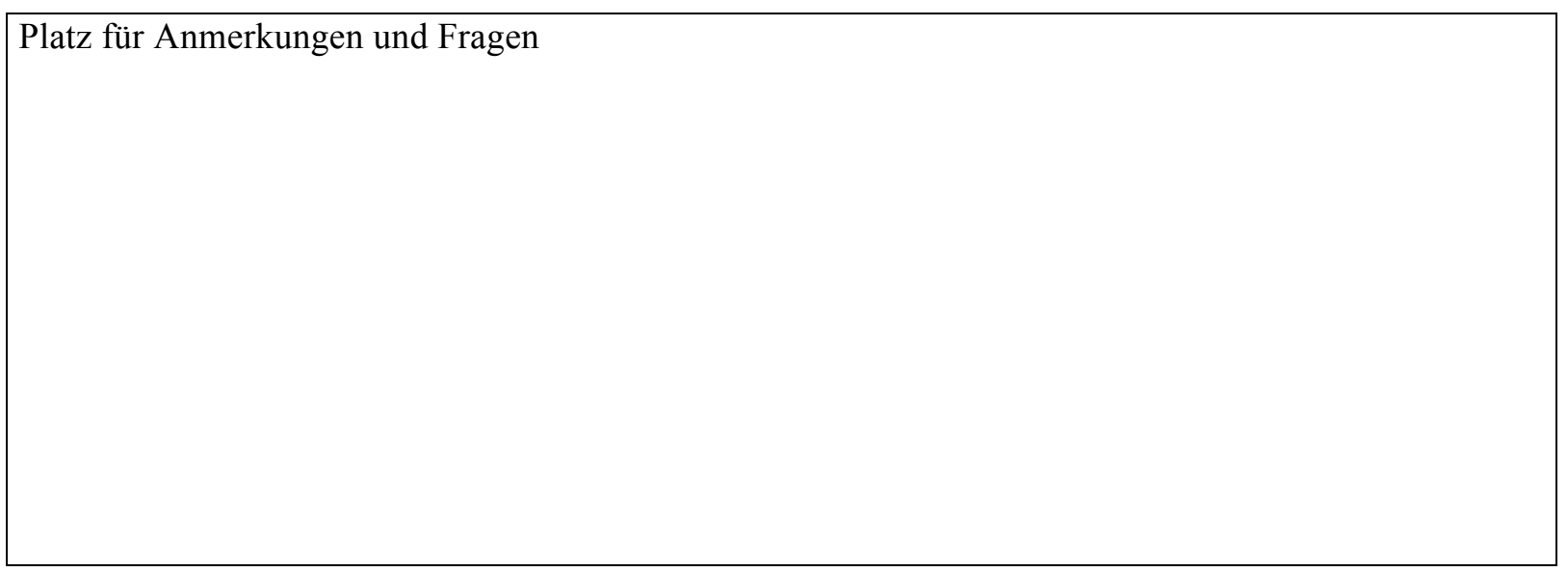

\begin{tabular}{|l|l|l|l|}
\hline Neurologische Symptome & Nein & \multicolumn{2}{|l|}{} \\
\hline & Ja & Welche? & \\
& & & \\
\cline { 2 - 4 } & unbekannt & & \multicolumn{2}{|l}{} \\
\hline
\end{tabular}

Schwangerschaft der Mutter

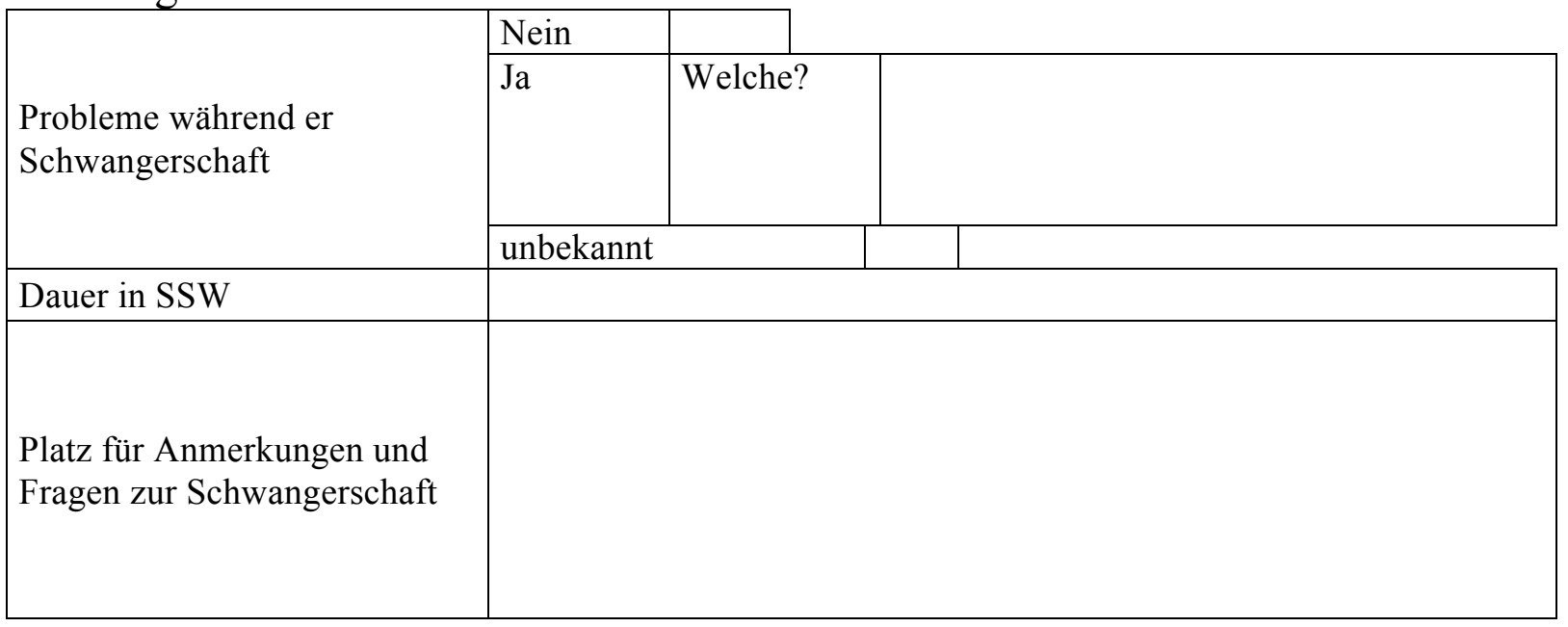

\section{Arztbesuche}




\begin{tabular}{|l|l|}
\hline Letzter Besuch, Datum & \\
\hline Letzter Besuch, Ort & \\
\hline
\end{tabular}

\section{Genetik}

\begin{tabular}{|l|l|}
\hline LOKALISATION des Gendefekts & \\
\hline NAME der VARIANTE & \\
\hline GENOTYP & \\
\hline AMINOSÄUREAUSTAUSCH & \\
\hline
\end{tabular}

\section{Allgemeinbefinden}

Zutreffendes bitte ankreuzen.

\begin{tabular}{|l|l|l|l|l|l|l|}
\hline Körperliches Wohlbefinden nach Splenektomie & Besser & & Schlechter & & Unverändert & \\
\hline
\end{tabular}

\begin{tabular}{|l|l|l|l|l|l|l|}
\hline Schlaganfall & Ja & & Nein & & unbekannt & \\
\hline
\end{tabular}

\begin{tabular}{|l|l|l|l|l|l|l|}
\hline Belastbarkeit im täglichen Leben & Besser & & Schlechter & & Unverändert & \\
\hline Belastbarkeit beim Sport & Besser & & Schlechter & & Unverändert & \\
\hline
\end{tabular}

\begin{tabular}{|l|l|l|}
\hline \multirow{3}{*}{ Physiotherapie/ Ergotherapie } & Nein & \\
\cline { 2 - 3 } & Ja & Weswegen? \\
\cline { 2 - 3 } & unbekannt & \\
\hline
\end{tabular}

\begin{tabular}{|l|l|l|l|l|l|l|}
\hline Bauchschmerzen & Besser & & Schlechter & & Unverändert & \\
\hline Appetit & Besser & & Schlechter & & Unverändert & \\
\hline Konzentrationsstörungen & Besser & & Schlechter & & Unverändert & \\
\hline Kopfschmerzen & Besser & & Schlechter & & Unverändert & \\
\hline Schwäche & Besser & & Schlechter & & Unverändert & \\
\hline Psyche & Besser & & Schlechter & & Unverändert & \\
\hline Depression & Besser & & Schlechter & & Unverändert & \\
\hline Schlafstörungen & Besser & & Schlechter & & Unverändert & \\
\hline
\end{tabular}

\begin{tabular}{|c|c|c|c|c|}
\hline Beruf & & & & \\
\hline & Nein & & & \\
\hline Beeinträchtigungen im Beruf & $\mathrm{Ja}$ & Welche & & \\
\hline & unbekannt & & & \\
\hline & Nein & & & \\
\hline Berufs-/Arbeitsunfähigkeit & $\mathrm{Ja}$ & Warum? & & \\
\hline & unbekannt & & & \\
\hline Vorgezogener Ruhestand & $\mathrm{Ja}$ & & Nein & unbekannt \\
\hline
\end{tabular}




\section{Literaturverzeichnis}

Abdullah F, Zhang Y, Camp M, Rossberg MI, Bathurst MA, Colombani PM, Casella JF, Nabaweesi R, Chang DC (2009): Splenectomy in hereditary spherocytosis: Review of 1,657 patients and application of the pediatric quality indicators. Pediatr Blood Cancer 52(7), 834-837

Bader-Meunier B, Gauthier F, Archambaud F, Cynober T, Mielot F, Dommergues JP, Warszawski J, Mohandas N, Tchernia G (2001): Long-term evaluation of the beneficial effect of subtotal splenectomy for management of hereditary spherocytosis. Blood 97(2), 399-403

Beck JS (1978): Relations between membrane monolayers in some red cell shape transformations. J Theor Biol 75(4), 487-501

Becker PS, Tse WT, Lux SE, Forget BG (1993): Beta spectrin kissimmee: a spectrin variant associated with autosomal dominant hereditary spherocytosis and defective binding to protein 4.1. J Clin Invest 92(2), 612-616

Bennett V (1990): Spectrin-based membrane skeleton: a multipotential adaptor between plasma membrane and cytoplasm. Physiol Rev 70(4), 1029-1065

Bennett V, Stenbuck PJ (1979): Identification and partial purification of ankyrin, the high affinity membrane attachment site for human erythrocyte spectrin. J Biol Chem 254(7), 2533-2541

Bennett V, Stenbuck PJ (1980): Association between ankyrin and the cytoplasmic domain of band 3 isolated from the human erythrocyte membrane. J Biol Chem 255(13), 64246432

Beutler E, Luzzatto L (1999): Hemolytic anemia. Semin Hematol 36(4 Suppl 7), 38-47

Bogue CO, Murphy AJ, Gerstle JT, Moineddin R, Daneman A (2010): Risk factors, complications, and outcomes of gallstones in children: a single-center review. J Pediatr Gastroenterol Nutr 50(3), 303-308

Byers TJ, Branton D (1985): Visualization of the protein associations in the erythrocyte membrane skeleton. Proc Natl Acad Sci U S A 82(18), 6153-6157

Celkan T, Alhaj S (2008): Prenatal diagnosis of hereditary spherocytosis with osmotic fragility test. Indian Pediatr 45(1), 63-64

Chapman RG, McDonald LL (1968): Red cell life span after splenectomy in hereditary spherocytosis. J Clin Invest $47(10), 2263-2267$

Christensen RD, Henry E (2010): Hereditary spherocytosis in neonates with hyperbilirubinemia. Pediatrics 125(1), 120-125 
Cooper RA, Jandl JH (1969): The role of membrane lipids in the survival of red cells in hereditary spherocytosis. J Clin Invest 48(4), 736-744

Croom RD, McMillan CW, Orringer EP, Sheldon GF (1986): Hereditary spherocytosis. Recent experience and current concepts of pathophysiology. Ann Surg 203(1), 34-39

Dacie J: The haemolytic anemias; Churchill Livinstone, Edinburgh 1985

Davies KA, Lux SE (1989): Hereditary disorders of the red cell membrane skeleton. Trends Genet 5(7), 222-227

Davis LH, Bennett V (1990): Mapping the binding sites of human erythrocyte ankyrin for the anion exchanger and spectrin. J Biol Chem 265(18), 10589-10596

Davis LH, Davis JQ, Bennett V (1992): Ankyrin regulation: an alternatively spliced segment of the regulatory domain functions as an intramolecular modulator. J Biol Chem 267(26), 18966-18972

de Jong K, Larkin SK, Eber S, Franck PF, Roelofsen B, Kuypers FA (1999): Hereditary spherocytosis and elliptocytosis erythrocytes show a normal transbilayer phospholipid distribution. Blood 94(1), 319-325

Delhommeau F, Cynober T, Schischmanoff PO, Rohrlich P, Delaunay J, Mohandas N, Tchernia G (2000): Natural history of hereditary spherocytosis during the first year of life. Blood 95(2), 393-397

Durakbasa CU, Timur C, Sehiralti V, Mutus M, Tosyali N, Yoruk A (2006): Pediatric splenectomy for hematological diseases: outcome analysis. Pediatr Surg Int 22(8), 635-639

Eber SW (2006): AWMF: Leitlinien zur Diagnostik und Therapie in der Pädiatrischen Onkologie und Hämatologie, Hereditäre Sphärozytose. http://www.uni-duesseldorf.de/WWW/AWMF/l//025-018.htm. Update: 01/2006

Eber SW, Lux SE (2004): Hereditary spherocytosis--defects in proteins that connect the membrane skeleton to the lipid bilayer. Semin Hematol 41(2), 118-141

Eber SW, Pekrun A, Neufeldt A, Schroter W (1992): Prevalence of increased osmotic fragility of erythrocytes in German blood donors: screening using a modified glycerol lysis test. Ann Hematol 64(2), 88-92

Eber SW, Belohradsky BH, Weiss M (2001): [Antiinfectious prophylaxis in asplenia]. Klin Padiatr 213 Suppl 1, A84-87

Evans EA, Hochmuth RM (1976): Membrane viscoelasticity. Biophys J 16(1), 1-11

Evans EA, Mohandas N, Leung A (1984): Static and dynamic rigidities of normal and sickle erythrocytes. Major influence of cell hemoglobin concentration. J Clin Invest 73(2), 477-488 
Fischer TM (1992): Bending stiffness of lipid bilayers. I. Bilayer couple or single-layer bending? Biophys J 63(5), 1328-1335

Friedman EW, Williams JC, Van Hook L (1988): Hereditary spherocytosis in the elderly. Am J Med 84(3 Pt 1), 513-516

Gardner K, Bennett V (1987): Modulation of spectrin-actin assembly by erythrocyte adducin. Nature 328(6128), 359-362

Garg PK, Kumar A, Teckchandani N, Hadke NS (2008): Hereditary spherocytosis coexisting with Gilbert's syndrome: a diagnostic dilemma. Singapore Med J 49(11), e308-309

Georgatos SD, Marchesi VT (1985): The binding of vimentin to human erythrocyte membranes: a model system for the study of intermediate filament-membrane interactions. J Cell Biol 100(6), 1955-1961

Grace RF, Mednick RE, Neufeld EJ (2009): Compliance with immunizations in splenectomized individuals with hereditary spherocytosis. Pediatr Blood Cancer 52(7), 865-867

Green DH, Bellingham AJ, Anderson MJ (1984): Parvovirus infection in a family associated with aplastic crisis in an affected sibling pair with hereditary spherocytosis. J Clin Pathol $\underline{37(10)}, 1144-1146$

Hafsia R, Zriba S, Gouider E, Ben Salah N, Borji W, Zaouche A (2009): [Splenectomy in hereditary hemolytic anemia: 82 Tunisian cases]. Tunis Med 87(5), 323-327

Hanel HK, Cohn J (1975): Intra-erythrocytary enzymes before and after splenectomy. Clin Chim Acta 65(2), 205-211

Hermann J, Hetzinger S (1989): [Diagnosis of hereditary spherocytosis]. Folia Haematol Int Mag Klin Morphol Blutforsch 116(5), 769-773

Herold G: Innere Medizin 2006; G. Herold, Köln 2006

Holcomb GW, Jr., Holcomb GW, 3rd (1990): Cholelithiasis in infants, children, and adolescents. Pediatr Rev 11(9), 268-274

Iglauer A, Reinhardt D, Schroter W, Pekrun A (1999): Cryohemolysis test as a diagnostic tool for hereditary spherocytosis. Ann Hematol 78(12), 555-557

Iolascon A, Avvisati RA (2008): Genotype/phenotype correlation in hereditary spherocytosis. Haematologica $\underline{93(9)}, 1283-1288$

Iolascon A, Perrotta S, Stewart GW (2003): Red blood cell membrane defects. Rev Clin Exp Hematol 7(1), 22-56

Jarolim P, Rubin HL, Brabec V, Palek J (1995 a): Comparison of the ankyrin (AC)n microsatellites in genomic DNA and mRNA reveals absence of one ankyrin mRNA allele in $20 \%$ of patients with hereditary spherocytosis. Blood $85(11), 3278-3282$ 
Jarolim P, Rubin HL, Brabec V, Chrobak L, Zolotarev AS, Alper SL, Brugnara C, Wichterle H, Palek J (1995 b): Mutations of conserved arginines in the membrane domain of erythroid band 3 lead to a decrease in membrane-associated band 3 and to the phenotype of hereditary spherocytosis. Blood 85(3), 634-640

Johns-Hopkins-University (2010): OMIM: Online Medelian Inheritance in Man, SPHEROCYTOSIS, TYPE 1; SPH1.

http://www.ncbi.nlm.nih.gov/entrez/dispomim.cgi?id=182900. Update: 26.02 .2009

Jonte F, Ramirez A, Medina J, Garcia Gala J, Roson C, Corte JR, Vargas M, Perez Lozana L (1995): [Hereditary spherocytosis: clinical characteristics and treatment with splenectomy]. Sangre (Barc) 40(1), 45-48

Kar R, Rao S, Srinivas UM, Mishra P, Pati HP (2009): Clinico-hematological profile of hereditary spherocytosis: experience from a tertiary care center in North India. Hematology 14(3), 164-167

Karinch AM, Zimmer WE, Goodman SR (1990): The identification and sequence of the actinbinding domain of human red blood cell beta-spectrin. J Biol Chem 265(20), 1183311840

Kemkes-Matthes B, Oehler G: Blutgerinnung und Thrombose. 3.Auflage; Thieme, Stuttgart 2001

Kimura F, Ito H, Shimizu H, Togawa A, Otsuka M, Yoshidome H, Shimamura F, Kato A, Nukui Y, Ambiru S, et al. (2003): Partial splenic embolization for the treatment of hereditary spherocytosis. AJR Am J Roentgenol 181(4), 1021-1024

Koletzko B: Kinder- und Jugendmedizin. 13.Auflage; Springer Medizin Verlag, Heidelberg 2007

Kutter D, Gulbis B (2005): Hereditary spherocytosis veiled by anemia and iron deficiency. Clin Lab 51(7-8), 411-418

Kuypers FA (1998): Phospholipid asymmetry in health and disease. Curr Opin Hematol $\underline{5(2)}$, $122-131$

Liu SC, Windisch P, Kim S, Palek J (1984): Oligomeric states of spectrin in normal erythrocyte membranes: biochemical and electron microscopic studies. Cell $\underline{37(2)}$, 587-594

Liu SC, Palek J, Yi SJ, Nichols PE, Derick LH, Chiou SS, Amato D, Corbett JD, Cho MR, Golan DE (1995): Molecular basis of altered red blood cell membrane properties in Southeast Asian ovalocytosis: role of the mutant band 3 protein in band 3 oligomerization and retention by the membrane skeleton. Blood 86(1), 349-358

Lux SE, Palek J: Disorders of the red cell membrane; in: Blood - Principles \& Practice of Hematology; hrsg. v. Handin R, Lux SE, Strossel TP; J.B. Lippincott Company, Philadelphia 1995, 1701-1818 
Mariani M, Barcellini W, Vercellati C, Marcello AP, Fermo E, Pedotti P, Boschetti C, Zanella A (2008): Clinical and hematologic features of 300 patients affected by hereditary spherocytosis grouped according to the type of the membrane protein defect. Haematologica 93(9), 1310-1317

Matsuoka Y, Li X, Bennett V (2000): Adducin: structure, function and regulation. Cell Mol Life Sci 57(6), 884-895

McGough AM, Josephs R (1990): On the structure of erythrocyte spectrin in partially expanded membrane skeletons. Proc Natl Acad Sci U S A 87(13), 5208-5212

McLellan NJ, Rutter N (1987): Hereditary spherocytosis in sisters unmasked by parvovirus infection. Postgrad Med J 63(735), 49-50

Mehta J, Harjai K, Vasani J, Banghar P, Sanklecha M, Singhal S, Pathare A, Tilve GH, Mehta BC, Patel JC (1992): Hereditary spherocytosis: experience of 145 cases. Indian J Med Sci 46(4), 103-110

Michaels LA, Cohen AR, Zhao H, Raphael RI, Manno CS (1997): Screening for hereditary spherocytosis by use of automated erythrocyte indexes. J Pediatr 130(6), 957-960

Mohandas N, Chasis JA (1993): Red blood cell deformability, membrane material properties and shape: regulation by transmembrane, skeletal and cytosolic proteins and lipids. Semin Hematol $\underline{30(3)}, 171-192$

Mortimer PP (1983): Hypothesis: the aplastic crisis of hereditary spherocytosis is due to a single transmissible agent. J Clin Pathol 36(4), 445-448

Nathan D, Ginsburg D, Orkin S, Look A: Nathan and Oski's hematology of infancy and childhood. 6.Auflage; Saunders, Elsevier, Philadelphia 2003

Neumeister B, Besenthal I, Böhm B: Klinikleitfaden Labordiagnostik. 4.Auflage; Elsevier, Urban \& Fischer, München 2009

Niessen KH: Pädiatrie. 6.Auflage; Thieme, Stuttgart 2001

Ogunfowora OB, Daniel OJ (2006): Neonatal jaundice and its management: knowledge, attitude and practice of community health workers in Nigeria. BMC Public Health $\underline{6}, 19$

Ohanian V, Wolfe LC, John KM, Pinder JC, Lux SE, Gratzer WB (1984): Analysis of the ternary interaction of the red cell membrane skeletal proteins spectrin, actin, and 4.1. Biochemistry 23(19), 4416-4420

Parpart AK, Lorenz PB, Parpart ER, Gregg JR, Chase AM (1947): The Osmotic Resistance (Fragility) of Human Red Cells. J Clin Invest 26(4), 636-640

Perkins LA, Jones SF, Bhargava RS (2009): Dural venous thrombosis following splenectomy in a patient with hereditary spherocytosis. South Med J 102(5), 542-545

Petrova A, Mehta R, Birchwood G, Ostfeld B, Hegyi T (2006): Management of neonatal hyperbilirubinemia: pediatricians' practices and educational needs. BMC Pediatr $\underline{6}, 6$ 
Premetis E, Stamoulakatou A, Loukopoulos D (1999): Erythropoiesis: Hereditary Spherocytosis in Greece: Collective Data on a Large Number of Patients. Hematology 4(4), 361-366

Reiche D: Roche Lexikon Medizin. 5.Auflage; Urban \& Fischer, München-Jena 2003

Reinhardt D: Therapie der Krankheiten im Kindes- und Jugendalter. 8.Auflage; Springer, Heidelberg 2007

Renooij W, Van Golde LM (1977): The transposition of molecular classes of phosphatidylcholine across the rat erythrocyte membrane and their exchange between the red cell membrane and plasma lipoproteins. Biochim Biophys Acta 470(3), 465-474

Ritter J, Gadner H, Gaedicke G, Niemeyer C: Pädiatrische Hämatologie und Onkologie; Springer Medizin Verlag, Heidelberg 2006

Romero RR, Poo JL, Robles JA, Uriostegui A, Vargas F, Majluf-Cruz A (1997): Usefulness of cryohemolysis test in the diagnosis of hereditary spherocytosis. Arch Med Res 28(2), 247-251

Rutherford CJ, Postlewaight BF, Hallowes M (1986): An evaluation of the acidified glycerol lysis test. Br J Haematol 63(1), 119-121

Salomao M, Chen K, Villalobos J, Mohandas N, An X, Chasis JA (2010): Hereditary spherocytosis and hereditary elliptocytosis: aberrant protein sorting during erythroblast enucleation. Blood 116(2), 267-269

Schilling RF (2009): Risks and benefits of splenectomy versus no splenectomy for hereditary spherocytosis--a personal view. Br J Haematol 145(6), 728-732

Schröter W, Eber SW (1989): [Molecular pathology of the erythrocyte membrane. Erythrocyte membrane defects as a cause of congenital hemolytic anemia]. Monatsschr Kinderheilkd 137(7), 368-379

Schröter W, Kahsnitz E (1983): Diagnosis of hereditary spherocytosis in newborn infants. J Pediatr 103(3), 460-463

Servey JT, Reamy BV, Hodge J (2007): Clinical presentations of parvovirus B19 infection. Am Fam Physician 75(3), 373-376

Sgro M, Campbell D, Shah V (2006): Incidence and causes of severe neonatal hyperbilirubinemia in Canada. CMAJ 175(6), 587-590

Sheetz MP, Singer SJ (1974): Biological membranes as bilayer couples. A molecular mechanism of drug-erythrocyte interactions. Proc Natl Acad Sci U S A 71(11), 44574461

Siegel DL, Branton D (1985): Partial purification and characterization of an actin-bundling protein, band 4.9, from human erythrocytes. J Cell Biol 100(3), 775-785 
Singer SJ, Nicolson GL (1972): The fluid mosaic model of the structure of cell membranes. Science 175(23), 720-731

Steiner LA, Gallagher PG (2007): Erythrocyte disorders in the perinatal period. Semin Perinatol 31(4), 254-261

STIKO (Ständige Impfkommission): Epidemiologisches Bulletin Nr.30. Robert-Koch-Institut. Berlin 27.07.2009

Stoehr GA, Stauffer UG, Eber SW (2005): Near-total splenectomy: a new technique for the management of hereditary spherocytosis. Ann Surg 241(1), 40-47

Streichman S, Gescheidt Y (1998): Cryohemolysis for the detection of hereditary spherocytosis: correlation studies with osmotic fragility and autohemolysis. Am J Hematol $\underline{\text { 58(3), 206-212 }}$

Tamary H, Aviner S, Freud E, Miskin H, Krasnov T, Schwarz M, Yaniv I (2003): High incidence of early cholelithiasis detected by ultrasonography in children and young adults with hereditary spherocytosis. J Pediatr Hematol Oncol 25(12), 952-954

Tchernia G, Mohandas N, Shohet SB (1981): Deficiency of skeletal membrane protein band 4.1 in homozygous hereditary elliptocytosis. Implications for erythrocyte membrane stability. J Clin Invest 68(2), 454-460

Thornburg CD, Ware RE (2003): The utility of the autohaemolysis test for children with congenital haemolytic anaemia. Clin Lab Haematol 25(1), 25-28

Troendle SB, Adix L, Crary SE, Buchanan GR (2007): Laboratory markers of thrombosis risk in children with hereditary spherocytosis. Pediatr Blood Cancer $49(6), 781-785$

Watchko JF, Maisels MJ (2003): Jaundice in low birthweight infants: pathobiology and outcome. Arch Dis Child Fetal Neonatal Ed 88(6), F455-458

Weed RI, LaCelle PL, Merrill EW (1969): Metabolic dependence of red cell deformability. $\mathrm{J}$ Clin Invest 48(5), 795-809

Zanella A, Izzo C, Rebulla P, Zanuso F, Perroni L, Sirchia G (1980): Acidified glycerol lysis test: a screening test for spherocytosis. Br J Haematol 45(3), 481-486 


\section{Danksagung}

An dieser Stelle möchte ich ganz besonders denjenigen danken, die mich im Verlauf der vorliegenden Promotionsarbeit unterstützt haben.

Ich danke Herrn Prof. Dr. M. Lakomek für die Bereitstellung der Dissertation und für die Möglichkeit, die Arbeitsbereiche der Pädiatrie I im Universitätsklinikum Göttingen nutzen zu dürfen.

Mein besonderer Dank gilt Frau Dr. med. Nina Kollmar, die mich während der Entstehungszeit dieser Arbeit betreut hat. Dank der eifrigen Diskussionen mit Dir, Nina, ist dieses Werk entstanden.

Bedanken möchte ich mich bei den Mitarbeitern der Pädiatrie 1, besonders bei Heidrun Ditges und „den Mädels“ aus dem Büro. Dank auch an die Mitarbeiter des ENERCA-Projektes und Silke Kullmann.

Ihnen und Euch allen vielen Dank! 


\section{Lebenslauf}

Ich wurde am 22.09.1978 als erstes Kind von Priv. Doz. Dr. med. Reinhard Kreische und seiner Ehefrau Cornelia Kreische-Przywara in Göttingen geboren.

Von 1985 bis 1989 besuchte ich die Grundschule „Hermann-Nohl-Schule“ in Göttingen. Daran schloss sich für zwei Jahre bis 1991 der Besuch der Orientierungsstufe „Bert-BrechtSchule" in Göttingen an. Von dort wechselte ich an das Felix-Klein-Gymnasium in Göttingen, an dem ich 1998 die allgemeine Hochschulreife erlangte.

Nach Abschluss meines Zivildienstes begann ich im Wintersemester 2000 das Sport- und Englischstudium auf Gymnasiallehramt an der Georg-August-Universität zu Göttingen. Im April 2002 begann ich an der selben Universität das Studium der Humanmedizin. Im März 2005 legte ich die ärztliche Vorprüfung ab. Im September 2006 begann ich mit dieser Dissertationsarbeit. Mein erstes Tertial des Praktischen Jahres absolvierte ich in der pädiatrischen Abteilung des Klinikums in Oldenburg, das zweite Tertial verbrachte ich in der Abteilung der Inneren Medizin des Reinhard-Nieter-Krankenhauses in Wilhelmshaven, im letzten Tertial war ich in der Chirurgie des Evangelischen Krankenhauses Weende in Göttingen. Im Oktober 2009 schloss ich mit Bestehen des Staatsexamens das Studium der Humanmedizin erfolgreich ab.

Seit Januar 2010 bin ich als Dozent an der Physiotherapeutischen Lehranstalt Dr. Blindow in Hannover und seit April 2010 als Arzt bei der Polizeiinspektion Göttingen tätig. 
